Cristiane Maria Defalque

Estratégias para incorporação das decisões de sequenciamento em um problema integrado de produção de bebidas

Dissertação de Mestrado

Pós-Graduação em Matemática 
Estratégias para incorporação das decisões de sequenciamento em um problema integrado de produção de bebidas

\begin{abstract}
Dissertação apresentada ao Instituto de Biociências, Letras e Ciências Exatas da Universidade Estadual Paulista "Julio de Mesquita Filho", Campus de São José do Rio Preto, São Paulo, para a obtenção do título de Mestre em Matemática.
\end{abstract}

Orientadora: Prof ${ }^{\mathrm{a}}$. Dra ${ }^{\mathrm{a}}$. Maria do Socorro Nogueira Rangel.

São José do Rio Preto 
Defalque, Cristiane Maria.

Estratégias para incorporação das decisões de sequenciamento em um problema integrado de produção de bebidas/ Cristiane Maria Defalque. São José do Rio Preto: [s.n.], 2010.

106 f.: il. ; $30 \mathrm{~cm}$.

Orientadora: Maria do Socorro Nogueira Rangel.

Dissertação (mestrado) - Universidade Estadual Paulista "Julio de Mesquita Filho", Instituto de Biociências, Letras e Ciências Exatas.

1.Otimização matemática. 2.Programação inteira. 3.Dimensionamento de lotes. 4.Sequenciamento da produção. I. Rangel, Maria do Socorro Nogueira II. Instituto de Biociências, Letras e Ciências Exatas III. Estratégias para incorporação das decisões de sequenciamento em um problema integrado de produção de bebidas.

CDU -519.85 
Cristiane Maria Defalque

\section{Estratégias para incorporação das decisões de sequenciamento em um problema integrado de produção de bebidas}

Dissertação apresentada para obtenção do título de Mestre em Matemática, área de Análise Aplicada junto ao Instituto de Biociências, Letras e Ciências Exatas da Universidade Estadual Paulista "Julio de Mesquita Filho", Campus de São José do Rio Preto.

BANCA EXAMINADORA

Prof $^{\mathrm{a}}$. Dr ${ }^{\mathrm{a}}$. Maria do Socorro Nogueira Rangel

Professor Adjunto

UNESP - São José do Rio Preto

Orientadora

Dra . Deisemara Ferreira

Pesquisadora

UFSCar - São Carlos

Prof. Dr. Silvio Alexandre Araujo

Professor Assistente Doutor

UNESP - São José do Rio Preto

São José do Rio Preto, 23 de Fevereiro de 2010. 
Aos meus pais Eunice e José.

Ao meu irmão Guilherme.

Dedico. 


\section{Agradecimentos}

Primeiramente à Deus, pelo milagre da vida e por mais esta oportunidade de crescimento intelectual e profissional.

À professora Socorro Rangel pela orientação, conselhos, amizade e por todo incentivo durante a elaboração deste trabalho.

À Deisemara Ferreira, pela colaboração durante o desenvolvimento do trabalho e pela disponibilização do código para a modelagem do modelo proposto.

Ao professor Silvio Araújo, pela disponibilização do código de geração de dados.

À minha família que sempre me apoiou e torceu por mim.

Ao Diego, pela compreensão, carinho e incentivo.

Aos amigos Alyne, Cintya, Fábio, Fernando, Heron, José Augusto, José Henrique, Jucilene, Junior, Manuella, Marcos, Michelli, Mirela, Regina, Wallace e a todos os outros colegas pelos dias e noites de estudos, pelas risadas e por todo apoio nos momentos mais difíceis.

Agradeço em especial à Alyne, Marcos e Manuella pela tolerância, amizade e por toda ajuda durante a elaboração da dissertação.

A todos aqueles, professores, funcionários e amigos do IBILCE que, direta ou indiretamente, contribuíram para a elaboração deste trabalho.

Aos professores de graduação que me incentivaram na decisão de lutar por mais esta conquista.

À Capes e CNPq, pelo auxílio financeiro. 


\section{Resumo}

Neste trabalho, propomos um modelo integrado de dimensionamento de lotes e programação da produção para uma fábrica de refrigerantes de pequeno porte denominado P1S1MTS. Neste modelo, as decisões de dimensionamento foram baseadas no modelo P1S1M encontrado na literatura, formulado com base no modelo GLSP. As decisões de sequenciamento foram modeladas utilizando restrições do problema do caixeiro viajante assimétrico. Para a validação do modelo proposto e comparação entre os modelos P1S1MTS e P1S1M foram feitos testes computacionais com exemplares ilustrativos. Foram realizados também testes com exemplares baseados em dados reais da fábrica de refrigerantes e exemplares gerados aleatoriamente. Os testes foram resolvidos pelo método Branch-and-Cut incluído no pacote computacional CPLEX 10.0. Notamos que com algumas modificações, é possível que ambos os modelos retratem a mesma situação. A partir destas modificações e com os resultados obtidos, concluímos que a resolução de exemplares do modelo P1S1MTS apresentou um tempo de execução computacional menor que a resolução de exemplares do modelo P1S1M gerados com os mesmos dados.

Palavras-chave: Dimensionamento de Lotes, Sequenciamento da Produção, Otimização Inteira Mista, Caixeiro Viajante. 


\section{Abstract}

In this work we propose a lot sizing and scheduling model, P1S1MTS, for a smallscale soft drink plant. In this model, the lot sizing decisions were based on the P1S1M model found in the literature. To model the scheduling decisions constraints of the asymmetric traveling salesman problem are used. For the validation of the proposed model and a comparison between the P1S1MTS and the P1S1M models computational tests were executed with illustrative examples. Tests were also executed with examples based on real data and randomly generated instances. The instances were solved by a Branch-and-Cut algorithm included in the software CPLEX 10.0. The results showed that, with some minor modifications, it is possible that both models depict the same situation. From the results obtained we concluded that the P1S1MTS model presented a computational time performance better than the P1S1M model.

Keywords: Lot sizing, Scheduling, Mixed Integer Problems, Traveling Salesman Problem. 


\section{Lista de Símbolos Usados nos Modelos}

\section{Matemáticos}

Conjuntos:

A: conjunto de arestas;

$J$ : conjunto de itens;

$L$ : conjunto de xaropes;

$N$ : conjunto de subperíodos;

$P R$ : Conjunto de todos os produtos onde $P R=1, \ldots, J$;

$Q$ : subconjunto do conjunto $V$;

$S_{t}$ : conjunto de subperíodos do período $t$;

$T$ : número total de períodos;

$V$ : conjunto de vértices.

Parâmetros:

$a_{j}$ : tempo necessário para produzir uma unidade do item $j$;

$a_{j}^{I I}$ : tempo necessário para produzir uma unidade do item $j$ no estágio II;

$b_{i j}$ : tempo de troca do item $i$ para o item $j$;

$b_{i j}^{I I}$ : tempo de troca na máquina (estágio II) do item $i$ para o item $j$;

$c o_{t}$ : custo unitário de hora extra no período $t$;

$d_{t}$ : quantidade da demanda no período $t$;

$d_{j t}$ : quantidade da demanda do item $j$ no período $t$;

$g$ : custo de atraso;

$g_{j}$ : custo de atraso de uma unidade do item $j$;

$h$ : custo de estoque;

$h_{j}$ : custo de estoque de uma unidade do item $j$; 
$I_{j 0}^{+}$: estoque inicial do item $j$;

$I_{j 0}^{-}$: quantidade em atraso do item $j$ no início do horizonte de planejamento;

$K_{t}$ : capacidade de produção da máquina em cada período $t$;

$K_{t}^{I I}$ : capacidade de produção da máquina em cada período $t$ (estágio II);

$K^{I}$ : capacidade total do tanque (Estágio I);

$l m_{t}$ : limite máximo de horas extras permitidas no período $t$;

$m_{j}$ : produção mínima do produto $j$;

$M$ : valor muito grande;

$q_{l}$ : quantidade mínima de xarope necessária para garantir a homogeneidade;

$r_{l j}$ : quantidade de xarope $l$ necessária para a produção de uma unidade do item $j$;

$S_{r}$ : Subrotas formadas;

st: custo/tempo de preparo da máquina;

$s t_{j}$ : custo/tempo de preparo da máquina para a produção do item $j$;

$s_{i j}$ : custo de troca do item $i$ para o item $j$;

$s_{i j}^{I I}$ : custo de troca na máquina (estágio II) do item $i$ para o item $j$;

$y_{j 0}^{I I}$ : preparo inicial da máquina (estágio II) para a produção do item $j$;

$\gamma_{l}$ : conjunto de itens que utilizam o xarope $l$ para serem produzidos;

$\delta_{t}$ : custo de iniciar a produção no período $t$;

$\rho_{j}$ : custo de preparo do item $j$.

Variáveis:

$\varphi_{t}$ : início da produção no período $t ;$

$\varphi_{j t}$ : início da produção do item $j$ no período $t$;

$I_{t}$ : estoque no final do período $t$;

$I_{j t}$ : estoque do item $j$ no final do período $t$;

$I_{t}^{+}$: quantidade em estoque no fim do período $t$

$I_{j t}^{+}$: quantidade em estoque do item $j$ no fim do período $t$;

$I_{t}^{-}$: quantidade em atraso no fim do período $t$;

$I_{j t}^{-}$: quantidade em atraso do item $j$ no fim do período $t$;

$n_{l t}$ : utilização parcial de um tanque do xarope $l$ no período $t$;

$O_{t}$ : quantidade de horas extras utilizadas no período $t$;

$u_{j}$ : ordem em que o vértice $j$ é visitado; 
$u_{j t}$ : posição em que o item $j$ é produzido no período $t$;

$w_{l t}$ : número de tanques do xarope $l$ que devem ser produzidos no período $t$;

$x_{j s}$ : produção do item $j$ no subperíodo $s$;

$x_{j s}^{I I}$ : produção na máquina (estágio II) do item $j$ no subperíodo $s$;

$x_{t}$ : produção no período $t$;

$x_{j t}$ : produção do item $j$ no período $t$

$x_{j t}^{I I}$ : produção na máquina (estágio II) do item $j$ no período $t$;

$y_{j s}$ : preparo da máquina para a produção do item $j$ no subperíodo $s$;

$y_{j s}^{I I}$ : preparo da máquina (estágio II) para a produção do item $j$ no subperíodo $s$;

$y_{t}:$ preparo da máquina no período $t$;

$y_{j t}$ : preparo da máquina para a produção do item $j$ no período $t$;

$y_{l s}^{I}$ : preparo do tanque (estágio I) para a produção do xarope $l$ no subperíodo $s$;

$y_{l t}^{I}$ : preparo do tanque (estágio I) para a produção do xarope $l$ no período $t$;

$z_{i j s}$ : troca do item $i$ para o item $j$ no subperíodo $s$;

$z_{i j s}^{I I}$ : troca na máquina (estágio II) do item $i$ para o item $j$ no subperíodo $s$;

$z_{i j t}$ : troca do item $i$ para o item $j$ no período $t$;

$z_{i j t}^{I I}$ : troca na máquina (estágio II) do item $i$ para o item $j$ no período $t$. 


\section{Sumário}

$\begin{array}{ll}\text { Introdução } & 1\end{array}$

1 Métodos de solução para problemas de otimização inteiro misto 3

1.1 Conceitos preliminares . . . . . . . . . . . . . . . 3

1.2 Inequações válidas . . . . . . . . . . . . . . . . . 6

1.2.1 Procedimento de Chvátal-Gomory . . . . . . . . . . . . . . . . . . 11

1.3 Método de Planos de Corte . . . . . . . . . . . . . . . . . . . 12

1.3.1 Corte Fracionário de Gomory . . . . . . . . . . . . . . . . . 12

1.4 Método Branch-and-Bound . . . . . . . . . . . . . . . . 15

2 Modelos de dimensionamento e sequenciamento de lotes 20

2.1 Problemas de dimensionamento de lotes . . . . . . . . . . . . . . . . . 20

2.2 Problemas de sequenciamento de lotes . . . . . . . . . . . . 25

2.2.1 O problema de sequenciamento da produção e o problema do caixeiro viajante . . . . . . . . . . . . . . . . . . . . 28

2.3 Problemas integrados de dimensionamento e sequenciamento de lotes . . . 28

2.3.1 Modelos integrados utilizando o problema do caixeiro viajante para incorporação do sequenciamento . . . . . . . . . . . . 34

3 Planejamento da Produção de Bebidas $\quad 41$

3.1 Histórico de produção . . . . . . . . . . . . . . . . . . . . . 41

3.1.1 Processo de produção de bebidas . . . . . . . . . . . . . . . 46

3.2 Modelo P1S1M . . . . . . . . . . . . . . . . . . . . . . . 48

3.3 Modelo P1S1MTS: Uma nova proposta . . . . . . . . . . . . . . . . . 52

3.4 Validação do modelo P1S1MTS . . . . . . . . . . . . . 58

3.4.1 Experimentos com exemplos ilustrativos - Exemplar 1 . . . . . . . 59 
3.4.2 Análise dos resultados fornecidos pelo modelo P1S1MTS no modelo P1S1M - Exemplar $1 \ldots \ldots \ldots 2$

3.4.3 Análise dos resultados fornecidos pelo modelo P1S1M no modelo P1S1MTS - Exemplar $1 \ldots \ldots \ldots 6$

3.4.4 Experimentos com exemplos ilustrativos - Exemplar 2 . . . . . . 68

3.4.5 Conclusão da análise feita na Seção 3.4 de validação do modelo . . 68

4 Estudos Computacionais $\quad 70$

4.1 Testes com exemplares baseados em dados reais . . . . . . . . . . . . . . 71

4.1.1 Comparação dos resultados: Fábrica $\times$ Modelos . . . . . . . . . . . 72

4.1.2 Comparação dos resultados: P1S1M × P1S1MTS . . . . . . . . . . 76

4.2 Exemplares Aleatórios . . . . . . . . . . . . . . . . . . . 81

4.2 .1 Geração dos dados . . . . . . . . . . . . . . . . . . 81

4.2 .2 Testes com dados aleatórios . . . . . . . . . . . . . . . . 82

$\begin{array}{llr}5 & \text { Conclusões e perspectivas futuras } & 87\end{array}$

$\begin{array}{lr}\text { Referências Bibliográficas } & 89\end{array}$

A Reformulações para o problema do caixeiro viajante $\quad 99$

A.1 Definição do problema e formulações . . . . . . . . . . . . . . . . . . . . 99

A.2 Reformulações para o PCV . . . . . . . . . . . . . . . . . . . 101

A.3 O problema do caminho hamiltoniano . . . . . . . . . . . . . . . 102

B Dados dos exemplares ilustrativos 104 


\section{Introdução}

Por causa das transformações que têm afetado a ordem econômica mundial, o Brasil tem experimentado profundas mudanças no seu setor produtivo no que diz respeito à modernização de seus processos de produção, melhoria da qualidade de seus produtos e racionalização administrativa. Por este motivo, as indústrias têm recebido um crescente estímulo para otimizar seus processos buscando ampliar seu potencial. O sucesso das indústrias está diretamente relacionado ao planejamento de sua produção que muitas vezes envolve a produção de diversos itens, utilizando várias máquinas a fim de atender à demanda de maneira eficiente visando por exemplo, reduzir custos.

Muitas vezes, o planejamento da produção envolve o dimensionamento dos lotes e o sequenciamento dos itens. O primeiro problema consiste em determinar o tamanho dos lotes de produção de cada item a ser produzido em uma ou mais máquinas em cada período ao logo do horizonte de planejamento. O segundo problema consiste em encontrar a ordem em que os itens devem ser produzidos em um dado conjunto de máquinas. Estes dois aspectos do planejamento da produção podem ser tratados de forma independente: em uma etapa é resolvido o problema de dimensionamento dos lotes, e na outra, realizada antes ou depois, é resolvido o problema de sequenciamento. Boa parte das empresas resolvem o problema do dimensionamento e sequenciamento dos lotes de produção em etapas diferentes. No entanto, uma tendência na literatura são trabalhos que apresentam modelos matemáticos que capturam simultaneamente as relações entre os dois problemas. Exemplos de problemas de dimensionamento e sequenciamento de lotes são encontrados nas decisões do planejamento de produção de indústrias de fabricação de bebidas [36], ração animal [89] e de fundição [11].

A natureza combinatória de tais problemas os torna de difícil solução do ponto de vista de complexidade computacional ( ver por exemplo [41] e [23]) e apesar do avanço da ciência e da tecnologia, ainda existem vários tipos de problemas que não possuem um 
método de solução capaz de fornecer uma solução ótima rapidamente, como é o caso dos modelos de programação inteira mista que integram os problemas de dimensionamento e sequenciamento de lotes considerando tempos e custos de preparos das máquinas. Por isso, é interessante o estudo de métodos de solução que ajudem na obtenção de bons resultados para estes modelos.

Neste trabalho apresentamos um modelo de programação inteira mista que modela o planejamento da produção de uma fábrica de refrigerantes de pequeno porte. O modelo proposto envolve as decisões de dimensionamento de lotes formuladas com base no modelo P1S1M proposto em [36] integradas às decisões de sequenciamento da produção, baseadas no problema do caixeiro viajante [60]. O modelo obtido foi resolvido utilizando um método que combina o método de planos de corte e o método Branch-and-Bound, conhecido como Branch-and-Cut [71] incluídos no pacote computacional CPLEX 10.0 [54].

No capítulo 1, discutimos resumidamente a teoria dos poliedros, reformulações e métodos de solução exatos para os problemas de programação inteira mista: o método de Planos de Corte, o método Branch-and-Bound e o método Brach-and-Cut.

No capítulo 2 é feita uma breve revisão bibliográfica dos problemas de dimensionamento de lotes, sequenciamento da produção e problemas integrados. São discutidos também trabalhos que formulam o sequenciamento dos itens com base no problema do caixeiro viajante e trabalhos que estudam a programação da produção de bebidas.

No capítulo 3 é descrito resumidamente o processo de produção de bebidas e são apresentados dois modelos que integram o dimensionamento e o sequenciamento de lotes para a produção de refrigerantes. O primeiro é um modelo encontrado na literatura baseado no modelo GLSP [36] e o segundo é o modelo proposto, mencionado acima. São apresentados também testes com exemplares ilustrativos para a validação do modelo proposto e para a comparação entre os modelos citados.

No capítulo 4 são apresentados os testes computacionais obtidos com a resolução de exemplares dos modelos pelo método Branch-and-Cut incluido no pacote computacional CPLEX 10.0 [54]. São apresentados também testes com dados de uma fábrica de refrigerantes de pequeno porte e com dados gerados aleatoriamente.

No capítulo 5 são apresentadas as conclusões e propostas futuras. 


\section{Capítulo 1}

\section{Métodos de solução para problemas de otimização inteiro misto}

Neste capítulo, são apresentados alguns conceitos básicos sobre a teoria dos poliedros e reformulações e apresentados resumidamente, alguns métodos de resolução para os problemas de otimização inteiro misto. Na teoria dos poliedros são discutidas formulações que se aproximam do envoltório convexo de um conjunto de pontos viáveis e que por isso, podem facilitar a resolução de Problemas de Otimização Inteiro ou Inteiro Misto por métodos de resolução exatos como o Branch-and-Bound e Branch-and-Cut. A inclusão de inequações válidas, ou planos de corte, de forma iterativa, pode levar ao melhoramento dos limites duais fornecidos durante o desenvolvimento do Branch-and-Bound. Uma dificuldade dos métodos exatos é que eles nem sempre fornecem uma solução em um tempo computacional viável para sua aplicação prática. Outros métodos também apresentados neste capítulo são os métodos heurísticos que buscam alcançar uma boa solução utilizando um esforço computacional razoável.

\subsection{Conceitos preliminares}

Considere as seguintes formulações de um problema de otimização linear inteiro [74] e [94].

$$
Z=\min \left\{c x: A x \geq b, x \in \mathbb{Z}_{+}^{n}\right\}
$$

E de um problema inteiro misto:

$$
Z=\min \left\{c x+f y: A x+B y \geq b,(x, y) \in \mathbb{R}_{+}^{n} \times \mathbb{Z}_{+}^{p}\right\} .
$$


onde: $A$ e $B$ são matrizes racionais de dimensões $(m \times n)$ e $(m \times p)$ respectivamente e que representam os coeficientes das restrições do problema e $b$ é um vetor com elementos racionais e dimensão $(m \times 1)$. Os coeficientes da função objetivo, $c$ e $f$, têm dimensões $(1 \times n)$ e $(1 \times p)$ respectivamente, $x$ e $y$ são os vetores das variáveis no qual $x$ possui dimensão $(n \times 1)$ e $y(p \times 1)$. Além disso, $Z$ representa o valor ótimo da função objetivo. As definições a seguir são dadas para $P I$, mas são análogas para PIM.

Definição 1.1. Dado um PI, o conjunto

$$
X=\left\{x \in \mathbb{Z}_{+}^{n}: A x \geq b\right\}
$$

é o conjunto das soluções viáveis.

Definição 1.2. Um subconjunto $P \subset \mathbb{R}^{n}$ é chamado poliedro se $P$ puder ser escrito como um conjunto finito de restrições lineares. Isto é, $P=\left\{x \in \mathbb{R}^{n}: A x \geq b\right\}$.

Um poliedro $P \subseteq \mathbb{R}^{n}$ limitado isto é, existe um $w \in \mathbb{R}_{+}$tal que $P \subseteq\left\{x \in \mathbb{R}^{n}\right.$ : $\left.-w \leq x_{j} \leq w, j=1, \ldots, n\right\}$, é denominado politopo.

Definição 1.3. Um poliedro $P \subseteq \mathbb{R}^{n}$ é uma formulação para o conjunto $X \subseteq \mathbb{Z}^{n}$ se $e$ somente se $X=P \cap \mathbb{Z}^{n}$.

A Figura 1.1 abaixo mostra duas formulações diferentes representadas pelas linhas contínuas e tracejadas, para um mesmo conjunto $X$.

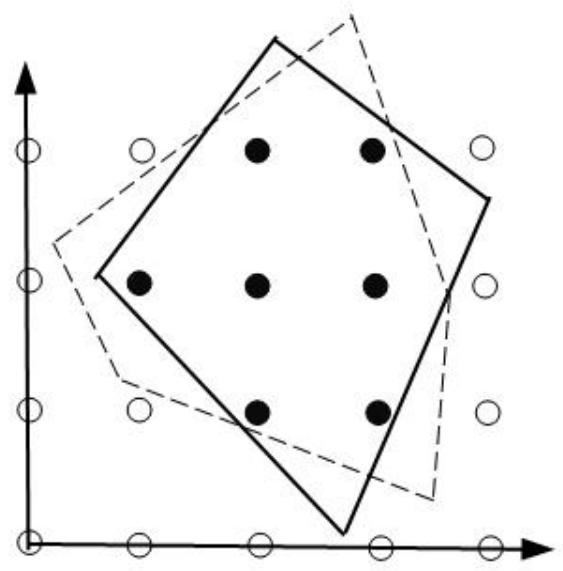

Figura 1.1: Duas formulações para X [74]

É importante observar que um PI pode ter várias formulações, mas como determinar qual é a melhor? Considere a Definição 1.4 abaixo.

Definição 1.4. Dado um PI e uma formulação $P$ para $X$ 


$$
z^{R L}=\min \{c x: x \in P\}
$$

é uma relaxação linear para PI.

Uma maneira de analisar essa questão é resolvendo a relaxação linear do problema relativa às formulações. De acordo com Wolsey [94], dadas duas formulações, dizemos que uma formulação é mais forte que a outra se a primeira fornece um limitante dual melhor, ou seja, no caso de um problema de minimização, um limitante inferior maior.

Dadas duas formulações $P^{1}$ e $P^{2}$ para $X$, dizemos que $P^{1}$ é melhor que $P^{2}$ se $P^{1} \subset P^{2} \mathrm{e}$

$$
z \geq z^{P 1} \geq z^{P 2} \text { onde } z^{P 1}=\min \left\{c x: x \in P^{1}\right\} \text { e } z^{P 2}=\min \left\{c x: x \in P^{2}\right\} .
$$

Na procura de formulações melhores, o objetivo é encontrar o envoltório convexo, definido a seguir.

Definição 1.5. Dado um conjunto $X \subseteq \mathbb{R}^{n}$, um ponto $x \in \mathbb{R}^{n}$ é uma combinação convexa de pontos de $X$ se existir um conjunto de pontos $\left\{x^{i}\right\}_{i=1}^{t}, x^{i} \in X$ tal que:

$$
x=\sum_{i=1}^{t} \lambda_{i} x^{i}, \quad \sum_{i=1}^{t} \lambda_{i}=1, \quad \lambda_{i} \geq 0
$$

Definição 1.6. $x \in P \subseteq \mathbb{R}^{n}$ é um ponto extremo de $P$ se não existem $x_{1}, x_{2} \in P$ tal que $x_{1} \neq x_{2}$ e $x=\frac{1}{2} x_{1}+\frac{1}{2} x_{2}$.

Ou seja, $x$ é um ponto extremo de $P$ se $x$ não pode ser escrito como combinação convexa de dois outros pontos diferentes de $x$ e pertencentes a $P$.

Definição 1.7. O envoltório convexo de $X, C o n v(X)$, é o conjunto de todos os pontos que são combinações convexas de pontos de $X$.

Proposição 1.1. Conv $(X)$ é um Poliedro.

Proposição 1.2. Os pontos extremos de Conv $(X)$ pertencem a $X$.

Logo, segue que o envoltório convexo é a melhor formulação para $X$. A Figura 1.2 ilustra o envoltório convexo dos pontos do conjunto $X$. 


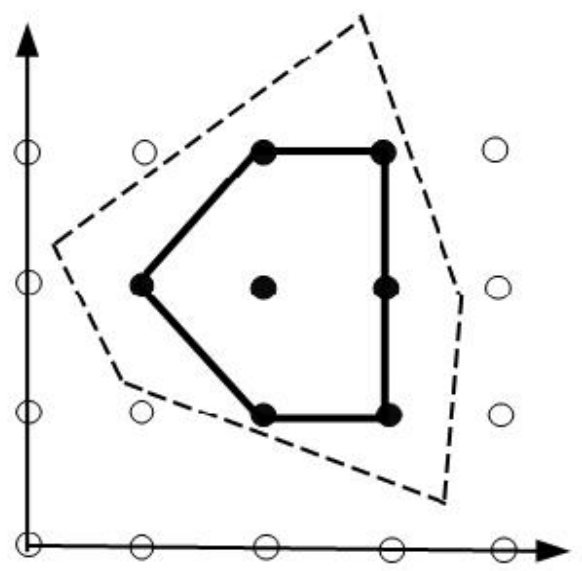

Figura 1.2: Envoltório Convexo dos pontos de X [74].

A grande vantagem de encontrar o envoltório convexo de um dado conjunto de pontos viáveis de um PI ou PIM é que o problema poderá ser resolvido como um Problema de Otimização Linear Contínuo, pois de acordo com a Proposição 1.2, os pontos extremos do $\operatorname{Conv}(X)$ pertencem a $X$. Entretanto, encontrar o envoltório convexo de um conjunto $X$, em geral, não é uma tarefa fácil.

Existem algumas maneiras de descrever o envoltório convexo, sendo que uma delas consiste em identificar os pontos extremos e através deles representar todos os pontos extremos desse poliedro.

Dados os pontos extremos de um politopo, podemos descrever o envoltório convexo por meio da combinação convexa desses pontos.

\subsection{Inequações válidas}

O envoltório convexo também pode ser descrito por meio de um conjunto de inequações, discutidas a seguir.

Proposição 1.3. $\pi x \geq \pi_{0}$ é uma inequação válida para $P=\{x: A x \geq b, x \geq 0\} \neq \emptyset$ se e somente se existe $u \geq 0$ tal que $u A \leq \pi$ e $u b \geq \pi_{0}$.

Proposição 1.4. A inequação $x \geq\lfloor b\rfloor$ é válida para $X=\{x \in \mathbb{Z}: x \geq b\}$.

No caso de um $P I$, dizer que uma inequação é válida para o conjunto $X$ de soluções viáveis desse problema é o mesmo que dizer que é válida para $P=\operatorname{Conv}(X)$. 
Definição 1.8. Se $\pi x \geq \pi_{0}$ e $\mu x \geq \mu_{0}$ são duas inequações válidas para o poliedro $P \subseteq \mathbb{R}_{+}^{n}$, então $\pi x \geq \pi_{0}$ domina $\mu x \geq \mu_{0}$ se existe $u>0$ tal que $\pi \leq u \mu$ e $\pi_{0} \geq u \mu_{0}$, e $\left(\pi, \pi_{0}\right) \neq\left(u \mu, u \mu_{0}\right)$.

Observe que se $\pi x \geq \pi_{0}$ domina $\mu x \geq \mu_{0}$, então $\left\{x \in \mathbb{R}_{+}^{n}: \pi x \geq \pi_{0}\right\} \subseteq\left\{x \in \mathbb{R}_{+}^{n}\right.$ : $\left.\mu x \geq \mu_{0}\right\}$.

Definição 1.9. Uma inequação válida $\pi x \geq \pi_{0}$ é redundante na descrição de um poliedro $P \subseteq \mathbb{R}^{n}$, se existe $k \geq 2$ inequações válidas $\pi^{i} x \geq \pi_{0}^{i}$ para $i=1, \ldots, k$ para $P$, e pesos $u^{i}>0$ para $i=1, \ldots, k$ tal que $\left(\sum_{i=1}^{k} u_{i} \pi^{i}\right) x \geq \sum_{i=1}^{k} u_{i} \pi_{0}^{i}$ domina $\pi x \geq \pi_{0}$.

Aqui podemos observar que $\left\{x \in \mathbb{R}_{+}^{n}: \pi^{i} x \geq \pi_{0}^{i}, i=1, \ldots, k\right\} \subseteq\left\{x \in \mathbb{R}_{+}^{n}:\left(\sum_{i=1}^{k} u_{i} \pi^{i}\right) x \geq \sum_{i=1}^{k} u_{i} \pi_{0}^{i}\right\} \subseteq\left\{x \in \mathbb{R}_{+}^{n}: \pi x \geq \pi_{0}\right\}$.

Exemplo 1.1. Tomando $n=2,\left(\pi ; \pi_{0}\right)=(1,3 ; 4),\left(\mu ; \mu_{0}\right)=(2,4 ; 9)$ e $u=\frac{1}{2}$, temos que $\pi \geq \frac{1}{2} \mu$ e $\pi_{0} \leq \frac{1}{2} \mu_{0}$, logo pela Definição 1.8 a inequação $x_{1}+3 x_{2} \leq 4$ domina $2 x_{1}+4 x_{2} \leq 9$. Veja a Figura 1.3.

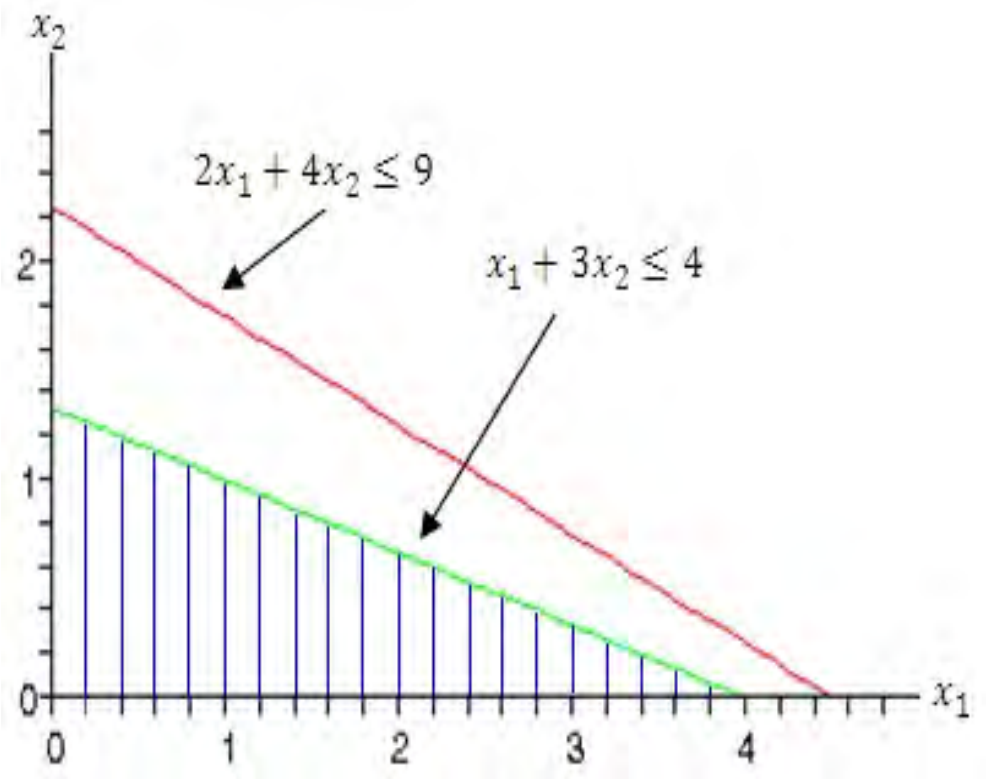

Figura 1.3: Dominância das inequações [94].

$N a$ Figura 1.4, temos $n=2$ e $P=\left\{x \in \mathbb{R}_{+}^{n}: 6 x_{1}-x_{2} \leq 9\right.$, $\left.9 x_{1}-5 x_{2} \leq 6\right\}$. Considere a inequação válida $5 x_{1}-2 x_{2} \leq 6$ para $P$. Tomando $u=\left(\frac{1}{3}, \frac{1}{3}\right)$ podemos ver que $5 x_{1}-2 x_{2} \leq 5$ é redundante. 


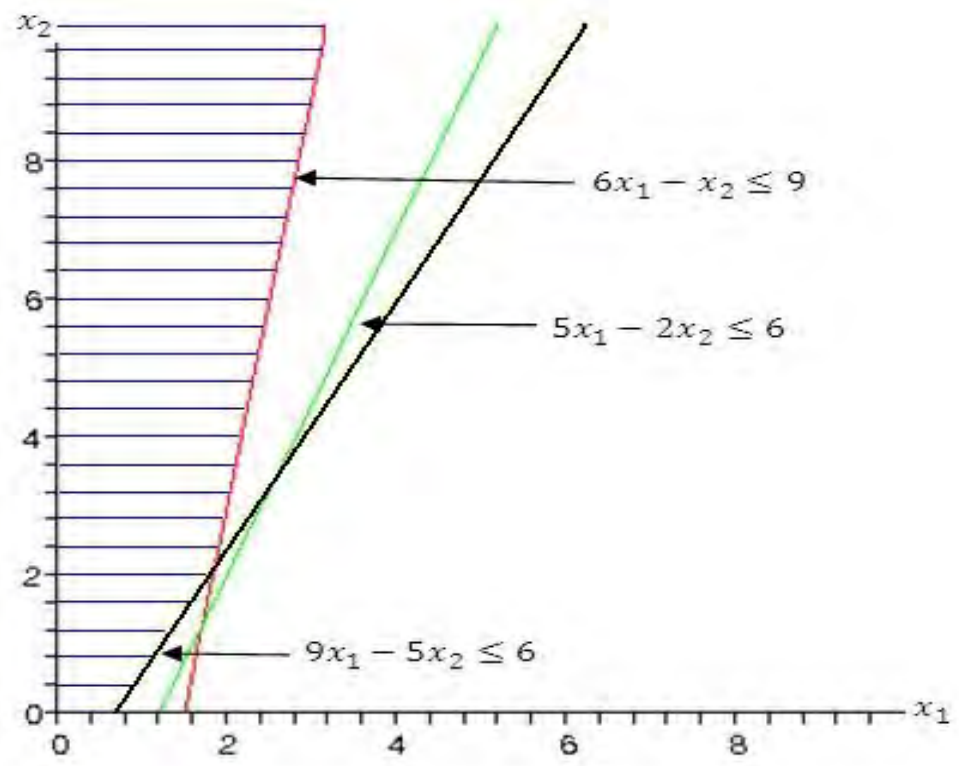

Figura 1.4: Dominância das inequações [94].

Quando $P=\operatorname{Conv}(X)$ não é explicitamente conhecido, checar redundância pode ser muito difícil. Teoricamente é importante conhecer quais inequações são necessárias ou são redundantes na descrição de $P$. Na prática, o importante é evitar usar inequações em que a dominância será certamente encontrada.

Definição 1.10. Um conjunto $x^{0}, x^{1}, \ldots, x^{k}$ de $k+1$ pontos em $\mathbb{R}^{n}$ são afim-independentes se a única solução de

$$
\sum_{i=0}^{k} \alpha_{i} x^{i}=0, \quad \sum_{i=0}^{k} \alpha_{i}=0
$$

é $\alpha_{i}=0$ para $i=0, \ldots, k$, Ou, equivalentemente, um conjunto $x^{0}, x^{1}, \ldots, x^{k}$ de $k+1$ pontos em $\mathbb{R}^{n}$ são afim-independentes se os $k$ vetores $x^{1}-x^{0}, \ldots, x^{k}-x^{0}$ são linearmente independentes.

Podemos observar que se um conjunto de pontos é linearmente independente, então os pontos são afim-independentes. Entretanto, se os pontos são afim-independentes eles não são necessariamente linearmente independentes.

Definição 1.11. Um poliedro $P \subseteq \mathbb{R}^{n}$ é de dimensão $k, \operatorname{dim}(P)=k$, se o número máximo de pontos afim-independentes em $P$ é $k+1$.

Assim, um poliedro $P \subseteq \mathbb{R}^{n}$ tem dimensão completa se e somente se $\operatorname{dim}(P)=n$.

Teorema 1.1. Se $P \subseteq \mathbb{R}^{n}$ é um poliedro de dimensão completa, ele tem uma descrição única e minima

$$
P=\left\{x \in \mathbb{R}^{n}: a^{i} x \geq b_{i} \text { para } i=1,2, \ldots, m\right\}
$$


onde cada inequação é única, a menos de um múltiplo positivo.

Isto significa que se uma das inequações da descrição mínima é removida, o poliedro resultante é menor que $P$, logo cada inequação é necessária. Por outro lado, toda inequação válida $\pi x \geq \pi_{0}$ para $P$ que não seja um múltiplo positivo de uma das inequações $a^{i} x \geq b_{i}, \quad i=1, \ldots, m$ é redundante pois é uma combinação não negativa de duas ou mais inequações válidas.

Definição 1.12. F define uma face do poliedro $P \subseteq \mathbb{R}^{n}$ se $F=\left\{x \in P: \pi x=\pi_{0}\right\}$ para alguma inequação válida $\pi x \geq \pi_{0}$ de $P$.

Definição 1.13. Seja $P \subseteq \mathbb{R}^{n}$ um poliedro. A inequação $\pi x \geq \pi_{0}$ será um hiperplano suporte de $P$ se $P \subseteq\left\{x \in \mathbb{R}^{n}: \pi x=\pi_{0}\right\}$, ou seja, todos os pontos de $P$ satisfazem $\pi x \geq \pi_{0}$ na igualdade.

Identificar inequações válidas para um poliedro $P$, que definem hiperplanos suporte, é importante na determinação da dimensão de $P$ além de serem essenciais para a descrição do poliedro.

Proposição 1.5. Sejam $P \subseteq \mathbb{R}^{n}$ e $\sigma$ o número de hiperplanos suporte que contém $P$, então $\operatorname{adim}(P)=n-\sigma$.

Exemplo 1.2. Considere um poliedro $P \subseteq \mathbb{R}^{3}$ definido pelas inequações (1.1)-(1.5):

$$
\begin{aligned}
2 x_{1}+x_{2}+x_{3} & \leq 2 \\
x_{2}+x_{3} & \geq 1 \\
2 x_{1} & \geq 1 \\
x_{2} & \leq 1 \\
-x_{3} & \leq 0
\end{aligned}
$$

Temos que os pontos que satisfazem as inequações (1.2) e (1.3) também satisfazem $2 x_{1}+x_{2}+x_{3} \geq 2$. Assim os pontos de $P$ deverão satisfazer $2 x_{1}+x_{2}+x_{3} \geq 2$ e as restrições (1.1). Logo, $P \subset\left\{x \in \mathbb{R}^{n}: 2 x_{1}+x_{2}+x_{3}=2\right\}$. Portanto, existe um hiperplano que contém P. Note também que, os pontos $(1,0,0),(0,1,0)$ e $(0,0,1)$ pertencem ao poliedro $P$ e são afim - independentes. Logo, podemos concluir que $\operatorname{dim}(P)=3-1=2$. 
Definição 1.14. (i) F é uma faceta de $P$ se $F$ é uma face de $P$ e $\operatorname{dim}(F)=\operatorname{dim}(P)-1$. (ii) Se $F$ é uma face de $P$ com $F=\left\{x \in P: \pi x=\pi_{0}\right\}$, a inequação válida $\pi x \geq \pi_{0}$ representa ou define a face $F$.

Proposição 1.6. Se $P \subseteq \mathbb{R}^{n}$ é um poliedro com dimensão completa, uma inequação válida $\pi x \geq \pi_{0}$ é necessária na descrição de $P$ se e somente se define uma faceta de $P$. Ou seja, para um poliedro com dimensão completa, $\pi x \geq \pi_{0}$ define uma faceta de $P$ se e somente se existem $n$ pontos de P afim - independentes satisfazendo a inequação válida na igualdade.

Exemplo 1.3. [94] Considere o poliedro $P \subset \mathbb{R}^{n}$ descrito pelas equações (1.6) - (1.12) e mostrado na Figura 1.5 a seguir:

$$
\begin{aligned}
x_{1} & \leq 2 \\
x_{1}+x_{2} & \leq 4 \\
x_{1}+2 x_{2} & \leq 10 \\
x_{1}+2 x_{2} & \leq 6 \\
x_{1}+x_{2} & \geq 2 \\
x_{1} & \geq 0 \\
x_{2} & \geq 0 .
\end{aligned}
$$

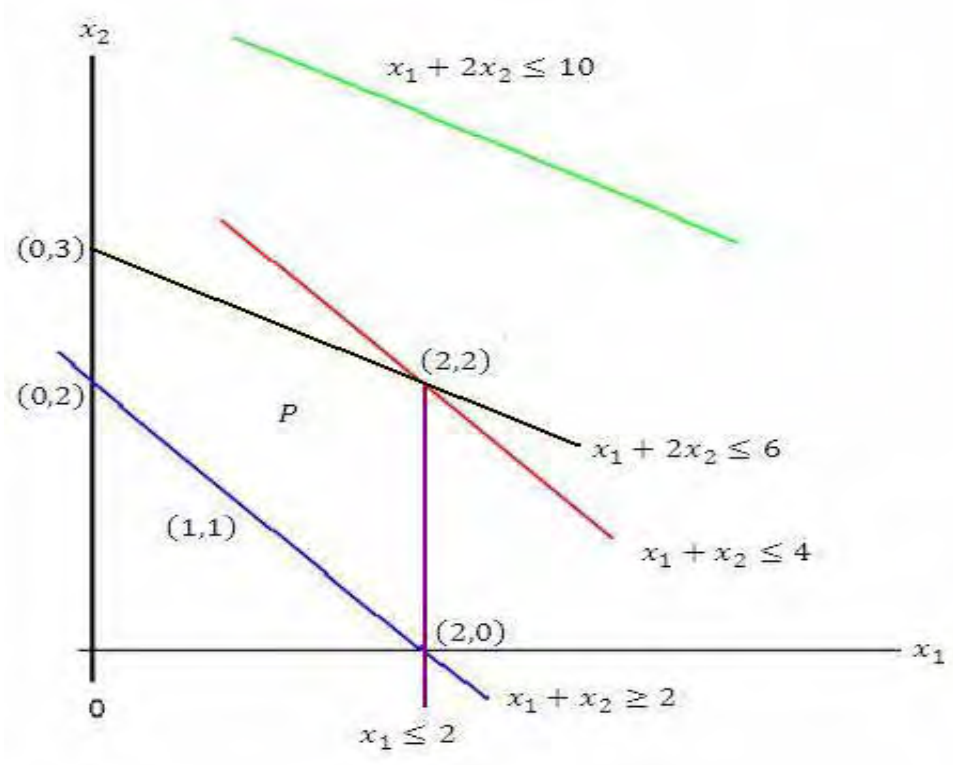

Figura 1.5: Facetas e faces de um poliedro [94]. 
Os pontos $(2,0),(1,1)$ e $(2,2)$ são três pontos afim-independentes de $P$, assim $P$ é um poliedro de dimensão completa.

$A$ inequação $x_{1} \leq 2$ define uma faceta de $P$, pois $(2,0)$ e $(2,2)$ são dois pontos afim - independentes que satisfazem $x_{1}=2$. Da mesma forma as inequações $x_{1}+2 x_{2} \leq 6$, $x_{1}+x_{2} \geq 2$ e $x_{1} \geq 0$ definem facetas.

Por outro lado, a inequação $x_{1}+x_{2} \leq 4$ define uma face consistindo de um único ponto $(2,2)$ de $P$ e então é redundante.

$A$ inequação $x_{2} \geq 0$ é a soma das inequações $x_{1} \leq 2 e-x_{1}-x_{2} \leq-2$, logo também é redundante.

Portanto a descrição mínima desse poliedro é dada pelas inequações (1.13)-(1.16):

$$
\begin{aligned}
x_{1} & \leq 2 \\
2 x_{1}+x_{2} & \leq 6 \\
x_{1}+x_{2} & \geq 2 \\
x_{1} & \geq 0 .
\end{aligned}
$$

Se uma inequação válida define uma faceta ou, de outra forma, ajuda a definir o envoltório convexo, podemos dizer que é uma inequação válida forte.

Na próxima seção, será descrito o procedimento de Chvátal- Gomory utilizado para a construção de inequações válidas.

\subsubsection{Procedimento de Chvátal-Gomory}

Seja $X=P \cap \mathbb{Z}^{n}$ onde $P=\left\{x \in \mathbb{R}_{+}^{n}: A x \leq b\right\}$ tal que $A \in \mathbb{R}^{m \times n}, A_{j}$ são colunas de $A$ e $u \in \mathbb{R}_{+}^{m}$. Um procedimento geral para a construção de uma inequação válida para o conjunto $X$ é conhecido como procedimento de Chvátal-Gomory e está descrito a seguir (veja por exemplo [12]).

Considere as Proposições 1.3 e 1.4. Então,

- a inequação $\sum_{j=1}^{n} u A_{j} x_{j} \leq u b$ é válida para $X$, pois $u \geq 0$ e $\sum_{j=1}^{n} A_{j} x_{j} \leq b$;

- a inequação $\sum_{j=1}^{n}\left\lfloor u A_{j}\right\rfloor x_{j} \leq b$ é válida para $X$, pois $x \geq 0$ e $\left\lfloor u A_{j}\right\rfloor \leq u A_{j}$; 
- a inequação $\sum_{j=1}^{n}\left\lfloor u A_{j}\right\rfloor x_{j} \leq\lfloor u b\rfloor$ é válida para $X$, pois $x \in \mathbb{Z}$ e, portanto, $\sum_{j=1}^{n}\left\lfloor u A_{j}\right\rfloor x_{j}$ é inteiro.

Teorema 1.2. Toda inequação válida para $X$ pode ser obtida aplicando o procedimento de Chvátal-Gomory um número finito de vezes.

Exemplo 1.4. Seja $X=\left\{x \in \mathbb{Z}_{+}^{4}: 5 x_{1}+7 x_{2}+4 x_{3}+6 x_{4} \leq 35\right\}$. Para encontrar um inequação válida que corte o ponto (0, 0, 0, 35/6), aplicaremos o procedimento de Chvátal-Gomory:

Multiplicando $X$ por $u=1 / 6$, temos

$\lfloor 5 / 6\rfloor x_{1}+\lfloor 7 / 6\rfloor x_{2}+\lfloor 4 / 6\rfloor x_{3}+x_{4} \leq\lfloor 35 / 6\rfloor$.

Segue que a inequação $x_{2}+x_{4} \leq 5$ é válida para $X$.

\subsection{Método de Planos de Corte}

Na Seção 1.2, tratamos de inequações válidas que, quando acrescentadas ao modelo, diminuem a região factível da relaxação linear sem "cortar"soluções inteiras, aproximandose assim, do envoltório convexo. Encontrar este tipo de inequação implica em encontrar um hiperplano que separe um ponto infactível da região factível [74]. Este problema é conhecido como problema da separação.

A idéia básica do método de planos de corte é tratar o problema de otimização linear inteiro como um problema de otimização linear contínuo e acrescentar a este problema, de forma iterativa, inequações válidas (planos de corte) ou seja, ele tenta se aproximar do envoltório convexo. Este corte é feito de forma a eliminar a solução ótima da relaxação linear obtida a cada iteração, quando este for infactível para o problema inteiro [63].

\subsubsection{Corte Fracionário de Gomory}

Seja o problema de programação inteira $(P I) Z=\min \{c x: A x=b, x \in \mathbb{Z}\}$ e sua relaxação linear $(P L) \bar{Z}=\min \{c x: A x=b, x \in \mathbb{R}\}$.

Considere a solução ótima de $\bar{Z}$ em que $x_{B_{i}}$ representa a $B_{i}$-ésima variável básica, $B$ representa a matriz das variáveis básicas e $N$ denota a matriz das variáveis não básicas. Considere também que $A_{j}$ é a $j$-ésima coluna de $A, \overline{A_{j}}=B^{-1} A_{j}$ e $\bar{b}=B^{-1} b$. Assim, temos que: 


$$
\begin{aligned}
& B x_{B}+N x_{N}=b \\
& x_{B}+B^{-1} N x_{N}=B^{-1} b \\
& x_{B}=B^{-1} b-B^{-1} N x_{N}
\end{aligned}
$$

$\log \mathrm{O}$

$x_{B}=\bar{b}-\sum_{j \in N B} \overline{A_{j}} x_{j}$.

Sejam $x_{B_{i}}$ a $B_{i}$-ésima variável básica e $\bar{a}_{B_{i} j}$ corresponde aos elementos de $A_{j}$. Então,

$$
x_{B_{i}}=\overline{b_{i}}-\sum_{j \in N B} \bar{a}_{B_{i j}} x_{j}
$$

que pode ser reescrito como :

$$
x_{B_{i}}+\sum_{j \in N B} \bar{a}_{B_{i j}} x_{j}=\overline{b_{i}}
$$

Aplicando o procedimento de Chvátal-Gomory à equação (2) obtemos:

$$
\begin{aligned}
& x_{B_{i}}+\sum_{j \in N B}\left\lfloor\bar{a}_{B_{i j}}\right\rfloor x_{j} \leq \overline{b_{i}} \\
& x_{B_{i}}+\sum_{j \in N B}\left\lfloor\bar{a}_{B_{i j}}\right\rfloor x_{j} \leq\left\lfloor\overline{b_{i}}\right\rfloor
\end{aligned}
$$

Substituindo (1) em (4), temos:

$$
\begin{aligned}
& \overline{b_{i}}-\sum_{j \in N B} \bar{a}_{B_{i j}} x_{j}+\sum_{j \in N B}\left\lfloor\bar{a}_{B_{i j}}\right\rfloor x_{j} \leq\left\lfloor\overline{b_{i}}\right\rfloor \\
& \sum_{j \in N B}\left(\left\lfloor\bar{a}_{B_{i j}}\right\rfloor-\bar{a}_{B_{i j}}\right) x_{j} \leq\left(\left\lfloor\bar{b}_{i}\right\rfloor-\overline{b_{i}}\right) \\
& \sum_{j \in N B}-f_{B_{i j}} x_{j} \leq-g_{i}
\end{aligned}
$$

Portanto, a inequação

$$
\sum_{j \in N B} f_{B_{i j}} x_{j} \geq g_{i}
$$


é válida e é chamada de plano de corte de Gomory.

onde $f_{B_{i j}}=\bar{a}_{i j}-\left\lfloor\bar{a}_{i j}\right\rfloor$ e $g_{i}=\bar{b}_{i}-\left\lfloor\bar{b}_{i}\right\rfloor$.

Exemplo 1.5. Sejam $S=\left\{x \in \mathbb{R}_{+}^{4}: 2 x_{1}+6 x_{2}+15 x_{3}+10 x_{4} \geq 20\right\} \cap \mathbb{Z}^{4}$ e $x^{*}=$ $(0,0,4 / 5,0)$. Para encontrar uma inequação válida que separe $x^{*}$ de $S$, considere que:

$2 x_{1}+6 x_{2}+15 x_{3}+10 x_{4}-x_{5}=20$

Então,

$$
\begin{aligned}
& \frac{2}{15} x_{1}+\frac{6}{15} x_{2}+x_{3}+\frac{10}{15} x_{4}-\frac{1}{15} x_{5}=\frac{20}{15} \\
& \left\lfloor\frac{2}{15}\right\rfloor x_{1}+\left\lfloor\frac{6}{15}\right\rfloor x_{2}+x_{3}+\left\lfloor\frac{10}{15}\right\rfloor x_{4}-\left\lfloor\frac{1}{15}\right\rfloor x_{5}=\left\lfloor\frac{20}{15}\right\rfloor
\end{aligned}
$$

Isolando $x_{3}$ em 1 , substituindo em 2 e fazendo algumas simplificações temos:

$$
\left(\frac{2}{15}-\left\lfloor\frac{2}{15}\right\rfloor\right) x_{1}+\left(\frac{2}{5}-\left\lfloor\frac{2}{5}\right\rfloor\right) x_{2}+\left(\frac{2}{3}-\left\lfloor\frac{2}{3}\right\rfloor\right) x_{4}+\left(\frac{1}{15}-\left\lfloor\frac{1}{15}\right\rfloor\right) x_{5} \geq\left(\frac{4}{3}-\left\lfloor\frac{4}{3}\right\rfloor\right)
$$

Portanto,

$$
\frac{2}{15} x_{1}+\frac{2}{5} x_{2}+\frac{2}{3} x_{4}+\frac{1}{15} x_{5} \geq \frac{1}{3}
$$

é uma inequação válida que separa $x^{*}=(0,0,4 / 5,0)$ de $S \quad$ (Plano de Corte de Gomory).

O Corte de Gomory discutido acima pode ser utilizado apenas em problemas de otimização linear inteiros. Uma extensão para problemas de otimização inteiro mistos pode ser encontrada por exemplo em [14], [46] e [94].

Além das inequações de Gomory tratadas aqui, existem outras inequações válidas que podem ser usadas como planos de corte, tais como: Inequações GUB (Generalized Upper Bounding)[47]; Inequações de cobertura [63]; Inequações de cobertura de fluxo [48] e [70]; Inequações de Cobertura de Caminho de Fluxo [92]; MIR (Mixed integer rounding) [62]; Corte de Cliques [13]; Implied Bound Cuts [52]. Tais inequações são utilizadas por pacotes de otimização como o CPLEX 10.0 que resolvem problemas gerais 
de otimização inteiro mistos. Mais detalhes sobre estas e outras inequações válidas podem ser encontrados em [71], [63] e [96].

Outro método exato muito conhecido na literatura é o método Branch-and-Bound.

\subsection{Método Branch-and-Bound}

Considere um problema de programação inteiro $P I$ e sua relaxação linear $P L$. Seja $Z$ o valor ótimo de $P I$ e suponhamos que conhecemos um limite inferior $L I^{0}$, e um limite superior $L S^{0}$ para $Z$. Uma forma de obter $Z$ seria seguindo o algoritmo: se $L S^{0}=L I^{0}$ então $Z$ é o valor ótimo de $P I$. Senão, devemos encontrar novos limitantes $L I^{0} \leq L I^{1} \leq L I^{s} \leq \ldots \leq Z \leq L S^{t} \leq \ldots \leq L S^{1} \leq L S^{0}$, até que $0 \leq\left(L S^{t}-L I^{s}\right)<\varepsilon$ [12]. Mas como encontrar esses limites?

Como dito anteriormente, em um problema de minimização, os limites inferiores, podem ser encontrados por meio da solução da relaxação linear do problema original. Já os limites superiores, podem ser obtidos de qualquer solução viável.

Para facilitar a resolução do problema, vamos fazer uma partição do conjunto $S$ em subconjuntos $S^{i}, i=1, \ldots, k$ de tal forma que $S=\bigcup_{i=1}^{k} S^{i}, S^{i} \cap S^{j}=\emptyset, \forall i \neq j$.

Proposição 1.7. Seja $Z_{P I}^{i}=\min \left\{c x: x \in S^{i}\right\}$, onde $S^{i}, i=1,2, \ldots, k$ é uma partição de S. Então

$$
Z_{P I}=\min Z_{P I}^{i}, \quad i=1,2, \ldots, k
$$

Fazer, então, essa partição de $S$ é uma boa idéia para resolver $P I$, porém mesmo após essa partição, os subproblemas podem ainda serem difíceis de se resolver. Assim, podemos repetir o processo de partição até que tenhamos subproblemas fáceis de serem resolvidos. O problema dessa idéia é que teremos que examinar um número exponencial de subproblemas, veja a Figura 1.6.

Uma forma de reduzir o número de subproblemas consiste em usar informações da relaxação linear dos subproblemas para executar um procedimento denominado enumeração implícita. A relaxação linear destes subproblemas fornecerá limites que servirão para avaliar a necessidade de novas partições. Esta estratégia é usada no método Branch-andBound.

Este método é geralmente representado por uma árvore de busca. Cada nó da árvore representa um subproblema. A raíz representa a relaxação linear do problema. 


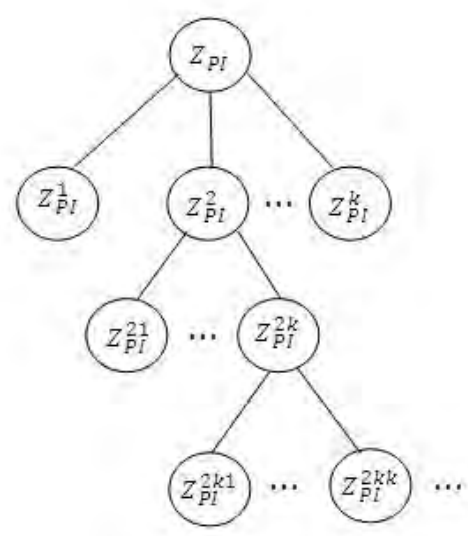

Figura 1.6: Subproblemas gerados no algoritmo Branch and Bound.

Quando qualquer nó ou subproblema é examinado são consideradas arestas incidentes neste nó e nos nós que representam subproblemas criados. A decisão de criar ou não novos subproblemas, depende das soluções dos subproblemas associados aos nós da árvore. Existem três razões para evitar novas partições na iteração $t$ :

- poda por ótimo: $Z_{P I}^{t}$ é resolvido;

- poda por limite: $L S \leq L I^{s}$, onde $L S$ é o valor de qualquer solução viável para $P I$;

- poda por inviabilidade: $S^{i}=\emptyset$.

Existem vários métodos para a escolha dos subproblemas, entre eles a busca em profundidade, busca em lagura e melhor limite inferior.

- Busca em profundidade

A busca em profundidade opta pelo subproblema que acabou de ser inserido na lista, ou seja, se o nó resolvido não for podado o próximo nó escolhido será um de seus filhos [33].

- Busca em largura

A busca em largura segue na árvore resolvendo todos os nós de um nível para depois passar para o próximo. Podemos definir nível como sendo a menor distância (número de nós) do nó corrente ao nó raíz [33].

- Melhor limite inferior 
Supondo que juntamente com o subproblema guardemos a solução de sua relaxação, o próximo nó escolhido será o que tem melhor limite inferior [33].

O algoritmo Branch-and-Bound é resumido no Quadro 1.

Seja $Z_{P I}^{*}$ o valor de alguma solução factível para o $P I$. Considere $L=\left\{P^{i}\right\}$ a lista de problemas e $Z_{P I}^{*}=\infty$ um limite superior inicial.

Passo 1. Se $L=\emptyset$, pare. Se não, selecione um subproblema $P^{i}$ e retire da lista.

Passo 2. Resolva a relaxação linear do subproblema $P^{i}$. Se $P^{i}$ for infactíel, ou $\overline{Z^{*}} \geq Z_{P I}^{*}$, onde $\overline{Z^{*}}$ é a solução ótima da relaxação linear de $P^{i}$, volte ao passo 1 . Se não, vá para o passo 3 .

Passo 3. Se a solução da relaxação linear de $P^{i}$ é inteira, guarde a solução e atualize o limite superior $\left(Z_{P I}^{*}=\overline{Z^{*}}\right)$. Volte ao passo 1 . Se não, vá para o passo 4 .

Passo 4. Escolha $x_{j}$ que não tenha valor inteiro na solução ótima de $P^{i}$.

Faça $x_{j}=\bar{b}_{i}$ e então, obterá dois novos problemas:

$P^{i+1}:=x_{j} \leq\left\lfloor\bar{b}_{i}\right\rfloor$ e $P^{i+2}:=x_{j} \geq\left\lfloor\bar{b}_{i}\right\rfloor+1$.

Volte ao passo 1.

Quadro 1: Algoritmo Branch-and-Bound

O Exemplo 1.6 ilustra a aplicação do o algoritmo Branch-and-Bound na resolução do problema de otimização.

\section{Exemplo 1.6.}

$$
Z=\text { Min }-17 x_{1}-12 x_{2}
$$

sujeito a:

$$
\begin{aligned}
10 x_{1}+7 x_{2} & \leq 40 \\
x_{1}+x_{2} & \leq 5 \\
x_{1}, x_{2} & \in \mathbb{Z}_{+}
\end{aligned}
$$

Seja $P^{0}$ a relaxação linear de $(P)$.

\section{Iteração 1}

$L=\left\{P^{0}\right\}$.

A solução da relaxação linear de $P^{0}$ é $\overline{Z^{*}}=-68.33, x_{1}=1.67, x_{2}=3.33$.

Como a solução não é inteira, vamos escolher $x_{1}$ para particionar. Temos então dois novos problemas $P^{1}$ e $P^{2}$, com o acréscimo das restrições $x_{1} \leq 2$ e $x_{1} \geq 3$ a $P$. 


\section{Iteração 2}

$L=\left\{P^{1}, P^{2}\right\}$. Vamos resolver $P^{1}$.

A solução de $P^{1}$ é $Z_{1}=-65, x_{1}=1, x_{2}=4$ que é inteira.

\section{Iteração 3}

$L=\left\{P^{2}\right\}$.

Resolvendo $P^{2}$ obtemos a solução $Z_{2}=-68.29, x_{1}=2, x_{2}=2.85$.

Como a solução não é inteira, vamos escolher $x_{2}$ para particionar. Temos então dois novos problemas $L=\left\{P^{3}, P^{4}\right\}$, com o acréscimo das restrições $x_{2} \leq 2$ e $x_{2} \geq 3$ a $P^{2}$.

\section{Iteração 4}

$L=\left\{P^{3}, P^{4}\right\}$. Vamos resolver $P^{4}$.

Resolvendo $P^{4}$ vemos que é infactivel.

\section{Iteração 5}

$L=\left\{P^{3}\right\}$

Resolvendo $P^{3}$ obtemos a solução $Z_{3}=-68.2, x_{1}=2.6, x_{2}=2$

Como a solução não é inteira, vamos escolher $x_{1}$ para particionar. Temos então dois novos problemas $L=\left\{P^{5}, P^{6}\right\}$, com o acréscimo das restrições $x_{1} \leq 2$ e $x_{1} \geq 3$ a $P^{3}$.

\section{Iteração 6}

$L=\left\{P^{5}, P^{6}\right\}$. Vamos resolver $P^{5}$.

Resolvendo $P^{5}$ obtemos a solução $Z_{5}=-58, x_{1}=2, x_{2}=2$ que é inteira.

\section{Iteração 7}

$L=\left\{P^{6}\right\}$.

Resolvendo $P^{6}$ obtemos a solução $Z_{6}=-68.14, x_{1}=3, x_{2}=1.43$

Como a solução não é inteira, vamos escolher $x_{2}$ para particionar. Temos então dois novos problemas $L=\left\{P^{7}, P^{8}\right\}$, com o acréscimo das restrições $x_{2} \leq 1$ e $x_{2} \geq 2$ a $P^{6}$.

\section{Iteração 8}

$L=\left\{P^{7}, P^{8}\right\}$. Vamos resolver $P^{8}$.

Resolvendo $P^{8}$, vemos que é infactível.

\section{Iteração 9}

$L=\left\{P^{7}\right\}$ 
Resolvendo $P^{7}$ obtemos a solução $Z_{7}=-68.1, x_{1}=3.3, x_{2}=1$

Como a solução não é inteira, vamos escolher $x_{1}$ para particionar. Temos então dois novos problemas $L=\left\{P^{9}, P^{10}\right\}$, com o acréscimo das restrições $x_{1} \leq 3$ e $x_{2} \geq 4$ a $P^{7}$.

\section{Iteração 10}

$L=\left\{P^{9}, P^{10}\right\}$. Vamos resolver $P^{10}$.

A solução de $P^{10}$ é $Z_{10}=-68, x_{1}=4, x_{2}=0$ que é inteira.

\section{Iteração 11}

$L=\left\{P^{9}\right\}$.

Resolvendo $P^{9}$ obtemos a solução inteira $Z_{9}=-63, x_{1}=3, x_{2}=1$.

\section{Iteração 12}

$L$ está vazia.

Analisando as soluções inteiras obtidas observamos que a solução ótima é $x_{1}=$ $4, x_{2}=0, Z_{1}=-68$.

A eficiência do Branch-and-Bound depende da obtenção de bons limites. Investir em heurísticas pode ser uma maneira de melhorar os limites superiores (ver por exemplo [45] e [94]). A melhora dos limites inferiores pode ser feita com técnicas de relaxação ou reformulando o problema com adição de inequações a priori (inequações válidas), ou adição de inequações a posteriori (planos de corte).

Uma estratégia para diminuir o número de nós na árvore de busca é combinar os métodos Branch-and-Bound e Planos de Corte. Nos nós da árvore Branch-and-Bound adicionam-se inequações válidas de modo a melhorar os limites duais. Se os planos de corte são aplicados apenas no nó raíz, este método é chamado Cut and Branch. Já se os planos de corte são aplicados em outros nós da árvore temos o método Branch and Cut [71]. 


\section{Capítulo 2}

\section{Modelos de dimensionamento e sequenciamento de lotes}

Neste capítulo, faremos uma revisão bibliográfica sobre os problemas de dimensionamento de lotes, sequenciamento da produção e problemas integrados. São apresentados também problemas encontrados na literatura que formulam o sequenciamento da produção baseados no problema do caixeiro viajante. Além disso, são discutidos trabalhos que estudam o planejamento da produção de bebidas.

\subsection{Problemas de dimensionamento de lotes}

O problema de dimensionamento de lotes consiste em planejar a quantidade de itens a ser produzida em uma ou várias máquinas, em cada período ao longo de um horizonte de tempo, de modo a atender uma certa demanda, muitas vezes sujeito a restrições de limite de capacidade e de acordo com algum critério de otimização, que pode ser, por exemplo, minimizar custos [8]. Algumas revisões bibliográficas sobre estes problemas podem ser encontradas em [19], [56], [58] e [74].

O modelo (2.1)-(2.3) a seguir descreve o problema básico de dimensionamento de lotes com apenas um item, uma máquina e $T$ períodos de tempo, onde $h$ representa o custo de estoque e $d_{t}$ representa a demanda no período $t$. As variáveis $x_{t}$ e $I_{t}$ representam respectivamente, as quantidades a serem produzidas no período $t$ e o estoque no final do período $t$. 


$$
\operatorname{Min} \sum_{t=1}^{T} h I_{t}
$$

sujeito a:

$$
\begin{array}{r}
I_{t-1}+x_{t}-I_{t}=d_{t}, \quad t=1, \ldots, T . \\
I_{t} \geq 0, x_{t} \geq 0, \quad t=1, \ldots, T .
\end{array}
$$

A função objetivo (2.1) minimiza o custo total de estoque. As inequações (2.2) garantem o atendimento da demanda e são conhecidas como restrições de balanceamento de estoque. As inequações (2.3) definem o domínio das variáveis.

Em muitos casos, deve ser levado em consideração restrições de capacidade. Seja $K_{t}$ a capacidade de produção em cada período $t$. Como a produção não pode ultrapassar essa capacidade, é necessário incluir no modelo (2.1) - (2.3) as seguintes restrições:

$$
x_{t} \leq K_{t} \quad t=1, \ldots, T \text {. }
$$

Logo, (2.1), (2.2), (2.3) e (2.4) formam um modelo de dimensionamento de lotes, único item com restrições de capacidade [81], [16].

Alguns modelos permitem atrasos na produção [74]. Neste caso, devemos substituir a variável $I_{t}$ em (2.1) - (2.3) pelas variáveis $I_{t}^{+}$e $I_{t}^{-}$que representam respectivamente as quantidades em estoque e em atraso no fim do período $t$ e acrescentar na função objetivo o custo $g$ pelo atraso na produção de uma unidade do produto de um período para o próximo.

$$
\begin{gathered}
\operatorname{Min} \sum_{t=1}^{T}\left(h I_{t}^{+}+g I_{t}^{-}\right) \\
\text {sujeito a: } \\
I_{t-1}^{+}-I_{t-1}^{-}+x_{t}-I_{t}^{+}+I_{t}^{-}=d_{t}, \quad t=1, \ldots, T . \\
I_{t}^{+} \geq 0, I_{t}^{-} \geq 0, x_{t} \geq 0, \quad t=1, \ldots, T .
\end{gathered}
$$

Se houver necessidade de garantir que só haverá produção se houver preparo das máquinas, devemos considerar um modelo com presença de custos e/ou tempos de preparo. 
Para essa finalidade, sejam $y_{t}$ uma variável binária que vale 1 se ocorre preparo na máquina e 0 caso contrário, $M$ um limite superior para $x_{t}$ e st um parâmetro que representa o custo de preparo da máquina. O modelo mais simples para representar essa situação foi proposto por Wagner e Whitin [93] e dado em (2.8)-(2.11).

$$
\begin{gathered}
\operatorname{Min} \sum_{t=1}^{T}\left(h I_{t}+s t y_{t}\right) \\
I_{t-1}+x_{t}-I_{t}=d_{t}, \quad t=1, \ldots, T . \\
x_{t} \leq M y_{t}, \quad t=1, \ldots, T . \\
I_{t} \geq 0, x_{t} \geq 0, y_{t} \in\{0,1\} \quad t=1, \ldots, T .
\end{gathered}
$$

A função objetivo (2.8) minimiza os custos de estoque e preparo. As restrições (2.10) impõem que $x_{t}=0$ se $y_{t}=0$ e que $x_{t} \geq 0$ se $y_{t}=1$.

Se substituirmos $M$ por $K_{t}$ estaremos considerando a capacidade e o preparo da máquina no mesmo modelo. Assim, se no lugar das restrições (2.10) considerarmos as restrições (2.12) o modelo obtido será um modelo de produção de um item com restrições de capacidade e preparo:

$$
x_{t} \leq K_{t} y_{t}, t=1, \ldots, T
$$

Podemos, também, considerar um modelo em que o início da produção é considerado. Isto porque apesar da máquina estar preparada, pode ser que a produção não comece imediatamente naquele período. Para isso, devemos levar em consideração a variável $\varphi_{t}$ (start-up) que vale 1 se há preparo no período $t\left(y_{t}=1\right)$ e não há preparo no período $t-1\left(y_{t-1}=0\right)$ e 0 caso contrário e incluir no modelo as restrições $(2.13),(2.14)$ e (2.15).

$$
\begin{array}{r}
\varphi_{t} \geq y_{t}-y_{t-1}, \quad t=1, \ldots, T . \\
\varphi_{t} \leq y_{t}, \quad t=1, \ldots, T . \\
\varphi_{t} \leq 1-y_{t-1}, \quad t=1, \ldots, T .
\end{array}
$$

O custo de iniciar a produção $(\delta)$ deve ser incluído na função objetivo. Assim, a função objetivo (2.8) deve ser substituída pela expressão dada em (2.16). 


$$
\operatorname{Min} \sum_{t=1}^{T}\left(h I_{t}+\delta \varphi_{t}\right)
$$

Entretanto, as restrições (2.14) e (2.15) podem ser desconsideradas, pois a função objetivo (2.16) minimiza os custos $\delta \geq 0$ de início da produção, garantindo que $\varphi_{t}$ assume valor 0 quando $y_{t}=0$ ([51], [74]). Portanto, a função objetivo (2.16) e as restrições (2.9), (2.11), (2.13), formam um modelo de um item, com restrições de capacidade considerando o início da produção.

No caso de modelos multi-itens teremos restrições para cada item $j$ e cada período t. O custo total a ser minimizado é obtido pela soma dos custos de todos os itens em todos os períodos. Neste caso, criamos a variável $I_{j t}$ para representar o estoque do produto $j$ no final do período $t$, e $x_{j t}$ para representar a quantidade do produto $j$ produzida no período t. O parâmetro $d_{j t}$ representa a demanda do produto $j$ no período $t$ e $h_{j}$ o custo de estoque por unidade do produto $j$. Modelos multi-itens podem ser encontrados em [74], [95]. Uma representação para modelos multi-itens é dado pelas expressões (2.17)-(2.19)

$$
\operatorname{Min} \sum_{j=1}^{J} \sum_{t=1}^{T} h_{j} I_{j t}
$$

sujeito a:

$$
\begin{array}{r}
I_{j, t-1}+x_{j t}-I_{j t}=d_{j t}, \quad j=1, \ldots, J, t=1, \ldots, T . \\
I_{j t} \geq 0, x_{j t} \geq 0, \quad j=1, \ldots, J, t=1, \ldots, T .
\end{array}
$$

Para um problema multi-item com restrições de capacidade [81], além de (2.17), (2.18) e (2.19), devem ser acrescentadas as restrições (2.20), onde $a_{j}$ é a capacidade de tempo necessária para produzir uma unidade do produto $j$.

$$
\sum_{j=1}^{J} a_{j} x_{j t} \leq K_{t}, t=1, \ldots, T .
$$

Se em um modelo multi-item houver necessidade de considerar o preparo, devemos acrescentar as restrições $(2.21)$, onde $x_{j t}=0$ se $y_{j t}=0$ e $x_{j t} \geq 0$ se $y_{j t}=1$.

$$
x_{j t} \leq M y_{j t}, t=1, \ldots, T
$$


Uma discussão mais detalhada sobre problemas multi-item com custo de preparo pode ser encontrada em [19], [67] e [91].

Assim como para um modelo único item, em um modelo multi-item pode-se considerar a capacidade e o preparo da máquina ao mesmo tempo.

O modelo expresso por (2.22)-(2.26) denominado Capacitated Lotsizing and Problem (CLSP) (ver por exemplo [30] e [91]), é uma variação do modelo multi-item descrito acima. O CLSP é um modelo multi-item, com restrições de capacidade, custo de preparo cuja função objetivo minimiza os custos de estoque e de preparo. Neste modelo, $\rho_{j}$ representa o custo de preparo para o item $j$. Araujo e Arenales [8] propõem um método heurístico para a resolução deste problema. Rangel e Ferreira [75] e Clark [25] fazem uma adaptação deste modelo para apresentar o planejamento da produção de uma fábrica de bebidas. A solução dos modelos é obtida com a utilização de um algorítmo híbrido que combina o método de planos de corte e o método Branch-and-Bound [75] e heurísticas de busca local [25]. Luche et al. [61] utilizam uma reformulação do modelo para o planejamento da produção de uma indústria de grãos eletrofundidos.

$$
\begin{gathered}
\operatorname{Min} \sum_{j=1}^{J} \sum_{t=1}^{T}\left(h_{j} I_{j t}+\rho_{j} y_{j t}\right) \\
\text { sujeito a: } \\
I_{j, t-1}+x_{j t}-d_{j t}=I_{j t}, \quad j=1, \ldots, J ; t=1, \ldots, T . \\
a_{j} x_{j t} \leq K_{t} y_{j t}, \quad j=1, \ldots, J, t=1, \ldots, T . \\
\sum_{j=1}^{J} a_{j} x_{j t} \leq K_{t}, \quad t=1, \ldots, T . \\
y_{j t} \in\{0,1\}, I_{j t} \geq 0, x_{j t} \geq 0, \quad j=1, \ldots, J, t=1, \ldots, T .
\end{gathered}
$$

Um problema multi-item considerando custo de preparo e o custo de início da produção (start-up) dado pelas expressões (2.27) - (2.34) pode ser encontrado em [27], onde as restrições (2.33) asseguram que haja produção de apenas um item por período. 


$$
\begin{aligned}
& \operatorname{Min} \sum_{j=1}^{J} \sum_{t=1}^{T}\left(h_{j} I_{j t}+\rho_{j} y_{j t}+\delta_{j} \varphi_{j t}\right) \\
& \text { sujeito a: } \\
& I_{j, t-1}+x_{j t}-d_{j t}=I_{j t}, \quad j=1, \ldots, J, t=1, \ldots, T . \\
& x_{j t} \leq K_{t} y_{j t}, \quad j=1, \ldots, J, t=1, \ldots, T . \\
& \varphi_{j t} \geq y_{j t}-y_{j, t-1}, \quad t=1, \ldots, T \text {. } \\
& \varphi_{j t} \leq y_{j t}, \quad t=1, \ldots, T . \\
& \varphi_{j t} \leq 1-y_{j, t-1}, \quad t=1, \ldots, T \text {. } \\
& \sum_{j=1}^{J} y_{j t} \leq 1, \quad t=1, \ldots, T . \\
& y_{j t} \in\{0,1\}, I_{j t} \geq 0, \varphi_{j t} \in\{0,1\}, x_{j t} \geq 0, \quad j=1, \ldots, J, t=1, \ldots, T .
\end{aligned}
$$

Ferreira [33] faz uma adaptação deste modelo para representar o planejamento da produção de uma fábrica de bebidas. A solução do modelo é obtida com a utilização de um algoritmo híbrido que combina o método de planos de corte e o método Branch-and-Bound [33].

Alguns autores consideram também o custo de produção (ver por exemplo [56],[74] e [91]). No caso de um modelo único item, basta acrescentar à função objetivo $c x_{t}$, em que $c$ será o custo de produção. Já no caso multi-item devemos acrescentar à função objetivo $c_{j} x_{j t}$ em que $c_{j}$ é o custo por unidade de produção do item $j$.

\subsection{Problemas de sequenciamento de lotes}

O sequenciamento da produção é uma importante área de pesquisa. O problema consiste em encontrar a ordem em que os itens devem ser produzidos em um dado conjunto de máquinas tal que um ou mais objetivos devem ser otimizados ([17] e [73]). Os problemas de sequenciamento da produção podem ser classificados com base em três propriedades: as características das máquinas, as características das operações e recursos, e o critério de otimização. Uma tarefa representa uma operação elementar, que para ser realizada necessita de um certo número de unidades de tempo e/ou recursos. Um job representa uma sequência conhecida de uma ou mais tarefas, as quais compõem a sequência tecnológica de fabricação de cada produto. Assim, num contexto de manufatura de 
produtos, um job pode representar a fabricação de um produto ou de um lote de uma família de produtos, que possuem a mesma sequência tecnológica de fabricação [21].

Os problemas de sequenciamento da produção são descritos pelo tripleto $\alpha|\beta| \gamma$ :

- o campo $\alpha$ descreve o ambiente das máquinas;

- o campo $\beta$ fornece as características do processamento e restrições;

- o campo $\gamma$ contém o critério de otimização.

Os seguintes ambientes de máquinas são considerados na classificação de problemas de sequenciamento:

- Uma máquina: quando todas as tarefas são executadas em apenas uma máquina;

- Flowshop: todos os jobs têm a mesma sequência nas máquinas, isto é, primeiro passam na máquina 1 depois na máquina 2 e assim por diante. Além disso, todos os jobs têm de ser processados em cada uma das máquinas;

- Openshop: é similar a um flowshop, exceto que as tarefas de um job podem ser processadas em qualquer ordem.

- Jobshop: os jobs podem ter sequências diferentes nas máquinas e podem usar a mesma máquina mais de uma vez. O flowshop é um caso especial do jobshop, deste modo os modelos desenvolvidos para resolver problemas de jobshop resolvem também os problemas de flowshop;

-Máquinas paralelas idênticas: quando todas as máquinas possuem a mesma velocidade;

-Máquinas paralelas diferentes: quando cada máquina possui uma velocidade, sendo classificadas como uniformes se a velocidade é constante e não depende da operação executada ou não uniformes se a velocidade depende da operação executada. 
As características das tarefas determinam as restrições do problema de sequenciamento. Entre elas podemos destacar: a cada instante, cada tarefa só pode ser realizada em no máximo uma máquina; a cada instante, cada máquina executa no máximo uma tarefa; quando uma tarefa é iniciada em uma máquina, ela não poderá ser interrompida. Além disso, podemos destacar restrições relacionadas aos tempos de preparação, que podem ser ou não dependentes da sequência de produção.

O critério de otimização a ser usado na solução do problema pode estar relacionado ao atraso na produção ou ao tempo de preparo das máquinas.

\section{Tempos e/ou custos de preparo dependentes da sequência de produção}

O tempo de preparação de uma máquina envolve todo o tempo gasto nas atividades necessárias para desmontar a máquina previamente preparada para executar uma determinada tarefa e montá-la para executar uma nova tarefa. Este tempo pode depender somente da tarefa a ser executada. Neste caso, o tempo de preparação é dito independente da sequência. Ou pode ser dependente também da tarefa que está sendo executada e da que virá em seguida. Nesta hipótese, o tempo gasto é dito dependente da sequência de produção [21].

De acordo com Aldowaisan et al. [3], o problema de sequenciamento com preparação da máquina apresentou um campo fértil para as pesquisas, e podem ser consideradas como trabalhos futuros, pesquisas voltadas para solucionar o problema de sequenciamento com tempos de preparação buscando otimizar objetivos como minimizar os custos de antecipação e/ou atraso.

Em algumas situações práticas, o tempo de preparação quando não é dependente da sequência, pode ser desconsiderado ou incorporado ao tempo de processamento, o que simplifica o problema. Porém, em muitos ambientes como em uma indústria de bebidas, o tempo de preparo da máquina não deve ser desconsiderado e não pode ser incorporado ao tempo de processamento, pois é variável e depende da sequência de produção. 


\subsubsection{O problema de sequenciamento da produção e o problema do caixeiro viajante}

Na literatura, encontramos muitos trabalhos que modelam o problema de sequenciamento de lotes como um problema do caixeiro viajante (PCV - ver Apêndice A). Desta forma, é possível utilizar algoritmos disponíveis para o PCV para resolvê-los. Bagchi et al. [15] faz uma revisão sobre abordagens baseadas no PCV para problemas com flowshop. Uma aplicação do PCV com tempos dependentes para problemas de sequenciamento com uma única máquina e atraso pode ser encontrada em Picard et al. [72]. Ozgur et al. [69] utiliza o problema do caixeiro viajante para modelar um problema com uma única máquina e sequência dependente.

Entre muitos dos problemas encontrados na literatura, cuja formulação é baseada no PCV, estão os problemas de roteamento de veículos. Um trabalho que estuda tal problema é o de Bozejko et al. [18] que utiliza o PCV na resolução e considera tempos de processamento e atraso. Encontramos também, na literatura, trabalhos que utilizam o PCV para resolver problemas de sequenciamento no processo de produção de indústrias, como é o caso apresentado em Fenato [31] e Hoto et al.[53] que propõem modelos baseados nos problemas do caixeiro viajante clássico e generalizado para a minimização dos custos de trocas de bobinas produzidas em máquinas tubeteiras.

Outros trabalhos que utilizam o caixeiro viajante para resolver o sequenciamento da produção são discutidos na próxima seção, onde são apresentados modelos encontrados na literatura que integram o dimensionamento e o sequenciamento de lotes.

\subsection{Problemas integrados de dimensionamento e sequen- ciamento de lotes}

$\mathrm{Na}$ literatura, existem modelos de otimização que representam simultaneamente as decisões sobre o tamanho dos lotes e a sequência na qual estes lotes devem ser produzidos. Revisões de literatura sobre tais problemas podem ser encontradas em [30] e [81]. A seguir faremos uma descrição dos principais modelos encontrados nos textos consultados. Na descrição dos modelos usaremos as variáveis e parâmetros definidos na Seção 2.1.

O modelo Discrete Lotsizing and Scheduling Problem (DLSP) [30] é descrito pelas 
expressões $(2.35)-(2.40)$ :

$$
\begin{gathered}
\operatorname{Min} \sum_{i=1}^{J} \sum_{t=1}^{T}\left(h_{j} I_{j t}+\delta_{j} \varphi_{j t}\right) \\
\text { sujeito a: } \\
I_{j, t-1}+x_{j t}-d_{j t}=I_{j t}, \quad j=1, \ldots, J ; t=1, \ldots, T . \\
a_{j} x_{j t}=K_{t} y_{j t}, \quad j=1, \ldots, J, t=1, \ldots, T . \\
\sum_{i=1}^{J} y_{j t} \leq 1, \\
\varphi_{j t} \geq y_{j t}-y_{j, t-1}, \quad j=1, \ldots, J ; t=1, \ldots, T . \\
y_{j t} \in\{0,1\}, \varphi_{j t} \geq 0, I_{j t} \geq 0, x_{j t} \geq 0, \\
\quad j=1, \ldots, J ; t=1, \ldots, T .
\end{gathered}
$$

A função objetivo (2.35) minimiza os custos de estoque e de preparo. As restrições (2.36) controlam o balanceamento de estoque. Diferente das restrições (2.24) encontradas no modelo CLSP, as restrições (2.37) determinam que se houver produção, a capacidade deve ser totalmente utilizada. Por causa disso, essa restrição é conhecida como restrição "tudo ou nada". O modelo DLSP se diferencia dos modelos de dimensionamento de lotes clássicos por restringir a produção a no máximo um item por período, como especificado nas restrições (2.38). As restrições (2.39) asseguram o início da produção de um novo lote ou seja, garantem que o preparo será contado apenas se houver o início da produção de um novo item (veja as restrições de start-up (2.13)). As restrições (2.40) referem-se ao domínio das variáveis.

Extensões do DLSP para problemas com máquinas em paralelo são apresentadas em [77]. Salomon et al. [78] apresentam uma reformulação do DLSP com tempos e custos de preparo dependentes da sequência usando o problema do caixeiro viajante. Gicquel et al. [43] fazem uma adaptação do DLSP considerando os tempos de preparo dos produtos dependentes da sequência de produção. Gicquel et al. [44] reformulam o modelo DLSP considerando que a descrição dos produtos produzidos dependem de atributos físicos. Estes atributos, no caso de uma fábrica de refrigerantes, podem ser, por exemplo, o tipo de vasilhame e o sabor.

Se as restrições (2.37) forem substituídas pelas restrições (2.41) a seguir, teremos o modelo Continuous Setup Lotsizing Problem (CSLP) [30]. As restrições (2.41) permitem que ocorra uma produção abaixo da capacidade da máquina. 


$$
a_{j} x_{j t} \leq K_{t} y_{j t}, \quad j=1, \ldots, J ; t=1, \ldots, T .
$$

O modelo Proportional Lotsizing and Scheduling Problem (PLSP) apresentado por Drexl e Haase [29], ocorre quando não é utilizada a capacidade total do período para a produção de um determinado item e, por isso, é programada a produção de um novo item para a utilização do restante desta capacidade [30]. Assim, para o obter o modelo PLSP, substituimos as restrições (2.37) no modelo DLSP pelas restrições (2.42) que permitem a produção de dois itens em um mesmo período. Portanto, as expressões (2.35), (2.36), (2.38), (2.39), (2.40),(2.42), formam o modelo PLSP.

$$
a_{j} x_{j t} \leq K_{t}\left(y_{j t}+y_{j, t-1}\right), \quad j=1, \ldots, J, t=1, \ldots, T \text {. }
$$

Com exceção do modelo PLSP, os modelos apresentados acima são do tipo small bucket [56], pois permitem que apenas um item seja produzido por período. Estes modelos são úteis em situações em que os períodos considerados possuem intervalos de tempo menores. Logo, ao se determinar o lote de produção de cada período, está sendo determinado o momento que cada produto será produzido, ou seja, a sequência de produção, além do tamanho dos lotes [32].

Uma outra proposta para integrar o dimensionamento e o sequenciamento de lotes é um modelo proposto por Fleischmann e Meyr [38] tipo big bucket [56], isto é, permite a produção de vários itens por período, que utiliza a idéia da subdivisão dos períodos em períodos menores denominados microperíodos ou subperíodos. O lote de produção é definido em termos dos subperíodos $s$ pertencentes aos conjuntos $S_{t}$, que são os conjuntos dos subperíodos do período $t$. A produção do item $j$ no período $t$ é a soma do que foi produzido daquele item em cada subperíodo $s$ do período $t\left(\sum_{s \in S_{t}} x_{j s}=x_{j t}\right)$. No máximo um tipo de item pode ser produzido por subperíodo, assim pode-se saber exatamente o que será produzido em cada subperíodo e, portanto, a sequência de produção de cada período. O tamanho de cada subperíodo é dado pelo quanto foi produzido neste subperíodo.

Seja $N$ o número total de subperíodos, $S_{t}$ indica quais subperíodos pertencem ao período $t$, então $N=\sum_{t=1}^{T}\left|S_{t}\right|$ onde $\left|S_{t}\right|$ corresponde ao número de subperíodos de 
cada período $t$. Na Figura 2.1, consideramos $N=9, S_{1}=\{1,2,3\}, S_{2}=\{4,5\}$ e $S_{3}=$ $\{6,7,8,9\}$.

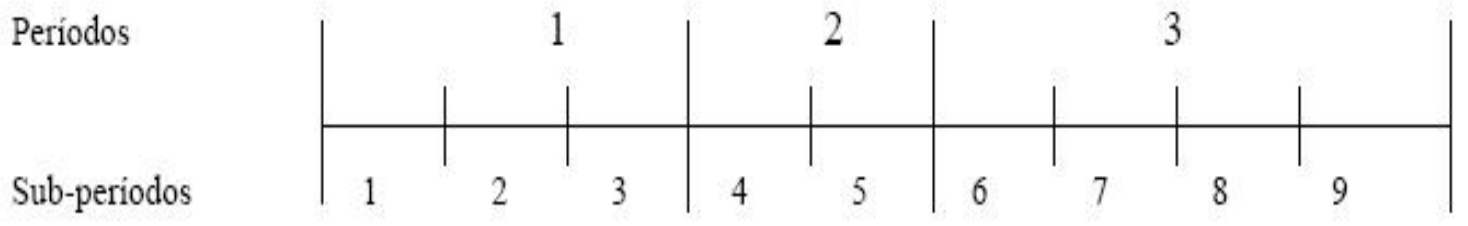

Figura 2.1: Exemplo da divisão de um período em subperíodos [32].

O modelo dado por (2.43) - (2.50) é conhecido como General Lotsizing and Scheduling Problem (GLSP) e pode ser encontrado em [30], [38], [64]. Neste modelo, as variáveis de produção $x_{j s}$, preparo $y_{j s}$ e troca $z_{i j s}$ não são definidas por período $t$, mas por subperíodo $s$. Apenas as variáveis de estoque $I_{j t}$ são indexadas por período. 


$$
\begin{gathered}
\operatorname{Min} \sum_{j=1}^{J} \sum_{t=1}^{T} h_{j} I_{j t}+\sum_{j=1}^{J} \sum_{s \in S_{t}} s_{i j} z_{i j s} \\
\text { sujeito a: } \\
I_{j, t-1}+\sum_{s \in S_{t}} x_{j s}-d_{j t}=I_{j t}, \\
a_{j} x_{j s} \leq K_{t} y_{j s}, \\
\sum_{j=1}^{J} \sum_{s \in S_{t}} a_{j} x_{j s} \leq K_{t} \\
\sum_{i=1}^{J} y_{j s}=1, \ldots, J, t=1, \ldots, T . \\
z_{i j s} \geq y_{i s}+y_{j, s-1}-1, \\
x_{j s} \geq m_{j}\left(y_{j s}-y_{j, s-1}\right), \\
s=1, \ldots, J, s \in S_{t} . \\
y_{j s} \in\{0,1\}, z_{i j s} \geq 0, I_{j t} \geq 0, x_{j s} \geq 0, \\
j=1, \ldots, J, t=1, \ldots, T \text { e } s \in S_{t} .
\end{gathered}
$$

A variável $z_{i j s}$ vale 1 se há troca de produção do item $i$ para o item $j$ no início do subperíodo $s$ e vale 0 caso contrário. O parâmetro $s_{i j}$ é o custo de realizar a troca do item $i$ para o item $j$. O parâmetro $m_{j}$ corresponde à produção mínima do produto $j$.

A função objetivo (2.43) minimiza os custos de estoque e troca. As restrições (2.44), (2.45) e (2.46) são respectivamente restrições de balanceamento de estoque, que controlam o preparo da máquina, ou seja, só há produção do item $j$ no subperíodo $s$ se a máquina foi preparada para isto, e restrições que controlam o limite de capacidade da máquina. As restrições (2.47) asseguram que um único item deve ser produzido por subperíodo. As restrições (2.48) controlam a mudança do item $i$ para o item $j$ na produção. Note que a variável $z_{i j s}$ de troca não foi definida como binária, isto porque as restrições de troca (2.48) mais o fato da variável estar na função objetivo implicam que ela assumirá valor 1 apenas se as variáveis de preparo $y_{i s}$ e $y_{j s-1}$ forem iguais a 1 , caso contrário ela assume valor 0. As restrições (2.49) garantem que se ocorre preparo de um item $i$, então deve haver uma produção mínima $m_{j}$ deste item. Estas restrições são importantes porque algumas vezes os custos e/ou tempos de preparo não satisfazem a desigualdade triangular. Isto é, fazer a troca de um item $i$ para um item $k$ e em seguida a troca de um item $k$ para um item $j$ é mais econômico que fazer a troca do item $i$ para o item $j$ [38]. Assim, se $s_{i k}$ é o custo de troca do item $i$ para o item $k, s_{k j}$ é o custo de troca do item $k$ para o item $j$ e $s_{i j}$ é o custo de troca do item $i$ para o item $j$ então: 


$$
s_{i k}+s_{k j} \leq s_{i j}, \quad i, j, k=1, \ldots, J .
$$

Alguns exemplos de situações práticas onde esta situação pode acontecer são indústrias químicas e de ração de animal [87] onde alguns itens podem servir como "limpantes", isto é, sua produção pode colaborar na retirada de resíduos que impeçam a produção do próximo item sem que haja necessidade de um preparo total da máquina. Assim, a produção mínima de um certo produto $k$ evitaria um tempo maior de preparo da máquina para um outro produto $j$, já que o produto $k$ seria usado como limpante.

Em algumas situações, é importante considerar o tempo de troca do item $i$ para o item $j, b_{i j}$, nas restrições de capacidade. Para isso, as restrições (2.46) devem ser substituídas pelas restrições (2.52) obtendo o modelo GLSP com tempo de troca [64].

$$
\sum_{i=1}^{J} \sum_{s \in S_{t}} a_{j} x_{j s}+\sum_{j=1}^{J} \sum_{j=1}^{J} \sum_{s \in S_{t}} b_{i j} z_{i j s} \leq K_{t}, \quad s \in S_{t} .
$$

Uma extensão do GLSP para máquinas paralelas pode ser encotrada em [65] onde é proposta uma combinação de um algoritmo de reotimização dual com uma heurística de busca local para resolver o problema. Toledo et al. [83] propõem meta-heurísticas para solucionar o problema geral de dimensionamento de lotes e programação da produção (GLSP) com e sem máquinas paralelas e com atrasos.

Na literatura, o GLSP é bastante utilizado para modelar situações práticas encontradas em problemas do mundo real. Araújo et al. [9] apresentam uma reformulação do modelo GLSP para uma indústria de fundição com tempos e custos de preparo independentes da sequência de produção. Araujo et al.[10] e Araujo et al.[11] também apresentam uma reformulação do modelo GLSP para o planejamento da produção de uma indústria de fundição e alguns métodos alternativos de resolução são utilizados tais como a heurística relax and fix e variações de métodos de busca local.

Toso et al. ([86], [89]), utilizam o GLSP para modelar o problema de dimensionamento e sequenciamento de lotes de uma indústria de suplementos para nutrição animal considerando custos de horas extras. Toledo et al. [82] formulam um problema multiestágio integrado de dimensionamento de lotes e programação da produção, extensão do 
modelo GLSP, para o planejamento da produção de uma fábrica de refrigerantes com máquinas paralelas que apresentam custos e tempos de preparo dependentes da sequência. O tamanho do subperíodo é fixo, e cada lote é um múltiplo dos subperíodos. Para determinar o tamanho do lote, tanto o início quanto fim da produção são controlados por variáveis que indicam em qual subperíodo cada lote de cada máquina foi iniciado e em qual subperíodo foi finalizado. Para relacionar os estágios de produção, há restrições que garantem que para haver produção em um estágio é necessário que o processo no outro estágio esteja preparado e portanto, haja sincronia entre eles.

Ferreira et al. [35] assim como em Toledo et al. [82] apresentam um problema de planejamento da produção multiestágio de uma fábrica de refrigerantes onde, em cada estágio, um problema de dimensionamento e sequenciamento de lotes com máquinas em paralelo, restrições de capacidade e tempos e custos de preparo dependentes da sequência de produção devem ser resolvidos. Diferente do trabalho de Toledo et al. [82], no trabalho de Ferreira et al. [35] o tamanho dos subperíodos varia de acordo com a quantidade produzida e são feitas simplificações do problema para obter o modelo. Para a resolução, são utilizadas uma abordagem de relaxação e várias estratégias da heurística relax and fix. Uma reformulação monoestágio para o modelo dois estágios encontrado em [35] é proposta por Ferreira et al. [37]. Ferreira et al. [34] e Ferreira et al. [36] propõem heurísticas relax and fix para resolução de um problema de programação da produção de uma fábrica de refrigerantes de pequeno porte considerando apenas um estágio. Estes modelos são melhor detalhados no Capítulo 3. Toledo et al. [84] propõem um algoritmo genético para resolução do problema para produção de bebidas apresentado em [35].

\subsubsection{Modelos integrados utilizando o problema do caixeiro viajante para incorporação do sequenciamento}

Na literatura, existem alguns trabalhos onde o modelo integrado de dimensionamento e sequenciamento de lotes é reformulado com base no problema do caixeiro viajante (PCV)(ver Apêndice A). Algumas revisões bibliográficas sobre o PCV podem ser encontradas em [60], [59], [20]. Os problemas mais comuns envolvendo o PCV estão relacionados ao roteamento de veículos [22], entretanto, o problema de sequenciamento de tarefas também pode ser interpretado como o PCV (ver Seção 2.2.1)

Para representar o sequenciamento usando o PCVA, para cada período $t$, temos 
um grafo $G=(V, A)$, onde $V$ corresponde a um conjunto de itens $j$ a serem produzidos em $t$ (ou seja, é um subconjunto do número total de produtos $J$ para os quais $x_{j t}>0$ ) e as arestas $A$ correspondem às possíveis trocas entre cada par de produtos $\left(z_{i j t}\right)$. O problema então consiste em encontrar um caminho hamiltoniano saindo de uma origem e passando por todos os vértices (ver Apêndice A).

Fleischmann [40] apresenta uma formulação para o DLSP incluindo custos de preparação dependentes da sequência e reformula o problema usando o problema do caixeiro viajante (PCV) com janelas de tempo. O problema é resolvido por um procedimento heurístico. Com base no modelo proposto em [40], Salomon et al. [78] formulam um modelo que inclui além dos custos, os tempos de preparo. Exemplares do modelo de tamanho mediano são resolvidos utilizando um método ótimo baseado em programação dinâmica. A reformulação do problema encontrado em [78] para o PCV é feita da seguinte forma:

- os nós do grafo representam as ocorrências de demandas de cada produto para cada período, assim como a demanda para períodos osciosos;

- as janelas de tempo sobre os nós asseguram que não ocorram atrasos;

- os custos relacionados aos nós representam os custos de estoque;

- os arcos representam transições factíveis entre demanda e períodos osciosos. Os arcos de custos representam os custos de transições de estado. Os arcos de tempo representam os tempos de produção e preparo relacionados às transições de estado.

Clark [26] apresenta um modelo de dimensionamento e sequenciamento de lotes integrado com máquinas paralelas e sequência dependente dos tempos de preparo. Neste trabalho é proposto um método de resolução em que o problema é decomposto da seguinte forma: as decisões de dimensionamento de lotes são tratadas em um modelo linear e as de sequenciamento são reformuladas com base no problema do caixeiro viajante assimétrico (PCVA). Diferente dos trabalhos de Fleischmann [40] e Salomon et al. [78] que apresentam um modelo matemático para o DLSP e depois reformulam o problema como um PCV, no trabalho de Clark [26] o problema é reformulado utilizando as equações clássicas do PCV para modelar as decisões do sequenciamento. Como a otimalidade só é encontrada para exemplares muito pequenos, uma heurística de busca local é utilizada como alternativa de resolução. Gupta e Magnusson [49] apresentam um modelo integrado de 
dimensionamento e sequenciamento de lotes em que para as decisões de dimensionamento, é utilizado o modelo CLSP única máquina com sequência dependente dos custos e tempos de preparo, e as decisões de sequenciamento são tratadas como um problema do caixeiro viajante considerando que no início de cada período o modelo deve "guardar"o estado de preparação da máquina no final do período anterior (setup carryover). Entretanto, este modelo não evita subrotas desconexas. Almada-Lobo et al. [5] apresentam um modelo com acréscimo de um novo conjunto de restrições que fornece uma formulação para este problema. Almada-lobo et al. [6] trazem uma extensão do modelo apresentado em [5] para uma indústria de contêiners de vidro considerando máquinas em paralelo. Almeder et al. [7] propõem modelos teóricos, extensões dos modelos GLSP e de um modelo que utiliza o CLSP para formular o dimensionamento de lotes e o problema do caixeiro viajante para modelar as decisões do sequenciamento considerando ainda vários estágios com sincronia como os propostos em [4] e [35]. Almada-Lobo et al. [4] sugerem um modelo com restrições de capacidade, sequência dependente dos tempos e custos de preparo, único estágio, múltiplos itens, única máquina utilizando os parâmetros e variáveis propostos na descrição do modelo (2.17) - (2.21) e na descrição das expressões (2.43) e (2.52) com o diferencial de não considerar subperíodos mas sim períodos, veja o modelo (2.53)-(2.60). Além disso, é considerada a variável $u_{j t}$ que representa a posição em que o item $j$ é produzido no período $t$ 


$$
\mathrm{Z}=\operatorname{Min} \sum_{i} \sum_{j} \sum_{t} b_{i j} z_{i j t}+\sum_{i} \sum_{t} h_{t} I_{i t}
$$

Sujeito a:

$$
\begin{array}{cc}
I_{i t}=I_{i, t-1}+x_{i t}-d_{i t}, & i=1, \ldots, J, t=1, \ldots, T \\
\sum_{i} a_{i} x_{i t}+\sum_{i} \sum_{j} b_{i j} z_{i j t} \leq K_{t}, & t=1, \ldots, T \\
x_{i t} \leq M_{i t}\left(\sum_{j} z_{j i t}+y_{i t}\right), & t=1, \ldots, J, t=1, \ldots, T \\
\sum_{i} y_{i t}=1, & i=1, \ldots, J, t=1, \ldots, T \\
y_{k t}+\sum_{i} z_{i k t}=y_{k, t+1}+\sum_{j} z_{k j t}, & \\
u_{i t}+J z_{i j t}-(J-1)-J y_{i t} \leq u_{j t}, & i=1, \ldots, J, j=1, \ldots, J, j \neq i, t=1, \ldots, T(2.5) \\
\left(x_{i t}, I_{i t}, u_{i t}, y_{i t}\right) \geq 0, z_{i j t} \in\{0,1\} . &
\end{array}
$$

Neste modelo, a função objetivo (2.53) minimiza a soma dos tempos de troca dependentes da sequência, além dos custos de estoque. Note que, a função objetivo minimiza os tempos de troca e não os custos de troca. As restrições (2.57) - (2.59) determinam a sequência de produtos na máquina em cada período e controlam o estado de configuração no começo de cada período por "guardar" o produto que uma máquina está pronta para processar no final do período anterior (setup carryover). Estas restrições são baseadas nas restrições existentes na formulação do PCV, pois as restrições (2.58) controlam o fluxo dos itens, onde o produto que "entra" é igual ao produto que "sai", juntamente com o estado de configuração inicial da máquina (setup carryover). Como tais restrições podem gerar subrotas, as restrições (2.59) são consideradas pois eliminam as possíveis subrotas existentes. Elas são adaptadas das restrições MTZ de eliminação de subrotas (ver apêndice A) para este modelo que considera setup carryover entre os períodos.

Em Toso et al. ([87], [88]) são propostos dois modelos para o planejamento da produção de uma indústria de suplementos para nutrição animal em que o sequenciamento é formulado com base no PCVA. Para o dimensionamento de lotes é apresentada uma reformulação do modelo CLSP considerando custos de horas extras e que os custos e tempos de setups são dependentes da sequência de produção. Em um modelo, o sequenciamento é formulado com base no PCVA, no outro, são incorporadas restrições de setup carryover. 
Para o modelo proposto nesta dissertação, as restrições de sequenciamento foram baseadas nas restrições existentes no modelo apresentado em [87] sem considerar as restrições de setup carryover. No trabalho de Toso et al. [87] assim como no trabalho de Clark [26], a estratégia é usar o PCVA para formular o sequenciamento sem decompor o modelo em dois modelos distintos. Para diminuir o número de variáveis e restrições e tornar o modelo viável computacionalmente, os produtos foram agregados em famílias, onde cada família só tem produtos pertencentes ao mesmo grupo de contaminação e com características comuns, como tempo de processamento e quantidade por batelada que corresponde ao lote mínimo produzido em cada operação. Cada família corresponde a um item. A quantidade produzida em cada batelada é limitada pelo tamanho do misturador e varia de um produto para outro, dependendo da densidade de cada produto. É um problema monoestágio e a capacidade de produção é determinada como o tempo disponível para a produção, e os tempos de preparação são dependentes da sequência de produção. Além disso, considera-se que cada item é produzido uma única vez em cada período e que a cada período uma nova sequência começa sem nenhuma relação com a anterior, ou seja, o dimensionamento é feito de forma simultânea para todo o horizonte de planejamento, mas as sequências em cada período são independentes entre si (sem restrições de setup carryover).

Para formular o modelo, Toso et al. [87] determinam um item para o qual a linha de produção esteja preparada no começo de cada período. Para isso foi usado o artifício do produto fantasma $i_{0}$ (ver Apêndice A). Para não interferir nos resultados do problema, este produto $i_{0}$ tem tempos e custos de produção e demanda com valores nulos. Diferente do que é apresentado no Apêndice A, o tempo de troca de um produto $i$ para o produto $i_{0}$ considerado no trabalho de Toso et al. [87] é $\infty$.

Para a formulação do modelo, são considerados os mesmos índices considerados no trabalho de Almada-Lobo et al. [4]. Entretanto, são considerados também, a variável de atraso $\left(I_{j t}^{-}\right)$e o custo associado. Além disso são considerados o lote mínimo e a inclusão de horas extras. Os seguintes parâmetros e variáveis são necessários.

$\mathrm{CO}_{t}$ custo unitário de hora extra no período $t$;

$i_{0} \quad$ produto para o qual a máquina foi preparada no início de cada período;

$l m_{t}$ limite máximo de horas extras permitidas no período $t$ de acordo com as leis 
trabalhistas;

$O_{t}$ variável que indica a quantidade de horas extras utilizadas no período $t$;

$\left|S_{r}\right|$ cardinalidade de qualquer subrota $S_{r}$ formada;

$P R$ conjunto de todos os produtos $(P R=1, \ldots, N)$

O modelo completo possui as expressões (2.61) - (2.71).

$$
\operatorname{Min} \mathrm{Z}=\sum_{j=1}^{J} \sum_{t=1}^{T}\left(h_{j t} I_{j t}^{+}+g I_{j t}^{-}\right)+\sum_{t=1}^{T} c o_{t} O_{t}+\alpha \sum_{i=1}^{J} \sum_{j=1}^{J} b_{i j} z_{i j t}
$$

Sujeito a:

$$
\begin{aligned}
& I_{j t}^{+}-I_{j t}^{-}=I_{j, t-1}^{+}-I_{j, t-1}^{-}+x_{j t}-d_{j t}, \quad j=1, \ldots, J, t=1, \ldots, T ; \\
& \sum_{j=1}^{J} a_{j} x_{j t}+\sum_{i=1}^{J} \sum_{j=1}^{J} b_{i j} z_{i j t} \leq K_{t}+O_{t}, \quad t=1, \ldots, T \text {; } \\
& a_{j} x_{j t} \leq\left(K_{t}+m_{t}\right) \sum_{i=1}^{J} z_{i j t}, \quad j=1, \ldots, J, t=1, \ldots, T ; \\
& x_{j t} \geq m_{j} \sum_{i=1}^{J} z_{i j t}, \quad j=1, \ldots, J, t=1, \ldots, T ; \\
& \sum_{j=1}^{J} z_{i_{0} j t} \geq \sum_{i=1}^{J} z_{i k t}, \quad k=1, \ldots, J, k \neq i_{0}, t=1, \ldots, T ; \\
& \sum_{i=1}^{J} z_{i k t} \geq \sum_{j=1}^{J} z_{k j t}, \quad k=1, \ldots, J, k \neq i_{0}, t=1, \ldots, T ; \\
& \sum_{j=1}^{J} z_{i j t} \leq 1, \quad i=1, \ldots, J, t=1, \ldots, T ; \\
& \sum_{i, j \in S_{r}} z_{i j t} \leq\left|S_{r}\right|-1, \quad t=1, \ldots, T, S_{r} \subset P R, 2 \leq\left|S_{r}\right| \leq J-2 ;(2.6 \\
& 0 \leq O_{t} \leq l m_{t}, \quad t=1, \ldots, T \\
& z_{i, i_{0} t}=0, z_{k k t}=0, \quad i, k=1, \ldots, J, t=1, \ldots, T ; \\
& I_{j t}^{+}, I_{j t}^{-} \geq 0, z_{i j t} \in\{0,1\}, x_{j t} \in \mathbb{Z}_{+}^{*}, \quad i, j=1, \ldots, J, t=1, \ldots, T .
\end{aligned}
$$

A função objetivo (2.61) traz como diferencial em relação ao modelo descrito em [4] a minimização da quantidade de horas extras e de atraso . As restrições (2.63) consideram a possibilidade de uma quantidade limitada de horas extras para aumentar a capacidade de produção. Note que o primeiro preparo deve ocorrer a partir do item fantasma e, assim, $b_{i_{0} j}=0$. As restrições (2.65) são responsáveis pelo lote mínimo e diferenciam-se 
das encontradas no modelo GLSP por causa da variável de preparo, pois, como em [4], o preparo $\left(y_{j t}\right)$ é considerado implicitamente quando $\sum_{i=1}^{J} z_{i j t}=1$. Tais restrições não estão presentes no modelo (2.53) - (2.60). As restrições (2.66) permitem uma troca de um produto $i$ para um produto $k$ qualquer, somente se houve uma troca de $i_{0}$ para um produto $j$ qualquer. Isto garante que $i_{0}$ esteja no começo da sequência em cada período. A presença do item fantasma no modelo de Toso et al. [87] é um diferencial em relação ao modelo proposto por Almada-Lobo [4], onde tal parâmetro não é considerado. As restrições (2.67) permitem uma troca de um item $k$ para um item $j$ qualquer, ( $k$ diferente de $\left.i_{0}\right)$ somente se houve troca de um item $i$ qualquer, para este item $k$. As restrições $(2.68)$ proíbem mais de uma troca a partir de um item $i$, o que significa que em cada período só pode ser produzido um único lote de cada item. Por causa das restrições (2.57) e (2.58) no modelo (2.53)-(2.60), este tipo de controle não é necessário. As restrições (2.69) são as restrições DFJ de proibição de subrotas (ver apêndice A) que diferem das encontradas no modelo (2.53)-(2.60), onde são consideradas as restrições MTZ (ver Apêndice A). As restrições (2.70) impõem um limite sobre as horas extras trabalhadas de acordo com as leis trabalhistas. As restrições (2.71) proíbem a troca entre itens iguais e garantem que não haja troca de um item $i$ qualquer, para o item fantasma $i_{0}$. Como $b_{i i_{0}}=\infty, \forall i$, elas podem acelerar a convergência do método de solução. As restrições (2.72) são de domínio das variáveis do modelo.

No próximo capítulo é apresentado com mais detalhes o planejamento da produção de bebidas e proposto um modelo que integra os problemas de dimensionamento e sequenciamento de lotes, onde as idéias para o dimensionamento são as mesmas encontradas em [36], e as idéias para o sequenciamento são baseadas nas propostas em [87]. 


\section{Capítulo 3}

\section{Planejamento da Produção de Bebidas}

Neste capítulo são discutidos resumidamente o processo de produção de bebidas e as dificuldades dos problemas de dimensionamento de lotes e da programação da produção associados a este tipo de processo. É apresentado também o modelo P1S1M proposto por Ferreira et al. [36], para representar a programação da produção de refrigerantes, formulado com base no modelo GLSP [38]. É apresentado um novo modelo para representar o problema cujas decisões de dimensionamento de lotes são baseadas nas do modelo P1S1M e as de sequeciamento são formuladas com base no problema do caixeiro viajante assimétrico. Para validar o modelo proposto, são comparados os resultados obtidos pelos dois modelos para um exemplar ilustrativo.

\subsection{Histórico de produção}

O consumo de bebidas não alcoólicas no Brasil tem aumentado significativamente nos últimos anos. De acordo com um relatório de 2008 feito pela Associação Brasileira de Indústria de Refrigerantes e Bebidas Não Alcoólicas - (ABIR) [1], ao prosseguir na tendência iniciada há cinco anos, o consumo de bebidas no Brasil cresceu mais de $5.0 \%$ e atingiu em torno de 65 bilhões de litros. Além disso, o consumo de bebidas não alcoólicas foi o principal responsável pelo crescimento do consumo de bebidas entre os brasileiros.

O mercado de bebidas não alcoólicas mudou significativamente em 1995 com a disponibilização da embalagem tipo PET (Polietileno Tereftalato) de boa qualidade, produzida localmente e de preços razoáveis. Contudo, a tributação subiu em 2003 sobre a embalagem de $200 \mathrm{ml}$ PET dos refrigerantes e desacelerou o índice de crescimento des- 
pertando novamente o interesse pelo vidro. Em 2007 houve um crescimento constante de bebidas embaladas com este material e a partir daí, a embalagem PET entrou significativamente no mercado das categorias de refrigerantes, água engarrafada e chás gelados e comanda atualmente $61 \%$ do mercado de bebidas não alcoólicas [1].

Ainda de acordo com a ABIR, dentro das bebidas não alcoólicas destacam-se os refrigerantes, que dominam as vendas no mercado por causa dos preços que são acessíveis a todos os consumidores. Eles lideraram com $25 \%$ do total do consumo de bebidas comerciais em 2007, apesar de terem perdido mercado para a água engarrafada e para os néctares.

A produção de refrigerantes no Brasil deu-se no início do século XX, com empresas desenvolvendo e produzindo refrescos, muitas vezes utilizando-se de suco de fruta misturado com água. O desenvolvimento econômico e o crescimento populacional experimentados pelo Brasil na primeira metade do século XX proporcionaram a instalação, nos anos 40, de grandes produtores no país [1].

Atualmente temos mais de 800 fábricas que se dedicam à este tipo de produção das quais aproximadamente 30\% (238) são empresas regionais que produzem refrigerantes com preço mais baixos e marca local conhecidos como tubaínas. A maioria dessas empresas regionais se concentra no sudeste do país e são empresas familiares e centenárias, que sobrevivem dentro de suas respectivas regiões, perto da comunidade e contribuem com o desenvolvimento local, como é o caso da empresa Vencetex localizada em Guararapes - SP. Juntas, as empresas regionais geram mais de 21.000 empregos diretos em todo o Brasil [2]. Das restantes, 17.3\% são ligadas à Ambev e 51.5\% à Coca-Cola.

De acordo com dados da Afrebras - Associação dos fabricantes de refrigerantes do Brasil [2], o sistema Coca-Cola é representado pelas marcas: Coca-Cola, Fanta, Kuat, Schweppes, entre outras. Essas empresas, que compõem o sistema Coca-Cola, geram cerca de 25.000 empregos no Brasil, em 36 unidades fabris. Já a Ambev, embora atue de forma mais abrangente no setor cervejeiro, detém as marcas Pepsi-Cola, Antarctica, Gatorade, entre outras. Estima-se que, no setor brasileiro de refrigerantes, essas empresas empreguem mais de 3.000 funcionários.

As Tabelas 3.1, 3.2 e 3.3 apresentam o volume mensal de consumo de refrigerantes em 2008 e no primeiro semestre de 2009, o faturamento obtido em 2008 e no primerio semestre de 2009 e o volume de vendas de refrigerantes de 1986 até o primeiro semestre 
de 2009. Note que o consumo aumentou 0,15\% em 2009 com relação ao mesmo período de 2008 e que o faturamento aumentou 3,89\% também em relação ao mesmo período. Pode-se perceber pela Tabela 3.3 que houve um aumento expressivo no consumo no ano de 1995, em relação aos anos anteriores. Os refrigerantes em garrafas PET foram os mais consumidos (80\%), seguidos pelas garrafas de vidro (12\%) e as latinhas $(7,8 \%)$ [1].

\begin{tabular}{clll}
\hline Mês & 2008 & 2009 & $\%$ \\
\hline \hline Janeiro & 1.452 .995 & 1.360 .212 & $-6,39$ \\
Fevereiro & 1.243 .445 & 1.271 .125 & 2,23 \\
Março & 1.231 .093 & 1.287 .964 & 4,62 \\
Abril & 1.177 .223 & 1.205 .806 & 2,43 \\
Maio & 1.115 .685 & 1.155 .523 & 3,57 \\
Junho & 1.078 .831 & 1.051 .422 & $-2,54$ \\
Julho & 1.055 .897 & 1.036 .084 & $-1,88$ \\
Agosto & 1.088 .046 & & \\
Setembro & 1.129 .367 & & \\
Outubro & 1.133 .870 & & \\
Novembro & 1.181 .863 & & \\
Dezembro & 1.260 .050 & & \\
Total & 14.148 .363 & 8.368 .136 & 0,16 \\
\hline
\end{tabular}

Tabela 3.1: Volume 2008 x 2009 - Mensal (Em Mil Litros) [1]. 


\begin{tabular}{clcc}
\hline Mês & 2008 & 2009 & $\%$ \\
\hline \hline Janeiro & 2.032 .369 & 1.997 .968 & $-1,69$ \\
Fevereiro & 2.032 .369 & 1.937 .216 & $-4,68$ \\
Março & 1.792 .702 & 1.980 .243 & 10,46 \\
Abril & 1.718 .763 & 1.853 .648 & 7,85 \\
Maio & 1.626 .158 & 1.788 .765 & 10 \\
Junho & 1.592 .230 & 1.646 .386 & 3,4 \\
Julho & 1.561 .180 & 1.632 .267 & 4,55 \\
Agosto & 1.607 .099 & & \\
Setembro & 1.674 .754 & & \\
Outubro & 1.680 .788 & & \\
Novembro & 1.752 .387 & & \\
Dezembro & 1.880 .584 & & \\
Total & 20.951 .383 & 12.836 .493 & 3,89 \\
\hline
\end{tabular}

Tabela 3.2: Faturamento 2008 x 2009 (Em Mil Reais) [1]. 


\begin{tabular}{|c|c|c|}
\hline Ano & Litros (em Mil) & $\%$ \\
\hline 1986 & 4.895 .835 & \\
\hline 1987 & 5.305 .593 & 8,37 \\
\hline 1988 & 5.095 .788 & $-3,95$ \\
\hline 1989 & 5.800 .108 & 13,82 \\
\hline 1990 & 5.769 .264 & $-0,53$ \\
\hline 1991 & 5.978 .175 & 3,62 \\
\hline 1992 & 5.147 .758 & $-13,89$ \\
\hline 1993 & 5.615 .803 & 9,09 \\
\hline 1994 & 6.440 .397 & 14,68 \\
\hline 1995 & 9.146 .041 & 42,01 \\
\hline 1996 & 9.861 .493 & 7,82 \\
\hline 1997 & 10.574 .528 & 7,23 \\
\hline 1998 & 11.029 .351 & 4,3 \\
\hline 1999 & 11.052 .303 & 0,21 \\
\hline 2000 & 11.516 .598 & 4,2 \\
\hline 2001 & 11.585 .868 & 0,6 \\
\hline 2002 & 11.968 .630 & 3,3 \\
\hline 2003 & 11.571 .945 & $-3,31$ \\
\hline 2004 & 12.208 .950 & 5,5 \\
\hline 2005 & 12.422 .058 & 1,75 \\
\hline 2006 & 13.012 .102 & 4,75 \\
\hline 2007 & 13.661 .293 & 4,99 \\
\hline 2008 & 14.148 .363 & 3,57 \\
\hline 2009 & 8.368 .136 & \\
\hline Média Anual & 13.090 .553 & 5,37 \\
\hline
\end{tabular}

Tabela 3.3: Volume de vendas de refrigerantes de 1986 a 2009 [1].

Com relação ao ranking mundial, segundo dados da ABIR [1], ao contrário do que se especula, o consumo de refrigerantes no Brasil é relativamente baixo se comparado ao de outros países. Estima-se que o brasileiro consome em média 66 litros de refrigerante ao ano, colocando o Brasil apenas em 12 lugar no ranking mundial de consumo per capta 
da bebida. Apesar disso, o consumo vem crescendo. Registros do consumo mundial de refrigerantes a partir do terceiro trimestre de 2009 foram obtidos de uma notícia do site da Tribuna Impressa [90] e diz que no terceiro trimestre de 2009, o volume de refrigerantes vendido no País cresceu $4 \%$ em relação ao mesmo trimestre de 2008. Nesse período, foram produzidos mais de 14 bilhões de litros de refrigerantes no país e o faturamento chegou a $\mathrm{R} \$ 20,7$ bilhões. A taxa de acréscimo registrada superou a média mundial, que foi de $2 \%$ [90]. Isso demonstra um potencial para crescimento. Este potencial para crescimento, o aumento do consumo, o crescimento do número de itens produzidos pelas fábricas, a concorrência e as exigências do mercado, aumentaram a preocupação das empresas em melhorar seus processos produtivos. Por esse motivo, muitas empresas têm implementado o uso de softwares para auxiliar a programação da produção determinando rapidamente o plano de produção. Na próxima seção é descrito o processo de produção de bebidas onde é possível perceber que a programação da produção utiliza várias informações como demanda de produtos, capacidade disponível, insumos necessários, tempos de preparo das linhas de produção, entre outros [32].

\subsubsection{Processo de produção de bebidas}

A produção de refrigerantes de diferentes sabores e tamanhos é feita basicamente em dois estágios principais: preparação de xarope e envase da bebida. O preparo do xarope possui duas etapas. Na primeira etapa os ingredientes são medidos, em quantidades denominadas kits. Após esta etapa o composto é enviado para um outro tanque denominado tanque de preparo, onde é adicionado açúcar líquido ou adoçante (para os sabores diet). Esta mistura é agitada por hélices que tornam o xarope uma mistura homogênea. Para que este composto seja bem misturado, é necessária uma quantidade mínima de xarope no tanque, suficiente para cobrir estas hélices. Um tanque pode abastecer ao mesmo tempo várias linhas de produção, mas uma linha recebe xarope de apenas um tanque por vez. Em geral, qualquer sabor de xarope pode ser preparado em um tanque, mas algumas fábricas reservam alguns tanques só para o preparo dos sabores light e diet [32].

No segundo estágio, a bebida é envasada em linhas de produção. Nelas, os vasilhames entram por uma esteira rolante onde são lavados e em seguida, passam por uma máquina que os enche com uma determinada quantidade de xarope e água carbonatada. Depois são fechados, rotulados, empacotados e então são levados para o estoque. Uma 
vez que os vasilhames são colocados na esteira, eles só podem ser retirados dela ao final do processo, quando são então transferidos para o depósito. Existe apenas uma entrada e uma saída de vasilhames na linha [32], [36]. A Figura 3.1 mostra o processo de produção de refrigerantes.

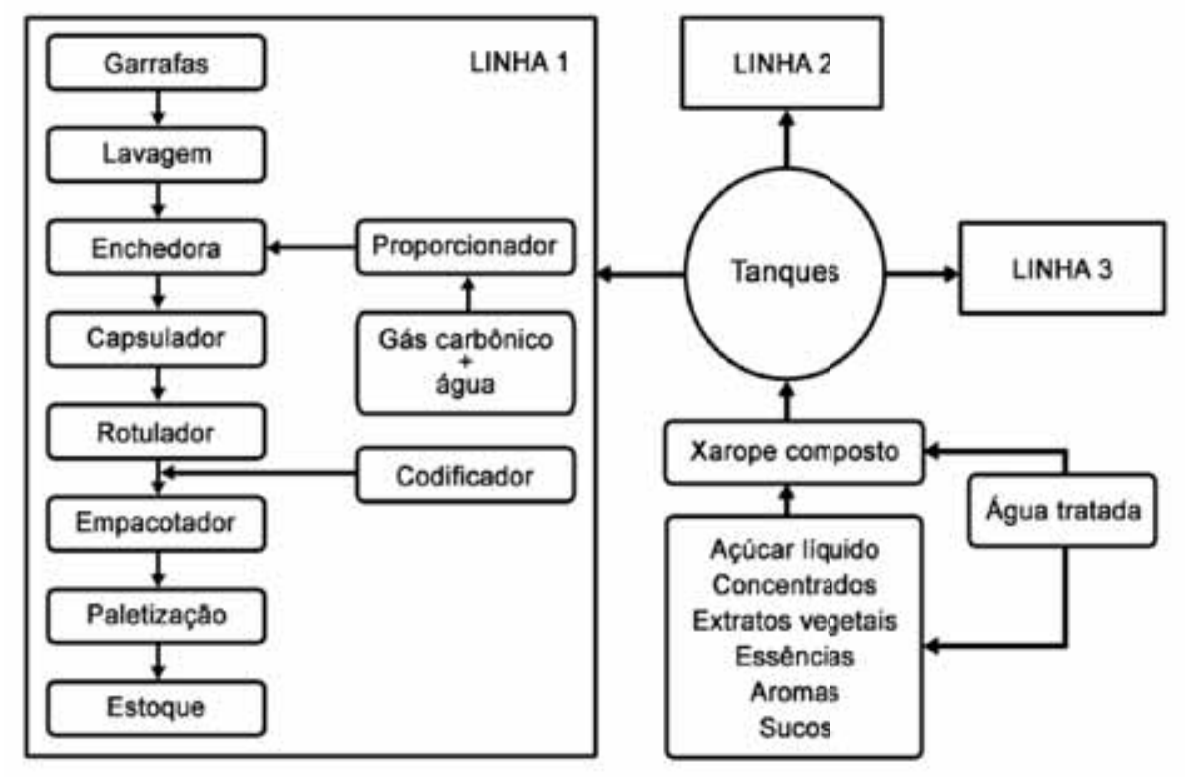

Figura 3.1: Etapas do processo de produção de refrigerantes [76].

Uma linha de produção é inicialmente ajustada para produzir bebidas de um dado sabor e tamanho. Para produzir uma bebida de um outro sabor e/ou tamanho, é necessário parar a produção e fazer toda a limpeza e/ou ajustes necessários para a produção de um outro tamanho de vasilhame e/ou xarope. Estes ajustes envolvem custos e tempos de preparos dependentes da sequência de produção. Além das linhas de envase, os tanques também passam por uma limpeza antes do próximo xarope ser preparado, e o tempo desta limpeza também é dependente da sequência de produção. Por exemplo, se após a produção de uma bebida normal se produzir uma bebida diet, a limpeza da máquina passa por mais processos do que na ordem contrária, o que consome mais tempo e pode gerar custos de atraso, preparo de máquinas, e estoque. A mudança da produção de uma bebida diet para normal pode alterar os tempos e custos de preparo significativamente. Como o preparo pode ser demorado e custoso, e pode gerar desperdícios de tempo e custos de produção, é fundamental que ele seja considerado na programação da produção [34].

Em algumas indústrias, um fator importante a ser considerado no planejamento da produção é a sincronia entre os dois estágios [35], [82]. Se a sincronia não é levada 
em conta, uma programação da produção pode ser infactível na prática. A máquina deve aguardar até que o xarope esteja pronto para ser enviado para o envase. Do mesmo modo, o envio de xarope para a máquina deve ocorrer somente se esta estiver pronta para o envase da bebida. Assim, se a sincronia não é considerada no modelo, não serão considerados as possíveis esperas que podem ocorrer da máquina pelo tanque e do tanque pela máquina.

No presente trabalho, o problema considerado é mais simples do que os apresentados, por exemplo, em [35] e [82]. A programação da produção estudada é a de uma fábrica de refrigerantes de pequeno porte com apenas uma linha de produção e o gargalo no estágio de envase. Supomos que vários tanques são dedicados a uma única máquina e por isso, não é necessário considerar a programação de xarope nos tanques e nem as trocas. É possível preparar um novo lote de xarope em um dado tanque enquanto a máquina está envasando um produto utilizando um xarope produzido em um outro tanque. Entretanto, o estágio I não é totalmente desconsiderado. A quantidade mínima de produção de xarope para garantir a homogeneidade, e a capacidade máxima do tanque são levadas em conta.

\subsection{Modelo P1S1M}

Como citado no Capítulo 2, alguns trabalhos na literatura estudam o planejamento da produção de bebidas [35], [36], [82] e [84]. A base para este trabalho foi [36] onde o estudo desenvolvido leva em consideração o planejamento da produção de uma fábrica de refrigerantes de pequeno porte. O modelo é baseado no modelo GLSP [38] (ver também Capítulo 2) e considera detalhadamente o estágio de envase, com uma linha de produção chamada máquina (Estágio II). É um modelo em que para obter o sequenciamento dos itens cada período é dividido em subperíodos. O tamanho de cada subperíodo varia de acordo com a quantidade produzida. O número total de subperíodos é definido como o número máximo de preparos em cada período. Apenas um item pode ser produzido por subperíodo. Um item aqui considera o tipo de vasilhame e o sabor, ou seja, um vasilhame de vidro de 2 litros de laranja corresponde a um item. Restrições de capacidade associadas aos lotes mínimo e máximo dos tanques são consideradas no estágio I para assegurar a homogeneidade nos tanques. É considerado também que uma vez que a máquina esteja preparada para produzir um produto, sempre existirá um tanque preparado com o xarope 
necessário para esta produção. Há porém, o limite de preparos que consequentemente impõe limite no número de vezes que os tanques podem ser utilizados.

Os parâmetros utilizados para formular o modelo um estágio uma máquina P1S1M (one-stage one-machine lot-scheduling problem) [36] são, em grande maioria, os mesmos utilizados para descrever o modelo GLSP ((2.43) - (2.50)) com a diferença de que alguns parâmetros e variáveis referentes ao estágio II (envase) possuem o índice II para diferenciar dos referentes ao estágio I (preparo do xarope) que possuem o índice I. As restrições de lote mínimo (2.49) presentes no modelo GLSP são encontradas no estágio I, entretanto referentes à produção mínima de xarope (3.8). Os índices, parâmetros e variáveis utilizados no modelo, são descritos a seguir.

Considere os seguintes parâmetros utilizados para descrever o modelo:

$J \quad$ número total de bebidas;

$L$ número total de xaropes;

$N$ número total de subperíodos, isto é, número de preparos no horizonte de planejamento;

$T$ número total de períodos.

Sejam $(i, j, l, t, s)$ o conjunto de índices definidos como:

$i, j \in\{1, \ldots, J\} ; l \in\{1, \ldots, L\} ; t \in\{1, \ldots, T\} ; s \in\{1, \ldots, N\} ;$

Considere também os conjuntos e parâmetros abaixo em que $I$ e $I I$ estão relacionados aos estágios $I$ (preparo do xarope) e $I I$ (envase) respectivamente.

Conjuntos:

$S_{t}$ conjunto de subperíodos em cada período $t$;

$\gamma_{l}$ conjunto de itens que utilizam o xarope $l$ para serem produzidos;

$\beta$ conjunto de xaropes que podem ser produzidos.

Parâmetros: 
$a_{j}^{I I}$ tempo necessário para a produção de uma unidade do item $j$;

$b_{i j}^{I I} \quad$ tempo de troca do item $i$ para o item $j$;

$d_{j t}$ demanda do item $j$ no período $t$;

$g_{j} \quad$ custo por atrasar uma unidade do item $j$;

$h_{j} \quad$ custo para estocar uma unidade do item $j$;

$I_{j 0}^{+} \quad$ estoque inicial do item $j$;

$I_{j 0}^{-} \quad$ quantidade em atraso do item $j$ no início do horizonte de planejamento.

$K^{I}$ capacidade total da xaroparia;

$K_{t}^{I I}$ tempo total da máquina no período $t$;

$q_{l}$ quantidade mínima de xarope $l$ a ser preparada no tanque para garantir a homogeneidade;

$r_{l j}$ quantidade necessária de xarope $l$ para produzir uma unidade do item $j$;

$s_{i j}^{I I} \quad$ custo de troca do item $i$ para o item $j$;

$y_{j 0}^{I I}=\left\{\begin{array}{cc}1 & \text { se a máquina está inicialmente preparada para a produção do item } j \\ 0 & \text { caso contrário }\end{array}\right.$

Variáveis:

$I_{j t}^{+} \quad$ quantidade de estoque do item $j$ no final do período $t$

$I_{j t}^{-} \quad$ quantidade em atraso do item $j$ no final do período $t$;

$x_{j s}^{I I} \quad$ quantidade de produção do item $j$ no subperíodo $s$;

$y_{l s}^{I}= \begin{cases}1 & \text { se há a produção do xarope } l \text { no subperíodo } s \\ 0 & \text { caso contrário }\end{cases}$

$y_{j s}^{I I}= \begin{cases}1 & \text { se a máquina está preparada para a produção do item } j \text { no subperíodo } s \\ 0 & \text { caso contrário }\end{cases}$

$z_{i j s}^{I I}= \begin{cases}1 & \text { se há troca na máquina do item } i \text { para o item } j \text { no subperíodo } s \\ 0 & \text { caso contrário }\end{cases}$

O modelo P1S1M conforme apresentado em [36] é dado pelas expressões (3.1)-(3.9). 


\section{Modelo P1S1M}

$$
\operatorname{Min} \mathrm{Z}=\sum_{j=1}^{J} \sum_{t=1}^{T}\left(h_{j} I_{j t}^{+}+g_{j} I_{j t}^{-}\right)+\sum_{s=1}^{N} \sum_{i=1}^{J} \sum_{j=1}^{J} s_{i j}^{I I} z_{i j s}^{I I}
$$

sujeito a:

Estágio II (Envase)

$$
\begin{array}{cc}
I_{j(t-1)}^{+}+I_{j t}^{-}+\sum_{s \in S_{t}} x_{j s}^{I I}-I_{j t}^{+}-I_{j(t-1)}^{-}=d_{j t}, & j=1, \ldots, J, t=1, \ldots, T . \\
\sum_{j=1}^{J} \sum_{s \in S_{t}} a_{j}^{I I} x_{j s}^{I I}+\sum_{i=1}^{J} \sum_{j=1}^{J} \sum_{s \in S_{t}} b_{i j}^{I I} z_{i j s}^{I I} \leq K_{t}^{I I}, & t=1, \ldots, T . \\
a_{j}^{I I} x_{j s}^{I I} \leq K_{t}^{I I} y_{j s}^{I I}, & j=1, \ldots, J, t=1, \ldots, T, s \in S_{t} . \\
\sum_{j=1}^{J} y_{j s}^{I I}=1, & s=1, \ldots, N . \\
z_{i j s}^{I I} \geq y_{i(s-1)}^{I I}+y_{j s}^{I I}-1, & i, j=1, \ldots, J, s=1, \ldots, N . \\
\sum_{i=1}^{J} \sum_{j=1}^{J} z_{i j s}^{I I} \leq 1, & s=1, \ldots N .
\end{array}
$$

Estágio I (Xaroparia)

$$
\begin{gathered}
q_{l} y_{l s}^{I} \leq \sum_{j \in \gamma_{l}} r_{l j} x_{j s}^{I I} \leq K^{I} y_{l s}^{I}, \\
I_{j t}^{+}, I_{j t}^{-} \geq 0, \quad j \in \beta, t=1, \ldots, T, s \in S_{t} . \\
x_{j s}^{I I}, z_{i j s}^{I I} \geq 0, y_{j s}, y_{l s}^{I}=0 / 1, \quad j=1, \ldots, J, t=1, \ldots, T, l \in \beta, s \in S_{t} .
\end{gathered}
$$

A função objetivo (3.1) minimiza a soma total dos custos de estoque, atraso, e troca de itens. No estágio II as restrições (3.2) são restrições de balanceamento de cada item em cada período. Como a variável de produção é definida para cada subperíodo, para obter a produção total do item $j$ no período $t$ é necessário somar sua produção em todos os subperíodos do período t. As restrições (3.3) representam a capacidade da máquina em cada período. As restrições (3.4) asseguram que o item $j$ será produzido somente se a máquina foi preparada. As restrições (3.5) estabelecem que ocorra exatamente um preparo por subperíodo. As restrições (3.6) controlam as trocas de itens em cada subperíodo $s$. As restrições (3.7) garantem que existe no máximo uma troca em cada subperíodo $s$. 
No estágio I, $\sum_{j \in \gamma_{l}} r_{l j} x_{j s}^{I I}$ corresponde à demanda do xarope $l$ em cada subperíodo $s$. As restrições (3.8) asseguram que se o tanque está preparado para a produção do xarope $l$, então poderá haver produção e a quantidade produzida deve estar entre a quantidade mínima necessária para garantir a homogeneidade e a capacidade máxima do tanque. As restrições (3.9) e (3.10) definem a não negatividade e a integralidade das variáveis.

\subsection{Modelo P1S1MTS: Uma nova proposta}

O modelo apresentado aqui é uma reformulação do modelo P1S1M em que, para o dimensionamento dos lotes, foram utilizadas restrições do modelo CLSP (Capacitated Lot sizing and Scheduling Problem) encontradas no modelo P1S1M, e para modelar as decisões do sequenciamento utilizamos idéias similares às apresentadas por Toso et al. [87], isto é, modelamos o sequenciamento utilizando restrições do problema do caixeiro viajante assimétrico (ATSP - Asymmetric Traveling Salesman Problem) (ver apêndice A). Podemos definir o sequeciamento dos itens da seguinte forma: para cada período $t$, temos um grafo $G=(V, A)$, onde $V$ corresponde aos itens que podem ser produzidos no período $t$ (ou seja, é um subconjunto do número total de produtos $J$ para os quais $\left.x_{j t}^{I I} \geq 0\right)$ e os arcos em $A$ correspondem às possíveis trocas entre cada par de produtos $\left(z_{i j t}^{I I}\right)$. O problema consiste em encontrar um caminho hamiltoniano partindo de uma origem e passando por todos os vértices (ver Apêndice A) [88].

Diferente da formulação apresentada em [87], neste trabalho, para o sequenciamento, o caminho hamiltoniano é definido de forma similar à apresentada no Apêndice A. Definimos um item fantasma $i_{0}$ e consideramos os tempos de troca associados a $i_{0}$ iguais a zero (isto é: $b_{i_{0} j}=0$ e $b_{j i_{0}}=0 \forall j$ ). Além disso, para impedir a troca entre itens iguais, consideramos nas restrições que $j \neq i$. Isto porque, na situação estudada, os tempos e custos de trocas entre os mesmos produtos possuem valores insignificantes e, portanto, são desconsiderados. As restrições de eliminação de subrotas consideradas em [87] são as propostas por Dantzig, Fulkerson e Johnson (DFJ) [60]. Neste trabalho, consideramos as restrições propostas por Miller, Tucker e Zemlim (MTZ) [60]. Diferente das restrições DFJ que devem ser incorporadas de forma dinâmica por causa do número elevado de possibilidades, as restrições MTZ podem ser incorporadas a priori e, apesar de em geral não fornecerem uma relaxação linear tão boa [80], forneceram bons resultados 
(ver Capítulo 4).

Assim, propomos um modelo um estágio uma máquina com as restrições do sequenciamento formuladas com base no problema do caixeiro viajante assimétrico (traveling salesman one-stage one-machine lot-scheduling problem - P1S1MTS).

Para formular o modelo P1S1MTS devem ser considerados, além dos parâmetros e variáveis usados no modelo P1S1M, os seguintes parâmetros e variáveis:

$i_{0}$ é o produto para o qual a máquina foi preparada no início de cada período;

$u_{j t}$ posição em que o item $j$ é produzido no período $t$;

$w_{l t} \quad$ é a variável que indica o número de tanques do xarope $l$ que devem ser produzidos no período $t$;

$n_{l t}$ é uma variável que corresponde à utilização parcial de um tanque do xarope $l$ no período $t$.

Função objetivo: A função objetivo (3.11) difere da encontrada no modelo P1S1M pela variável de troca que é definida em função dos índices $(i, j, t)$.

$$
\sum_{j=1}^{J} \sum_{t=1}^{T}\left(h_{j} I_{j t}^{+}+g_{j} I_{j t}^{-}\right)+\sum_{t=1}^{T} \sum_{i=1}^{J} \sum_{j=1, j \neq i}^{J} s_{i j}^{I I} z_{i j t}^{I I}
$$

\section{Restrições - Estágio II - Dimensionamento de lotes}

Balanceamento: As restrições (3.12) representam o balanceamento da produção de cada item em cada período. Podemos notar que, diferente do modelo P1S1M, a quantidade produzida é definida em função dos índices $(j, t)$.

$$
I_{j(t-1)}^{+}+I_{j t}^{-}+x_{j t}^{I I}-I_{j t}^{+}-I_{j(t-1)}^{-}=d_{j t}, \quad j=1, \ldots, J, t=1, \ldots, T .
$$

Capacidade: As restrições (3.13) de capacidade consideram os tempos de troca e de produção e diferem das encontradas no modelo P1S1M justamente pelas variáveis de produção e troca que são definidas em função dos índices $(j, t)$ e $(i, j, t)$ respectivamente. 


$$
\sum_{j=1}^{J} a_{j}^{I I} x_{j t}^{I I}+\sum_{i=1}^{J} \sum_{j=1, j \neq i}^{J} b_{i j}^{I I} z_{i j t}^{I I} \leq K_{t}^{I I}, \quad t=1, \ldots, T .
$$

Preparo: As restrições (3.14) asseguram que o item $j$ será produzido somente se a máquina foi preparada. Diferente do modelo P1S1M, onde o preparo da máquina é determinado pela variável $y_{j s}^{I I}$, o modelo P1S1MTS considera o preparo implícito quando $\sum_{j=1}^{J} z_{i j t}^{I I}=1$.

$$
a_{j}^{I I} x_{j t}^{I I} \leq K_{t}^{I I} \sum_{i=i_{0}}^{J} z_{i j t}^{I I}, \quad j=1, \ldots, J, j \neq i, t=1, \ldots, T .
$$

Restrições Estágio II - Sequenciamento da produção

a) As restrições (3.15) garantem que somente haverá troca de um item $i$ qualquer para um item $k$ qualquer se existir uma troca do item inicial $i_{0}$ para algum item $j$ no período $t$.

$$
\sum_{j=1, j \neq i_{0}}^{J} z_{i_{0} j t}^{I I} \geq \sum_{i=1}^{J} z_{i k t}^{I I}, \quad k=1, \ldots, J, k \neq i, t=1, \ldots, T
$$

b) As restrições (3.16) proíbem mais de uma troca a partir de um item $i$, o que significa que em cada período só pode ser produzido um único lote de cada produto.

$$
\sum_{j=i_{0}}^{J} z_{i j t}^{I I} \leq 1, \quad i=1, \ldots, J, i \neq j, t=1, \ldots T .
$$

c) As restrições (3.17) garantem que se ocorre uma troca de um item $i$ para um item $k$, então haverá uma troca deste item $k$ para um item $j$.

$$
\sum_{i=1}^{J} z_{i k t}^{I I}=\sum_{j=1}^{J} z_{k j t}^{I I}, \quad k=1, \ldots, J, k \neq i, k \neq j, t=1, \ldots, T .
$$

d) As restrições (3.18) controlam o número total de trocas que podem ocorrer na máquina no período $t$. Comparadas às restrições do modelo P1S1M, estas restrições correspondem ao número total de subperíodos em um período $t\left(\left|S_{t}\right|\right)$. 


$$
\sum_{i=1}^{J} \sum_{j=1, j \neq i}^{J} z_{i j t}^{I I} \leq\left|S_{t}\right|, \quad i \neq j, t=1, \ldots, T .
$$

Note que, como já observado, diferente do modelo P1S1M, no modelo P1S1MTS não são consideradas trocas entre itens iguais. Assim, para uma comparação mais fiel entre os modelos, o limite máximo para o número de preparos por período no modelo P1S1M deveria ser maior que no modelo P1S1MTS. Como estamos modelando o planejamento da produção de uma fábrica de refrigerantes e queremos retratar o mais próximo possível as decisões da fábrica, para a resolução dos dois modelos vamos considerar o mesmo número de preparos existentes na fábrica. Na próxima seção, esta discussão sobre as diferenças entre os modelos P1S1M e P1S1MTS será retomada.

e) As restrições (3.15), (3.16) e (3.17) sozinhas podem gerar subrotas, ou seja, no caso do sequenciamento dos itens, subcaminhos desconexos. Desta forma, as restrições (3.19) propostas por Miller, Tucker e Zemlin [60](ver Apêndice A) são consideradas para proibição dessas subrotas.

$$
u_{j t} \geq u_{i t}+1-(J-1)\left(1-z_{i j t}^{I I}\right), \quad i, j=2, \ldots, J, i \neq j, t=1, \ldots, T .
$$

Restrições - Estágio I

f) As restrições (3.20), (3.21), (3.22), (3.23) e (3.24) são similares às restrições propostas por Clark [25] e juntas garantem que o xarope necessário para a produção do item esteja pronto no momento do envase deste item. As restrições (3.20) garantem que se o tanque está preparado para a produção do xarope $l$, então haverá produção e a quantidade produzida é igual ao número máximo de tanques do xarope $l$ que podem ser produzidos naquele período. A variável $n_{l t}$ permite o uso parcial do tanque respeitando a quantidade mínima $\left(q_{l}\right)$ necessária para garantir a homogeneidade, como especificado nas restrições (3.21). As restrições (3.22) garantem que só haverá produção do xarope $l$ se o tanque estiver preparado $\left(y_{l t}=0\right)$ ou seja, $w_{l t}=0$ se $y_{l t}=0$ e $1 \leq w_{l t} \leq\left|S_{t}\right|$ caso contrário. De acordo com as restrições (3.23), a soma total do número de tanques produzidos no período $t$ deve ser limitada pelo número total de preparos do tanque em $t$. As restrições (3.24) referem-se ao domínio das variáveis do modelo. 


$$
\begin{array}{cc}
\sum_{j \in \gamma_{l}} r_{l j} x_{j t}^{I I}=K^{I}\left(w_{l t}-n_{l t}\right), & l \in \beta, t=1, \ldots, T . \\
n_{l t} \leq 1-\left(\frac{q_{l}}{K^{I}}\right), & l \in \beta, t=1, \ldots, T . \\
y_{l t}^{I} \leq w_{l t} \leq\left|S_{t}\right| y_{l t}^{I}, & l \in \beta t=1, \ldots, T . \\
\sum_{l \in \beta} w_{l t} \leq\left|S_{t}\right|, & t=1, \ldots, T . \\
x_{j t}^{I I} \geq 0, z_{i j t}^{I I}, y_{l t}^{I}=0 / 1, w_{l t} \in \mathbb{Z}_{+}, 0 \leq n_{l t}, & j=1, \ldots, J, t=1, \ldots, T, l \in \beta .
\end{array}
$$

Podemos notar então que, diferente do modelo P1S1M, onde de acordo com as restrições (3.8), a produção de xarope no modelo é limitada a um tanque por subperíodo e, no caso de produção do mesmo tipo de xarope, sem reaproveitamento do xarope que restou no subperíodo anterior, as restrições (3.20), (3.21) (3.22) e (3.23) permitem que a sobra no tanque de um xarope produzido para um produto em um período $t$ seja reaproveitada para um outro produto que utilize o mesmo xarope neste mesmo período. Isto faz com que, dependendo da quantidade necessária de produtos a ser produzida, o número de preparos do tanque necessários para a produção destes itens seja menor no modelo P1S1MTS que no modelo P1S1M. O Exemplo 3.1 ilustra as principais diferenças entre P1S1M e P1S1MTS.

Portanto, o modelo completo P1S1MTS é dado por (3.11) - (3.24).

\section{Modelo P1S1MTS}

$\operatorname{Min} \mathrm{Z}=\sum_{j=1}^{J} \sum_{t=1}^{T}\left(h_{j} I_{j t}^{+}+g_{j} I_{j t}^{-}\right)+\sum_{t=1}^{T} \sum_{i=1}^{J} \sum_{j=1, j \neq i}^{J} s_{i j}^{I I} z_{i j t}^{I I}$

sujeito a:

Estágio II (Envase)

$$
\begin{aligned}
& I_{j(t-1)}^{+}+I_{j t}^{-}+x_{j t}^{I I}-I_{j t}^{+}-I_{j(t-1)}^{-}=d_{j t}, \quad j=1, \ldots, J, t=1, \ldots, T . \\
& \sum_{j=1}^{J} a_{j}^{I I} x_{j t}^{I I}+\sum_{i=1}^{J} \sum_{j=1, j \neq i}^{J} b_{i j}^{I I} z_{i j t}^{I I} \leq K_{t}^{I I}, \quad t=1, \ldots, T . \\
& a_{j}^{I I} x_{j t}^{I I} \leq K_{t}^{I I} \sum_{i=1}^{J} z_{i j t}^{I I}, \quad j=1, \ldots, J, j \neq i, t=1, \ldots, T . \\
& \sum_{j=1, j \neq i_{0}}^{J} z_{i_{0} j t}^{I I} \geq \sum_{i=1}^{J} z_{i k t}^{I I}, \quad k=1, \ldots, J, k \neq i, t=1, \ldots, T .
\end{aligned}
$$


$\sum_{j=1}^{J} z_{i j t}^{I I} \leq 1, \quad i=1, \ldots, J, i \neq j, t=1, \ldots T$
$\sum_{i=1}^{J} z_{i k t}^{I I}=\sum_{j=1}^{J} z_{k j t}^{I I}, k=1, \ldots, J, \quad k \neq i, k \neq j, t=1, \ldots, T$.
$\sum_{i=1}^{J} \sum_{j=1}^{J} z_{i j t} \leq\left|S_{t}\right|, \quad i \neq j, t=1, \ldots, T$.
$u_{j t} \geq u_{i t}+1-(J-1)\left(1-z_{i j t}^{I I}\right), \quad i, j=2, \ldots, J, \quad i \neq j, t=1, \ldots, T$.

\section{Estágio I}

$$
\begin{aligned}
& \sum_{j \in \gamma_{l}} r_{l j} x_{j t}^{I I}=K^{I}\left(w_{l t}-n_{l t}\right), \quad l \in L, t=1, \ldots, T . \\
& n_{l t} \leq 1-\left(\frac{q_{l}}{K^{I}}\right), \quad l \in L, t=1, \ldots, T . \\
& y_{l t}^{I} \leq w_{l t} \leq\left|S_{t}\right| y_{l t}^{I}, \quad l \in L, t=1, \ldots, T . \\
& \sum_{l \in L} w_{l t} \leq\left|S_{t}\right|, \quad t=1, \ldots, T . \\
& x_{j t}^{I I} \geq 0, z_{i j t}^{I I}, y_{l t}^{I}=0 / 1, w_{l t} \in \mathbb{Z}_{+}, 0 \leq n_{l t}, j=1, \ldots, J, t=1, \ldots, T, l \in L .
\end{aligned}
$$

Exemplo 3.1. Consideremos um único periodo $(T=1)$, 3 itens produzidos por um mesmo xarope l, tal que o item 1 necessita de $30 \%$ da capacidade de um tanque para produção de sua demanda total, o item 2 de $40 \%$ e o item 3 de $50 \%$. Consideremos também que nesse período poderá haver no máximo dois preparos do tanque (2 subperíodos) .

Suponhamos que a sequência ótima de produção seja item 1, item 2 e item 3 e que os preparos dos respectivos xaropes podem ter ocorrido em um mesmo tanque ou em tanques diferentes. A Figura 3.2 representa a produção do xarope nos tanques de acordo com o modelo P1S1M.

Podemos observar que como o número de preparos (subperíodos) é limitado em dois, a produção do item 3 fica em atraso. Assim, seria necessário o preparo de mais um tanque do xarope para a produção do item 3, o que de acordo com as condições do Exemplo 3.1, que representa simplificadamente uma situação prática, é inviável.

A Figura 3.3 mostra os itens produzidos de acordo com o modelo P1S1MTS. Note que, neste caso, o xarope l produzido no $1^{\circ}$ tanque foi utilizado para a produção da demanda total dos itens 1 e 2 e demanda parcial do item 3. Houve necessidade de um novo preparo 


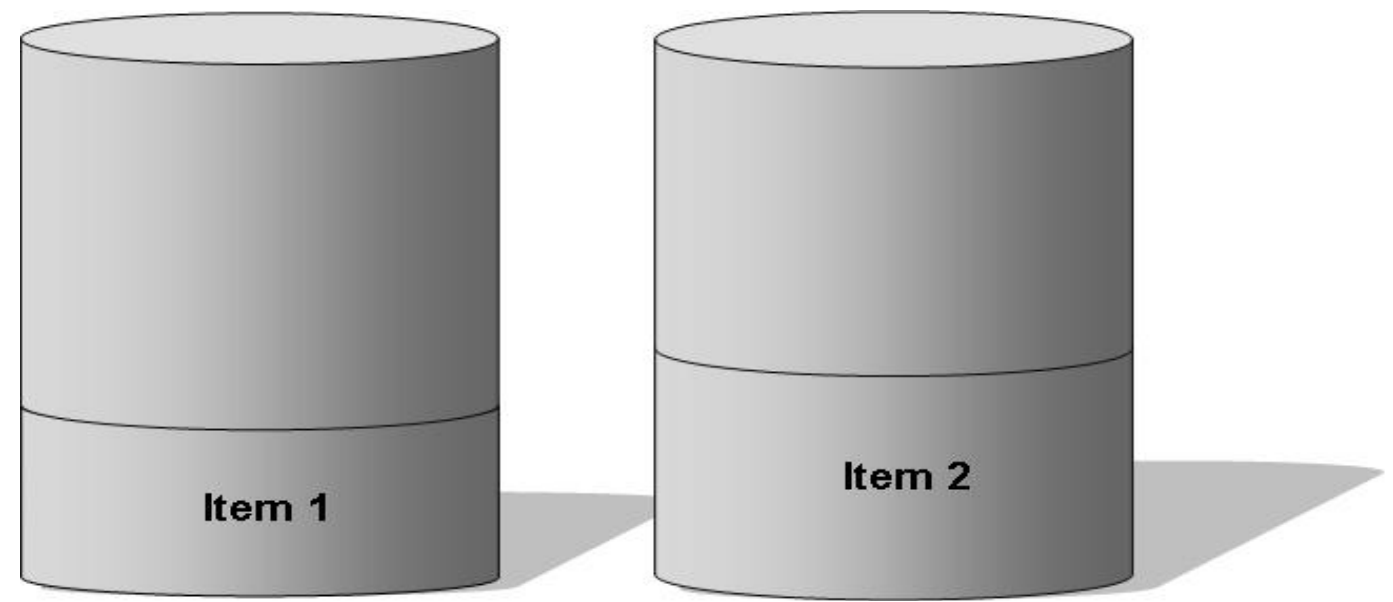

Figura 3.2: Exemplo 3.2-Produção dos xaropes nos tanques de acordo com P1S1M do xarope. Assim, o $2^{\circ}$ tanque do xarope l foi utilizado para produzir o restante do item 3 e, portanto, não houve atraso do item 3.

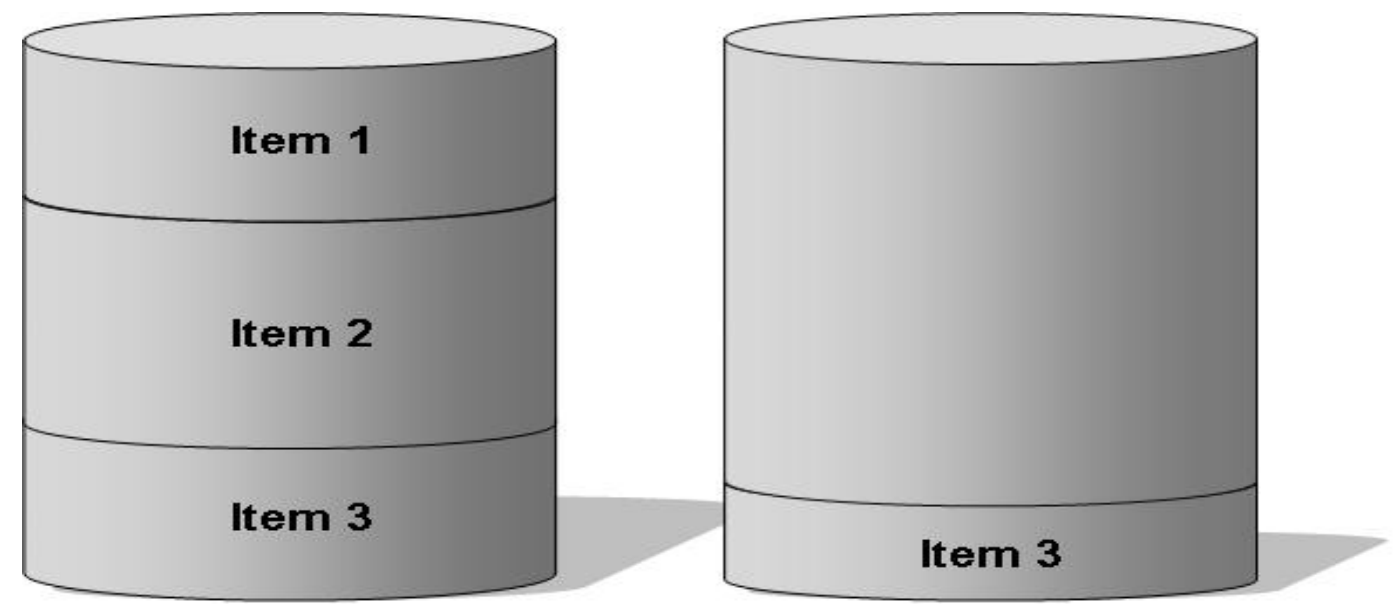

Figura 3.3: Exemplo 3.3-Produção dos itens nos tanques de acordo com P1S1MTS

\subsection{Validação do modelo P1S1MTS}

Com o intuito de validar o modelo P1S1MTS e analisar se os modelos P1S1M e P1S1MTS retratam a mesma situação, nesta seção serão apresentados testes computacionais com dois exemplares ilustrativos sendo que o primeiro (Exemplar 1) considera que mais de um item utiliza o mesmo xarope para a sua produção e o segundo (Exemplar 2) em que diferentes itens utilizam xaropes diferentes para a sua produção. Para o Exemplar 1, são apresentados os resultados fornecidos pelos modelos P1S1M e P1S1MTS. Em seguida, é analisado o comportamento do modelo P1S1M quando as variáveis de produção $x_{j s}^{I I}$ são 
fixadas de acordo com a solução do modelo P1S1MTS. Serão analisados vários cenários, até que a solução obtida pelo modelo P1S1MTS seja factível para o modelo P1S1M. É feita, também, a análise inversa, ou seja, como o modelo P1S1MTS se comporta se as variáveis de produção $\left(x_{j t}^{I I}\right)$ forem fixadas nos valores da solução fornecida pelo modelo P1S1M e em qual situação a solução fornecida pelo modelo P1S1M é viável para o modelo P1S1MTS. No caso do Exemplar 2, não foi necessária essa análise, pois foi observado que neste tipo de situação, ambos os modelos possuem o mesmo comportamento.

\subsubsection{Experimentos com exemplos ilustrativos - Exemplar 1}

Consideremos o exemplar ilustrativo adaptado de [32] com 4 itens e 2 períodos. Para o modelo P1S1M, cada período $t$ é divido em 6 subperíodos, resultando em um total de $N=12$ subperíodos, onde $S_{1}=\{1,2,3,4,5,6\}$ e $S_{2}=\{7,8,9,10,11,12\}$. No caso do modelo P1S1MTS o número máximo de preparos é $\left|S_{1}\right|=6$ para o primeiro período e $\left|S_{2}\right|=6$ para o segundo período. São considerados dois xaropes: 1 e 2 ; o xarope 1 é necessário para a produção do item 4 e o xarope 2 é necessário para a produção dos demais itens. Os estoques iniciais são nulos. Além disso, para melhor entendimento das diferenças entre os modelos P1S1M e P1S1MTS, consideramos que a quantidade mínima de xarope a ser produzida é igual à capacidade máxima do tanque. Ou seja, sempre deverá ser produzido um tanque completo de xarope. Detalhes deste exemplar são apresentados no Apêndice B.

A Tabela 3.4 mostra os custos de estoque, atraso e troca dos itens e os custos totais da solução ótima do exemplar ilustrativo associados às soluções dos modelos P1S1M e P1S1MTS.

\begin{tabular}{cc|cc|cc|cc}
\hline \multicolumn{2}{c|}{ Estoque } & \multicolumn{2}{c|}{ Atraso } & \multicolumn{2}{c|}{ Troca } & \multicolumn{2}{c}{ Z } \\
\hline \hline P1S1M & P1S1MTS & P1S1M & P1S1MTS & P1S1M & P1S1MTS & P1S1M & P1S1MTS \\
\hline 36,50 & 13,50 & $167.741,00$ & $122.768,70$ & 36,80 & 42,40 & $167.814,00$ & $122.824,60$ \\
\hline
\end{tabular}

Tabela 3.4: Resultados para o Exemplar 1 - solução ótima

Note que a solução fornecida pelo modelo P1S1M possui um valor mais elevado que a fornecida pelo modelo P1S1MTS. Neste caso, esta distinção de valores é causada principalmente pelas diferenças entre os custos de atraso. Isto pode acontecer por causa das diferenças entre as restrições de produção de xarope nos modelos (restrições (3.8)(3.10) no modelo P1S1M e (3.20)-(3.24) no modelo P1S1MTS), onde a produção de xarope 
no modelo P1S1M é limitada a um tanque por subperíodo e, no caso de produção do mesmo tipo de xarope, sem reaproveitamento do xarope que restou no subperíodo anterior, ao contrário do que acontece no modelo P1S1MTS onde pode haver reaproveitamento do xarope produzido, como comentado no Exemplo 3.1.

As Figuras 3.4 e 3.5 representam o dimensionamento e o sequenciamento de lotes de produção para os modelos P1S1M e P1S1MTS respectivamente. No eixo vertical das figuras estão indicados os períodos do horizonte de planejamento. O eixo horizontal indica a capacidade disponível da máquina, 1000 unidades de tempo. Os lotes são representados pelas barras cinzas e os tempos de troca são representados pelas barras em preto. Para indicar o início de um novo subperíodo, na Figura 3.4 é utilizada uma linha branca pontilhada. A bebida produzida é indicada à cima das barras cinzas pelo seu respectivo número. Por exemplo, na Figura 3.4, na solução do modelo P1S1M no primeiro período, a sequência de produção é: bebida 1 , bebida 2 e bebida 4 com seus respectivos tempos de troca indicados entre os lotes. Podemos observar que a cada subperíodo é produzido um novo lote de item e de xarope necessário para a sua produção e que nos dois períodos foram necessários vários lotes de xarope para a produção de uma mesma bebida (bebida 4). Isto aconteceu porque a quantidade de xarope necessária para produção do lote foi maior que um tanque. Note também que a quantidade produzida pelo modelo P1S1M não ocupou a capacidade total da máquina, mesmo não sendo produzida toda a demanda. Isto ocorreu porque a produção mínima de itens está relacionada com a produção mínima de xarope que é igual à capacidade total do tanque. Assim, a produção de mais um item deveria ser de 3448,28 unidades fazendo com que a soma dos tempos de produção e dos tempos disponíveis para as trocas ultrapassassem a capacidade da máquina (ver restrições $(3.3))$.

No caso do modelo P1S1MTS, como explicado na Seção 3.3, a produção de xarope é reaproveitada para um outro produto que utilize o mesmo xarope no mesmo período. Observe na Figura 3.5 que a sequência de produção é bebida 3, bebida 1, bebida 2 e bebida 4 para ambos os períodos. Na solução fornecida pelo modelo P1S1MTS ocorrem dois preparos do tanque para o xarope necessário para a produção dos itens 1,2 e 3 no primeiro período, e vários preparos para a bebida 4 nos dois períodos, o que significa que vários lotes de xarope foram necessários para a produção dos itens. Logo, por causa do reaproveitamento de xarope necessário para a produção de diferentes tipos de itens, não 
é necessária a produção de exatamente 3448,28 itens em cada lote. Assim, a capacidade da máquina pode ser utilizada totalmente. As trocas entre itens iguais não geram custos adicionais, pois o custo de troca de uma bebida para ela mesma é nulo. Entretanto, podem afetar a capacidade disponível da máquina, pois geram muitas esperas. A máquina só pode iniciar o envase depois que o xarope estiver pronto [35]. Na situação estudada, consideramos que toda vez que ocorre produção de um item, o xarope necessário para a sua produção estará pronto.

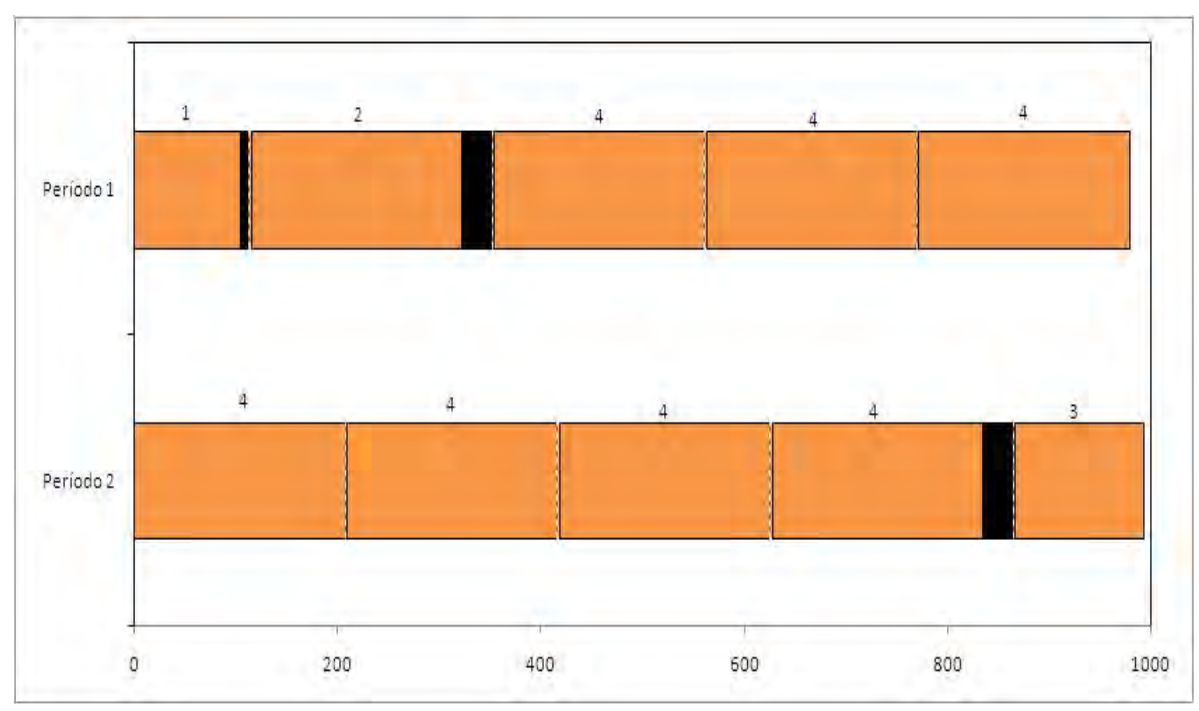

Figura 3.4: Programação da produção na máquina para o exemplar ilustrativo fornecida pelo modelo P1S1M.

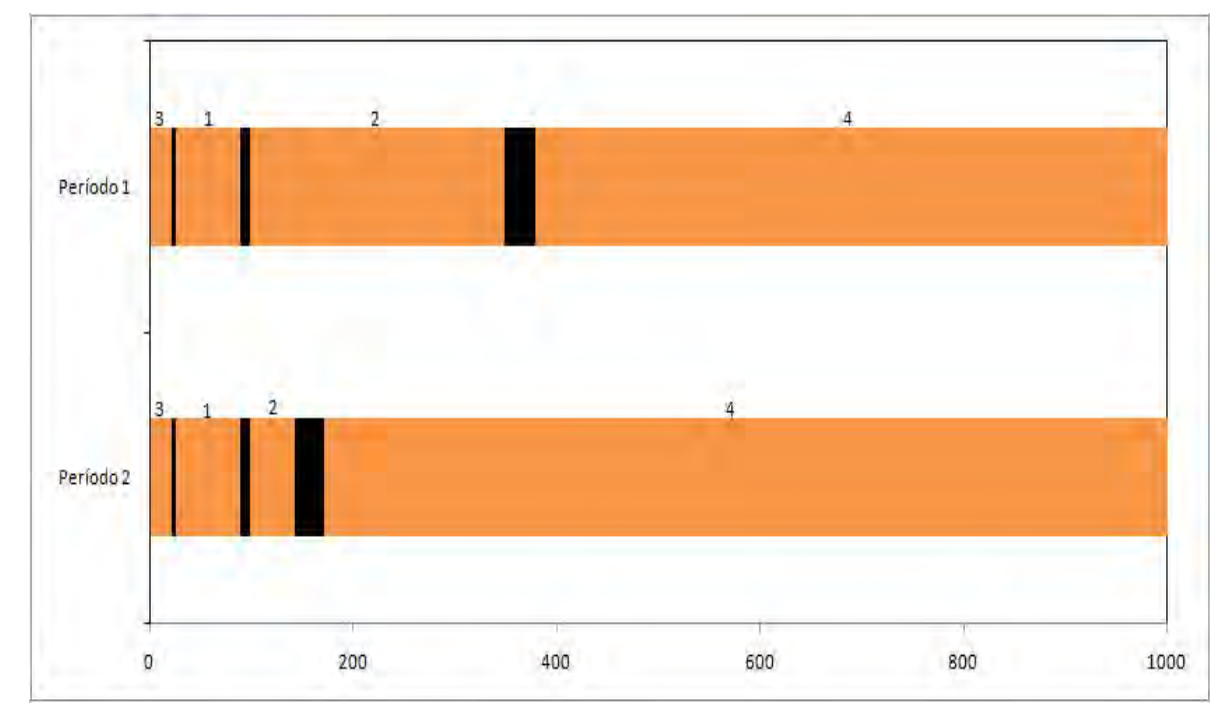

Figura 3.5: Programação da produção na máquina para o exemplar ilustrativo fornecida pelo modelo P1S1MTS. 


\subsubsection{Análise dos resultados fornecidos pelo modelo P1S1MTS no modelo P1S1M - Exemplar 1}

Para entender melhor as diferenças entre os modelos P1S1M e P1S1MTS, vamos analisar as quantidades produzidas pelo modelo P1S1MTS utilizando os dados do exemplar ilustrativo descrito na Seção 3.4 .1 e de como o modelo P1S1M se comporta se as variáveis de produção $x_{j s}^{I I}$ forem fixadas nestes valores. Seja $s$ o índice que representa os subperíodos e $t$ o que representa os períodos. As variáveis $x_{j t}^{I I}$ e $x_{j s}^{I I}$ representam respectivamente a produção do item $j$ do período $t$ e subperíodos $s$ dos modelos P1S1MTS e P1S1M. A Tabela 3.5 mostra os itens produzidos $(j)$, os períodos em que estes itens foram produzidos $(t)$, a quantidade produzida de itens $\left(x_{j t}^{I I}\right)$, os custos de estoque (Estoque) e atraso (Atraso) fornecidos pelo modelo P1S1MTS. A sequência de produção é itens 3, 1, 2 e 4 nos dois períodos.

\begin{tabular}{rrrrr}
\hline $\mathrm{j}$ & $\mathrm{t}$ & $x_{j t}^{I I}$ & Estoque & Atraso \\
\hline \hline 3 & 1 & 753,00 & 0 & 0 \\
1 & 1 & 2104,99 & 640,99 & 0 \\
2 & 1 & 4176,18 & 0 & 514,82 \\
4 & 1 & 10344,84 & 0 & 2613,17 \\
3 & 2 & 746,00 & 0 & 0 \\
1 & 2 & 2109,43 & 1291,43 & 0 \\
2 & 2 & 729,17 & 0 & 2504,64 \\
4 & 2 & 13793,10 & 0 & 1486,07 \\
\hline
\end{tabular}

Tabela 3.5: Produção dos itens de acordo com o modelo P1S1MTS - Exemplo 1.

Para fixar as variáveis de produção do modelo P1S1M de acordo com a solução do modelo P1S1MTS, devemos igualar a soma das variáveis de produção do modelo P1S1M à variável de produção do modelo P1S1MTS $\left(x_{j t}^{I I}\right)$ ( ou seja, $\left.\sum_{s \in S_{t}} x_{j s}^{I I}=x_{j t}^{I I}\right)$. Contudo, ao fazer isso, podemos observar que as restrições (3.8) do modelo P1S1M são violadas, pois a quantidade produzida de cada lote dos itens deve respeitar uma quantidade mínima em cada subperíodo. No exemplar ilustrativo considerado, esta quantidade mínima é igual à quantidade de itens que um tanque completo de xarope consegue produzir $\left(q_{l}=K^{I}\right)$, ou seja, toda vez que houver produção em um subperíodo, deverá ser utilizada a capacidade 
total do tanque (3448,28 itens no caso dos itens 1, 2 e 4 e 4219,41 no caso do item 3).

Assim, para fazermos com que a quantidade produzida pelo modelo P1S1MTS também seja produzida pelo P1S1M sem que as restrições (3.8) sejam violadas, a produção do modelo P1S1M será fixada nos valores produzidos pelo P1S1MTS somada a uma quantidade complementar que resulta na quantidade mínima exigida para a produção dos itens pelo modelo P1S1M (ver Tabela 3.6). O modelo P1S1MTS produziu 753 unidades do item 3 no período 1. O modelo P1S1M produzirá as mesmas 753 unidades do item 3 mais 3466,41 unidades. O mesmo acontecerá com o item 1 produzido no período 1 e com os itens 3, 1 e 2 produzidos no período 2. Dois tanques são necessários para a produção do item 2 no período 1 pelo modelo P1S1M. Como um tanque produz 3448,28 itens, faltam ainda 729,9 unidades do item 2 para completar a produção fixa de acordo com o modelo P1S1MTS. Assim é necessário um novo tanque e serão produzidos mais 3448,28 unidades deste item com uma "sobra"de 2718,38 itens. Para a quantidade produzida do item 4 no período 1 são necessários exatamente 3 tanques. No entanto, como especificado acima, o primeiro período é limitado a apenas 6 tanques. Logo, restam apenas dois tanques para serem utilizados para a produção do item 4. Portanto, será produzido $x_{4 s}^{I I}=3448,28$ e $x_{4 s}^{I I}=3448,28$ e haverá um atraso de 3448,28 unidades na produção do item 4 no período 1. Esta situação se repete para o item 4 no período 2. São necessários exatamente 4 tanques para que o modelo P1S1M consiga produzir a quantidade fixa produzida pelo modelo P1S1MTS. Entretanto, só há 3 tanques disponíveis no segundo período para esta produção. Logo, serão produzidos $\sum_{s \in S_{t}} x_{4 s}^{I I}=10.344,84$ e haverá um atraso de 3448,28 unidades do item 4 no período 2 . 


\begin{tabular}{c|c|c|c|c}
\hline $\mathrm{j}$ & $\mathrm{t}$ & $x_{j t}^{I I}$ & Complemento & $\sum_{s \in S_{t}} x_{j s}^{I I}=x_{j t}^{I I}+$ Complemento \\
\hline \hline 3 & 1 & 753 & $3.466,41$ & $4.219,41$ \\
\hline 1 & 1 & $2.104,99$ & $1.343,29$ & $3.448,28$ \\
\hline 2 & 1 & $4.176,18$ & $2.720,38$ & $6.896,56$ \\
\hline 4 & 1 & $6.896,56$ & 0 & $6.896,56$ \\
\hline 3 & 2 & 746 & $3.473,41$ & 4219,41 \\
\hline 1 & 2 & $2.109,4$ & $1.338,88$ & 3448,28 \\
\hline 2 & 2 & 729,1 & $2.719,18$ & 3448,28 \\
\hline 4 & 2 & $10.344,84$ & 0 & 10344,84 \\
\hline
\end{tabular}

Tabela 3.6: Valor das variáveis de produção do modelo P1S1M a partir das variáveis de produção do modelo P1S1MTS - Exemplar 1.

De acordo com as restrições (3.3), a soma dos tempos de produção e dos tempos disponíveis para as trocas deve respeitar a capacidade da máquina. Pelo ajuste da solução de P1S1MTS exibido na Tabela 3.6, a quantidade a ser produzida na máquina pelo modelo P1S1M é maior que a produzida pelo modelo P1S1MTS. A soma dos tempos de produção associada a esta solução são maiores que a capacidade da máquina. Portanto, a solução do modelo P1S1MTS para este exemplar estudado não é viável para o modelo P1S1M. Para obter uma situação em que a solução do modelo P1S1MTS seja viável para o modelo P1S1M, vamos fazer algumas modificações neste exemplar.

Considere que o valor mínimo de produção de xarope $\left(q_{l}\right)$ seja igual à quantidade de xarope necessária para a produção do item 3 no período 2 pelo modelo P1S1MTS (176,8 litros). Esta é a menor quantia de xarope utilizada para a produção dos itens pelo modelo P1S1MTS. Considere também $t$ dividido em 7 subperíodos, resultando em um total de $N=14$ subperíodos, onde $S_{1}=\{1,2,3,4,5,6,7\}$ e $S_{2}=\{8,9,10,11,12,13,14\}$.

Fixando novamente a produção $\sum_{s \in S_{t}} x_{j s}^{I I}$ nos valores fornecidos pelo modelo P1S1MTS, obtém-se a solução para o modelo P1S1M, mostrada na Tabela 3.7. Podemos observar que com a diminuição do valor da quantidade mínima e com o aumento do número de subperíodos, o modelo P1S1M conseguiu produzir exatamente as quantidades fixas nos valores fornecidos pelo modelo P1S1MTS apresentados na Tabela 3.5. 


\begin{tabular}{rrrr}
\hline $\mathrm{j}$ & $\mathrm{t}$ & $\mathrm{s}$ & \multicolumn{1}{c}{$x_{j s}^{I I}$} \\
\hline \hline 3 & 1 & 1 & 753,00 \\
1 & 1 & 2 & 2104,99 \\
\hline 2 & 1 & 3 & 727,90 \\
2 & 1 & 4 & 3448,28 \\
\hline 4 & 1 & 5 & 3448,28 \\
4 & 1 & 6 & 3448,28 \\
4 & 1 & 7 & 3448,28 \\
\hline 4 & 2 & 8 & 3448,28 \\
4 & 2 & 9 & 3448,28 \\
4 & 2 & 10 & 3448,28 \\
4 & 2 & 11 & 3448,28 \\
\hline 3 & 2 & 12 & 746,00 \\
1 & 2 & 13 & 2109,43 \\
2 & 2 & 14 & 729,17 \\
\hline
\end{tabular}

Tabela 3.7: Solução fornecida pelo modelo P1S1M para o Exemplar 1 modificado

Entretanto, apesar das modificações feitas no exemplar ilustrativo, o custo de troca dos itens no modelo P1S1M ainda é diferente do valor do custo de troca fornecido pelo modelo P1S1MTS, como mostrado na Tabela 3.8. Isto acontece porque nas restrições (3.6) que são responsáveis pelas trocas dos itens, a troca entre o último item produzido em um período e o primeiro item produzido no período seguinte é contada, ao contrário do que acontece no modelo P1S1MTS onde o sequenciamento é feito de forma independente entre os períodos. Logo, para que a troca entre períodos não seja contada, as restrições (3.25) que controlam a troca serão definidas sem o primeiro subperíodo de cada período $\left(P_{t}\right)$, isto é, sem contar as trocas entre os períodos.

$$
z_{i j s}^{I I} \geq y_{i(s-1)}^{I I}+y_{j s}^{I I}-1, i, j=1, \ldots, J, s \in S_{t}-P_{t} .
$$

\begin{tabular}{cccc}
\hline Estoque & Atraso & Troca & Z \\
\hline \hline 13,50 & $122.768,70$ & 48,60 & $122.830,80$ \\
\hline
\end{tabular}

Tabela 3.8: Solução fornecida pelo modelo P1S1M usando as restrições (3.6) 
Por exemplo, a solução fornecida pelo modelo P1S1M usando as restrições (3.6) possui a seguinte sequência de itens: bebida 3 , bebida 1 , bebida 2 , bebida 4 no primeiro período e bebida 3 , bebida 1 e bebida 2 no segundo período. A solução fornecida pelo modelo P1S1M usando as restrições (3.25) fornece a seguinte sequência de itens: bebida 3 , bebida 1 , bebida 2 e bebida 4 para o primeiro período e bebida 3 , bebida 1 , bebida 2 e bebida 4 para o segundo período. Isto é, as trocas são feitas separadamente a cada período. Assim, na Tabela 3.9, observamos que o custo de troca dos itens fornecido pelo modelo P1S1M é igual ao custo de troca de itens do modelo P1S1MTS.

\begin{tabular}{cccc}
\hline Estoque & Atraso & Troca & Z \\
\hline \hline 13,50 & $122.768,70$ & 42,40 & $122.824,60$ \\
\hline
\end{tabular}

Tabela 3.9: Solução fornecida pelos modelos P1S1M usando as restrições (3.25) no lugar das restrições (3.6)

\subsubsection{Análise dos resultados fornecidos pelo modelo P1S1M no modelo P1S1MTS - Exemplar 1}

Nesta seção, é analisado como o modelo P1S1MTS se comporta se as variáveis de produção $\left(x_{j t}^{I I}\right)$ forem fixadas nos valores da solução fornecida pelo modelo P1S1M para o exemplar apresentado na Seção 3.4.1. Para isso, temos que a quantidade produzida pelo modelo P1S1MTS $\left(x_{j t}^{I I}\right)$ será exatamente a soma das quantidades produzidas pelo modelo P1S1M em cada subperíodo de cada período $\left(\sum_{s \in S_{t}} x_{j s}^{I I}=x_{j t}^{I I}\right)$. A Tabela 3.10 mostra os itens produzidos $(j)$ na respectiva ordem de produção fornecida pelo modelo P1S1MTS , os períodos em que estes itens foram produzidos $(t)$ e a quantidade produzida pelo modelo P1S1MTS $\left(x_{j t}^{I I}\right)$ a partir da soma em $s \in S_{t}$ das quantidades fixas produzidas pelo modelo P1S1M. 


\begin{tabular}{ccc}
\hline $\mathrm{j}$ & $\mathrm{t}$ & $x_{j t}^{I I}$ \\
\hline \hline 1 & 1 & 3448,28 \\
2 & 1 & 3448,28 \\
4 & 1 & 10344,84 \\
3 & 2 & 4219,41 \\
4 & 2 & 13793,10 \\
\hline
\end{tabular}

Tabela 3.10: Valor das variáveis de produção do modelo P1S1MTS fixas de acordo com as variáveis de produção do modelo P1S1M.

Note que o modelo P1S1MTS consegue produzir exatamente os valores fixos das variáveis de produção à solução do modelo P1S1M. Todavia, a sequência de produção apresentada pela solução fornecida pelo modelo P1S1MTS (bebida 1, bebida 2 e bebida 4 no primeiro período, bebida 3 e bebida 4 no segundo período) não é a mesma sequência apresentada na solução fornecida pelo modelo P1S1M, mostrada na Figura 3.4 (bebida 1, bebida 2 e bebida 4 no primeiro período, bebida 4 e bebida 3 no segundo período). Isto acontece porque o modelo P1S1M não considera a troca entre o último item produzido em um período (período 1) e o primeiro item produzido no próximo período (período 2) ao contrário do modelo P1S1MTS, como discutido na Seção 3.4.1. Logo, os custos de troca e, em consequência, os custos totais, fornecidos pela solução do modelo P1S1MTS com os valores fixos das variáveis de produção à solução do modelo P1S1M mostrados na Tabela 3.11 são menores que os custos fornecidos pelo modelo P1S1M apresentados na Tabela 3.4 .

\begin{tabular}{cccc}
\hline Estoque & Atraso & Troca & Z \\
\hline \hline 36,61 & $167.741,00$ & 30,60 & $167.808,21$ \\
\hline
\end{tabular}

Tabela 3.11: Solução fornecida pelos modelos P1S1MTS e P1S1M representando a mesma situação

Descontando, assim, as trocas entre o último item produzido em um período e o primeiro item produzido no próximo período (restrições (3.25)) no modelo P1S1M, obtemos a mesma solução para os dois modelos. 


\subsubsection{Experimentos com exemplos ilustrativos - Exemplar 2}

Consideremos agora uma modificação do Exemplar 1 em que consideramos 4 xaropes, e o item 1 necessita do xarope 1, o item 2 do xarope 2, o item 3 do xarope 3 e o item 4 do xarope 4 para suas respectivas produções. Consideremos também no modelo P1S1M que não serão contadas as trocas entre os períodos. As soluções obtidas pelos dois modelos, P1S1M e P1S1MTS, foram iguais (custo total=167.808,19). Como cada item utiliza um xarope diferente para sua produção, não há necessidade de reaproveitamento de xarope. Assim, não são necessárias modificações nos dados dos modelos para garantir que a solução de um modelo seja factível para o outro, como foi necessário para o Exemplar 1. Por exemplo, considerando apenas 8 preparos, 4 no primeiro período e 4 no segundo notamos que o valor da solução fornecida pelos dois modelos é a mesma (custo total $=257.842,08)$. Assim, em uma situação com produtos não compartilham o mesmo xarope, ambos os modelos retratam a mesma situação.

\subsubsection{Conclusão da análise feita na Seção 3.4 de validação do modelo}

De acordo com a análise dos modelos utilizando os Exemplares 1 e 2, observamos que em situações como a do Exemplar 1 (itens que utilizam o mesmo xarope, número de preparos pequeno,capacidade total do tanque e capacidade de produção apertada), as chances dos resultados obtidos pelo modelo P1S1MTS serem factíveis para o modelo P1S1M são pequenas. Para uma comparação exata entre os modelos, o sequenciamento no modelo P1S1M deve ser feito sem contar a troca entre o último item de um período e o primeiro item do próximo período, como acontece no modelo P1S1MTS (ver Seção 3.4.2). Entretanto, a análise inversa mostra que para que as soluções fornecidas pelo modelo P1S1M sejam factíveis para o modelo P1S1MTS, basta que sejam descontadas as trocas entre os períodos. Portanto, com pequenas modificações é possível que a solução fornecida pelo modelo P1S1MTS seja factível para o modelo P1S1M e que a solução apresentada pelo modelo P1S1M seja factível para o modelo P1S1MTS.

No caso do Exemplar ilustrativo 2 (itens que utilizam diferentes xaropes), não há necessidade de reaproveitamento de xarope pelo modelo P1S1MTS e, por isso, não são necessárias modificações nos dados dos modelos para garantir que a solução de um modelo 
seja factível para o outro. 


\section{Capítulo 4}

\section{Estudos Computacionais}

Neste capítulo serão relatados os testes computacionais realizados com a formulação P1S1M e a formulação proposta, P1S1MTS, apresentadas no Capítulo 3. Os dados utilizados foram os mesmos usados por Ferreira et al. [36], baseados em informações coletadas em visitas a uma fábrica de refrigerantes de pequeno porte. Ferreira et al. [36] apresentam resultados para 7 diferentes estratégias do CPLEX. No presente trabalho, tanto com o modelo P1S1M como com o modelo P1S1MTS, os exemplares foram resolvidos utilizando a primeira estratégia considerada no artigo (default do CPLEX). Isto porque os resultados obtidos pelo modelo P1S1MTS utilizando esta estratégia, foram satisfatórios. Os testes realizados para o modelo P1S1M foram processados novamente por causa da utilização de um computador com processador e memórias diferentes do utilizado no trabalho de Ferreira et al. [36] para realização dos testes, resultando em uma pequena diferença nos resultados. Foram realizados testes com dados gerados aleatoriamente, como proposto em Ferreira [32], a partir dos dados coletados na fábrica. Os resultados obtidos com o modelo P1S1MTS a partir dos dados fornecidos pela fábrica, foram comparados com os resultados obtidos com o modelo P1S1M, sendo que os resultados obtidos a partir do exemplar S1 também foram comparados com a programação da produção da fábrica. Os resultados obtidos a partir dos exemplares gerados aleatoriamente foram comparados entre si, de acordo com a solução fornecida por cada um dos modelos.

Os modelos foram escritos na sintaxe do AMPL [42] e resolvidos pelo método Branch-and-Cut incluído no pacote computacional CPLEX 10.0 [54] com os parâmetros default. Foi utilizado um computador AMD Athlon $(2,81 \mathrm{GHz})$ com 1,87 GB de memória RAM, sob a plataforma Windows XP. 


\subsection{Testes com exemplares baseados em dados reais}

Para gerar os exemplares, foram usados os dados associados às demandas, custos e tempos de troca, capacidades do tanque e da máquina, custos de estoque e atraso, tempos de produção de cada item, quantidade necessária de xarope para a produção de cada item e estoque inicial de cada item obtidos por meio de visitas a uma fábrica de refrigerantes de pequeno porte que possui apenas uma linha de envase em embalagens PET [32], [36]. Estes dados foram usados para gerar 10 exemplares de cada um dos modelos P1S1M e P1S1MTS. Os exemplares S1 e S6 foram gerados com base em dois conjuntos de dados reais coletados na fábrica. Os dados são apresentados para uma máquina, que pode produzir 27 itens de diferentes sabores e tamanhos. Dez xaropes diferentes são necessários para produzir este conjunto de itens. A capacidade da xaroparia é de 84000 litros. Foi considerado um horizonte de planejamento de 5 semanas (períodos). O tempo disponível para a produção em cada período é de 6.840 minutos, exceto para o primeiro período, que possui apenas dois dias de produção e, portanto, a capacidade disponível é de apenas 2.280 minutos. Por esse mesmo motivo, o número de preparos das máquinas ou subperíodos, no caso do modelo P1S1M, foi de 8 para o primeiro período e de 24 para os demais. Portanto, o número total de preparos, ou de subperíodos no caso do modelo P1S1M, foi de 104. Foi disponibilizada apenas a programação da produção da fábrica do exemplar S1. Por esse motivo, a comparação dos resultados dos modelos P1S1M e P1S1MTS com resultados da fábrica será feita apenas com os resultados do exemplar S1. Nas soluções fornecidas pelos modelos P1S1M e P1S1MTS para todos os exemplares (S1-S10) foram contados os custos de troca entre períodos, pois na fábrica, a produção é contínua e assim, estes custos são considerados. Os outros 8 exemplares foram gerados modificando parte dos dados usados nos exemplares reais, 4 exemplares (S2-S5) modificando o exemplar S1 e os outros 4 exemplares (S7-S10) modificando o exemplar S6. Assim, os 10 exemplares representam 10 diferentes cenários. Todos os exemplares do modelo P1S1M possuem 80.404 restrições, 82.796 variáveis, das quais 3.848 são binárias. Os exemplares do modelo P1S1MTS possuem 4.481 restrições, 4.541 variáveis, das quais 3.830 são binárias. A Tabela 4.1 resume as diferenças entre os exemplares. 


\begin{tabular}{cl}
\hline Exemplares & \multicolumn{1}{c}{ Modificações } \\
\hline \hline $\mathrm{S} 1(\mathrm{~S} 6)$ & Dados reais \\
$\mathrm{S} 2(\mathrm{~S} 7)$ & Capacidade da máquina de $\mathrm{S} 1(\mathrm{~S} 6)$ reduzida em $25 \%$ \\
$\mathrm{~S} 3(\mathrm{~S} 8)$ & Custos de estoque de $\mathrm{S} 1(\mathrm{~S} 6)$ foram dobrados \\
$\mathrm{S} 4(\mathrm{~S} 9)$ & Custos de troca de $\mathrm{S} 2(\mathrm{~S} 7)$ reduzidos em $1 / 3$ \\
$\mathrm{~S} 5(\mathrm{~S} 10)$ & Custos de estoque de $\mathrm{S} 4(\mathrm{~S} 9)$ foram dobrados \\
\hline
\end{tabular}

Tabela 4.1: Modificações dos exemplares S1-S10 [36].

\subsubsection{Comparação dos resultados: Fábrica $\times$ Modelos}

Na Tabela 4.2 são apresentados os custos de estoque (Estoque), troca de bebidas (Troca) e o custo total da programação da produção da fábrica $(Z)$. Na primeira coluna da tabela é indicado o período a que se refere cada custo. Na última linha está o total de cada um dos custos. A Figura 4.1 ilustra a programação da produção da linha da fábrica nos 5 períodos. O eixo horizontal representa a capacidade disponível da linha, 6.840 minutos, (apenas o primeiro período tem capacidade menor 2.280 minutos). O eixo vertical é a programação da linha em cada período. Os retângulos em cinza são os lotes de cada bebida, e os retângulos pretos são os tempos de troca. A bebida envasada é indicada pelo número logo acima do lote [32].

\begin{tabular}{cccc}
\hline Período & Estoque & Troca & $\mathrm{Z}$ \\
\hline \hline 1 & $1.509,54$ & $19.631,04$ & \\
2 & $1.110,30$ & $24.173,76$ & \\
3 & $1.220,45$ & $41.758,08$ & \\
4 & $1.409,88$ & $47.848,32$ & \\
5 & $1.012,70$ & $49.695,36$ & \\
Total & $6.262,87$ & $183.106,56$ & $189.369,43$ \\
\hline
\end{tabular}

Tabela 4.2: Custos de programação - Fábrica [32]. 


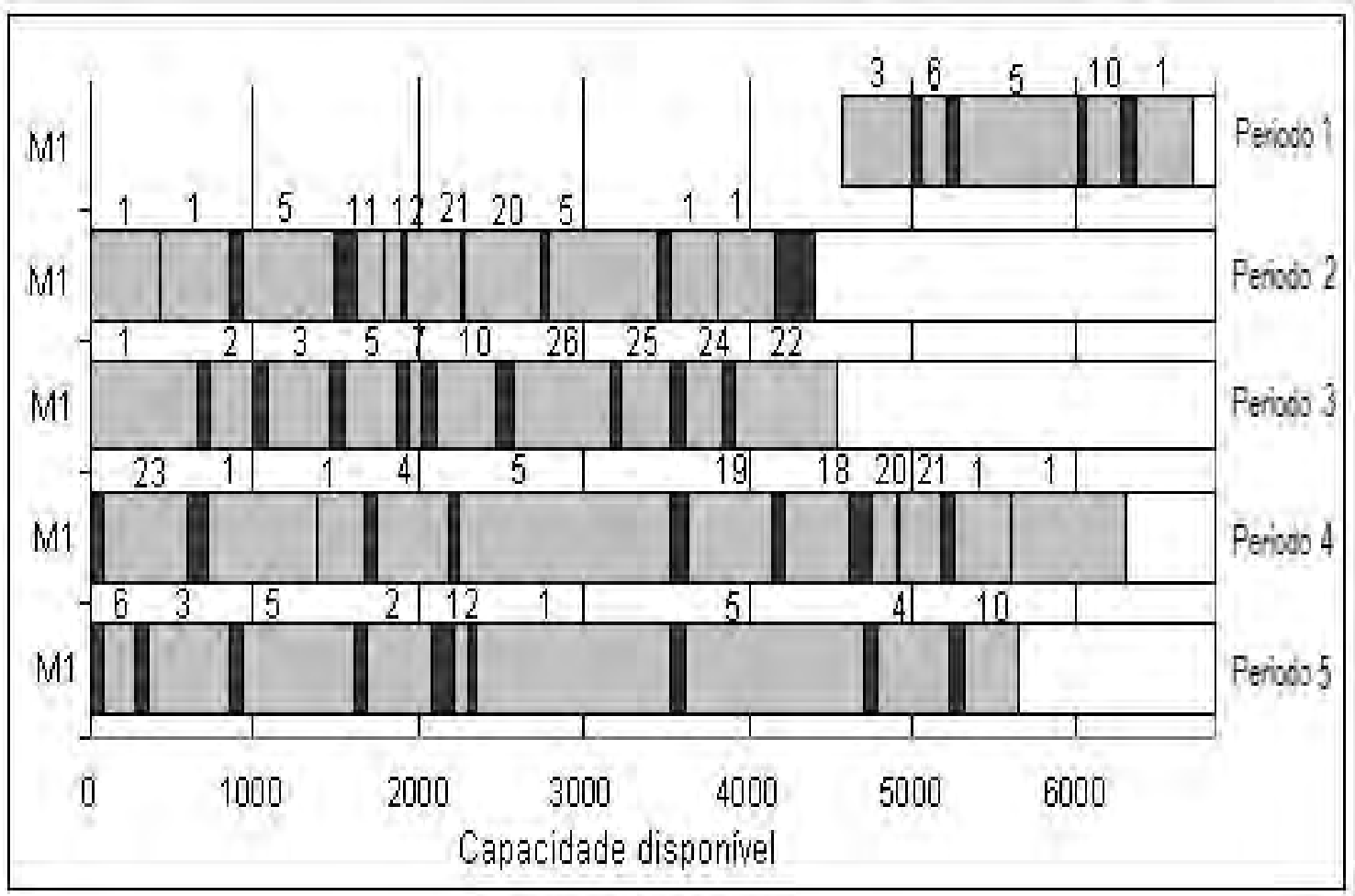

Figura 4.1: Programação da produção na linha - Fábrica [32]

O exemplar S1 foi resolvido pelo pacote de otimização CPLEX 10.0, com limite de tempo de 3 horas de processamento tanto para o modelo P1S1M quanto para o modelo P1S1MTS. A Tabela 4.3 apresenta na primeira, segunda e terceira colunas, respectivamente, os custos totais de estoque, atraso e troca de bebidas obtidos pelos dois modelos, na quarta coluna é apresentado o custo total, e na última coluna o percentual da solução em relação à solução da fábrica, sendo que um percentual positivo significa uma solução pior que a da fábrica .

\begin{tabular}{cccccc}
\hline & Estoque & Atraso & Troca item & Z & Percentual \\
\hline \hline P1S1M & $2.209,00$ & $37.428,00$ & $306.744,00$ & $346.381,00$ & 45,32 \\
P1S1MTS & $6.947,33$ & 0 & $82.280,00$ & $89.227,33$ & $-52,88$ \\
\hline
\end{tabular}

Tabela 4.3: Custos de programação - P1S1M e P1S1MTS.

De acordo com a Tabela 4.3 podemos observar que o modelo P1S1M obteve uma solução 45,32\% pior que a solução de 189.369,43 da fábrica. Note que os custos de troca na solução do modelo P1S1M foram bem mais altos que os custos apresentados pela fábrica (ver Tabela 4.2). Já o modelo P1S1MTS obteve um bom desempenho, com uma solução 
52,88\% melhor que a solução da fábrica. Note que os custos de troca, ao contrário do modelo P1S1M, são bem menores que os apresentados pela fábrica (ver Tabela 4.2).

As Figuras 4.2 e 4.3 apresentam a programação da produção da máquina dos modelos P1S1M e P1S1MTS para o exemplar da fábrica. Note que, tanto na programação da produção da fábrica quanto na programação da produção do modelo P1S1M existem itens produzidos mais de uma vez em um mesmo período, o que nunca acontece na programação da produção do modelo P1S1MTS, por causa da modelagem. Assim, toda a quantidade necessária de cada item é produzida de uma só vez em cada período, respeitando as capacidades da máquina e do tanque. Do ponto de vista teórico, isto diminui o número de trocas, entretanto, nem sempre é aplicável praticamente, devido, por exemplo, às demandas sazonais. Logo, observamos que o modelo P1S1M e P1S1MTS estão analisando regiões factíveis diferentes. Podemos notar no trabalho de Ferreira et al. [36] que com as estratégias utilizadas para a resolução dos exemplares, a solução fornecida pelo modelo P1S1M obteve um custo muito menor que o apresentado pela fábrica para o exemplar S1. 


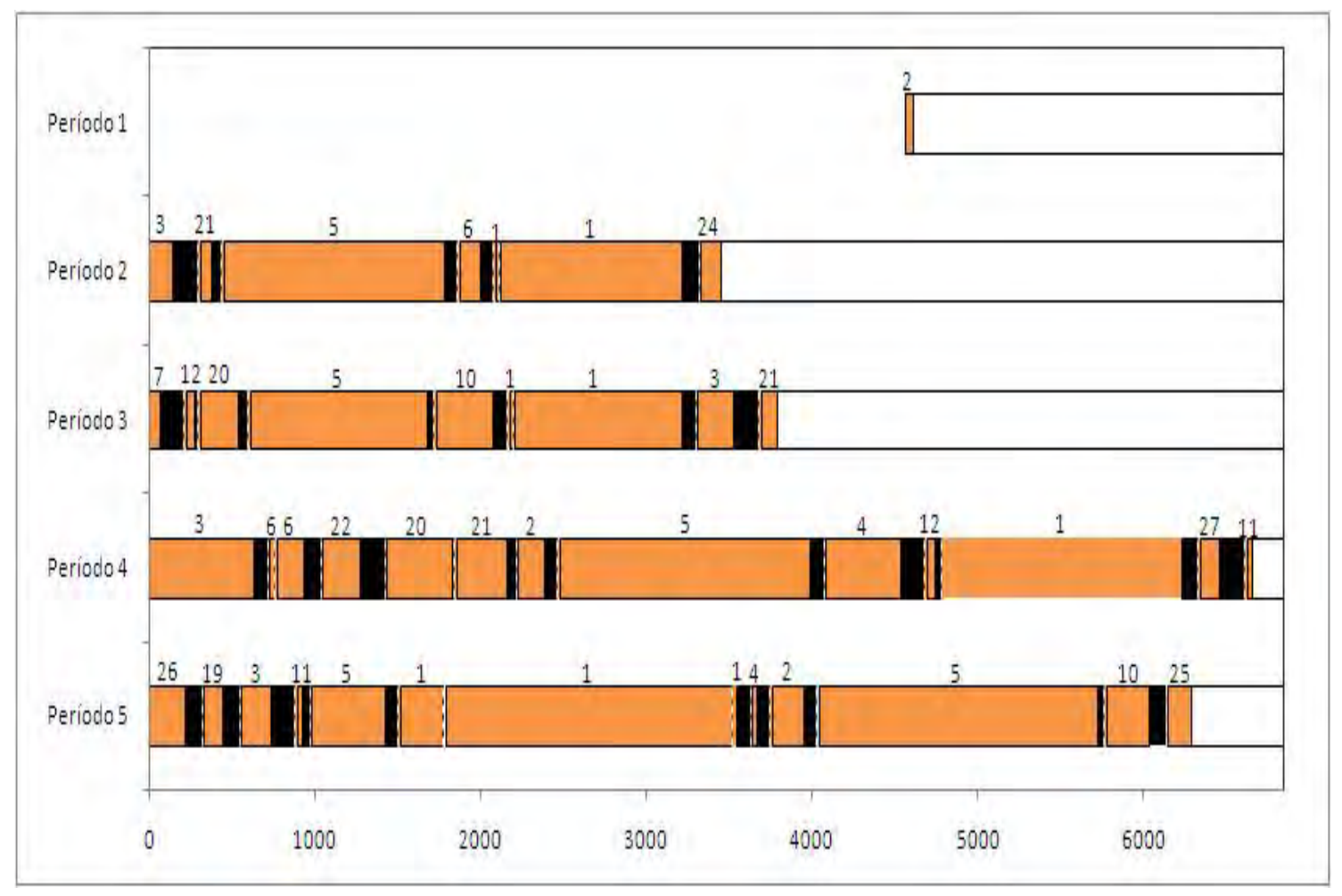

Figura 4.2: Programação da produção na linha - P1S1M.

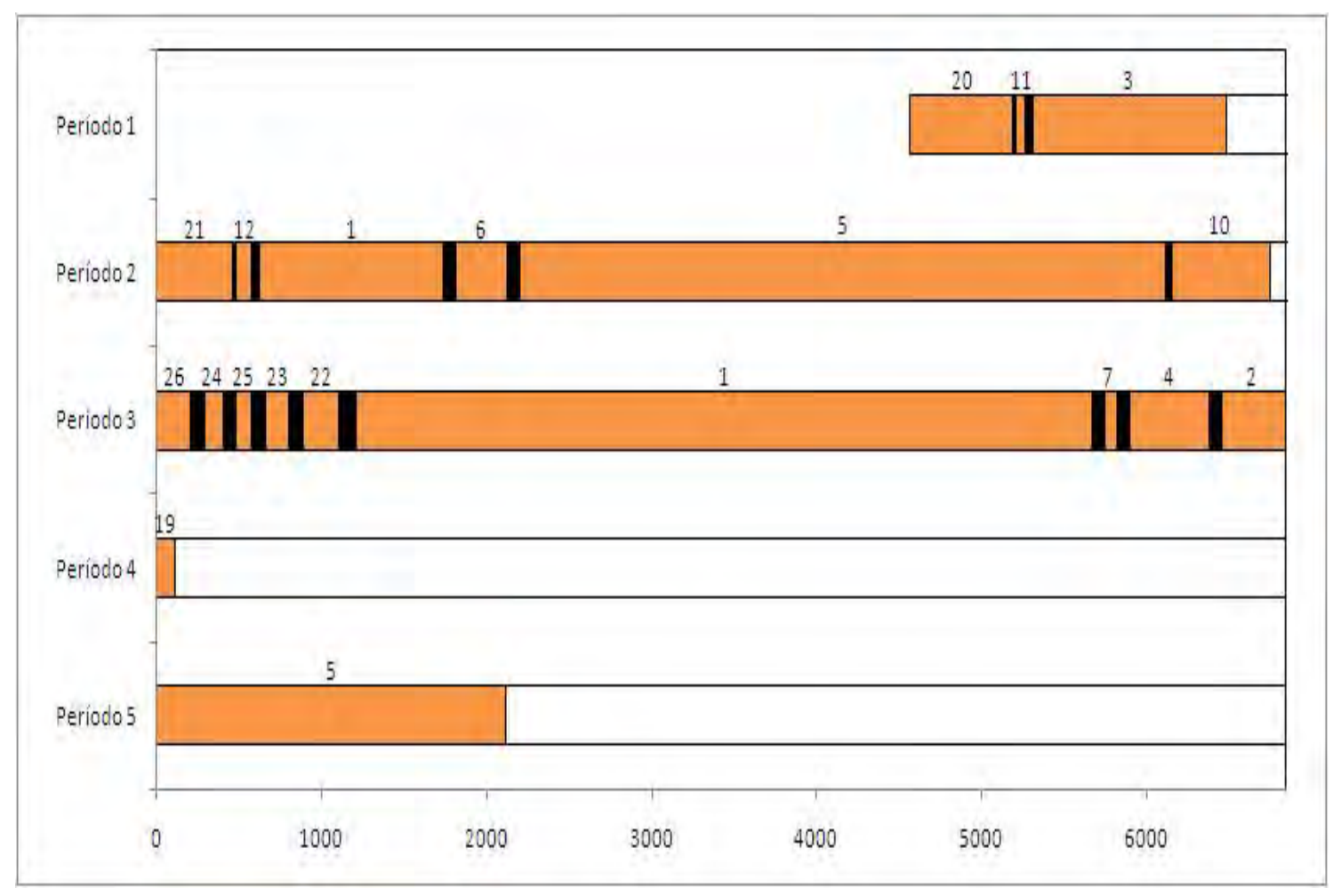

Figura 4.3: Programação da produção na linha - P1S1MTS. 


\subsubsection{Comparação dos resultados: P1S1M × P1S1MTS}

Observando os resultados fornecidos pelos modelos P1S1M e P1S1MTS para o exemplar S1 (ver Tabela 4.3), podemos notar que o modelo P1S1MTS fornece uma solução $74,24 \%$ melhor que a solução fornecida pelo modelo P1S1M. De acordo com o resultado apresentado na Tabela 4.3, isto acontece principalmente por causa dos custos de troca, que são 73,17\% maiores no modelo P1S1M do que no modelo P1S1MTS. Nas Figuras 4.2 e 4.3 o número de trocas obtidas na solução do modelo P1S1M foi muito maior que o número de trocas fornecidas pela solução do modelo P1S1MTS. Como mencionado acima, na programação da produção do modelo P1S1M existem itens produzidos mais de uma vez em um mesmo período, podendo ocasionar, assim, uma solução com mais trocas que a solução gerada pelo modelo P1S1MTS. As soluções obtidas pelos dois modelos para os exemplares S1 a S10 são apresentadas na Tabela 4.4 juntamente com o valor do GAP que é dado em porcentagem e calculado da seguinte maneira:

$$
G A P=\frac{\text { Limite Superior }- \text { Limite Inferior }}{\text { Limite Superior }} \times 100 \%
$$

O valor do GAP está relacionada principalmente com a obtenção de bons limites superiores e inferiores. Assim, para um problema de minimização, o objetivo é obter soluções viáveis com valores menores e relaxações lineares com valores maiores, isto é, mais próximas do valor ótimo. Podemos observar na Tabela 4.4 que nenhuma das soluções obtidas pelos modelos P1S1M e P1S1MTS para todos os exemplares foi ótima. 


\begin{tabular}{|c|c|c|c|}
\hline Exemplares & Modelos & $\mathrm{Z}$ & $\operatorname{GAP}(\%)$ \\
\hline \multirow[t]{2}{*}{ S1 } & P1S1M & $346.381,00$ & 99,48 \\
\hline & P1S1MTS & $89.227,33$ & 30,16 \\
\hline \multirow[t]{2}{*}{ S2 } & P1S1M & $266.634,00$ & 99,21 \\
\hline & P1S1MTS & $88.092,50$ & 27,36 \\
\hline \multirow[t]{2}{*}{ S3 } & P1S1M & $374.659,10$ & 98,87 \\
\hline & P1S1MTS & $96.985,30$ & 26,41 \\
\hline \multirow[t]{2}{*}{$\mathrm{S} 4$} & P1S1M & $109.988,20$ & 98,07 \\
\hline & P1S1MTS & $35.288,36$ & 27,51 \\
\hline \multirow[t]{2}{*}{$\mathrm{S} 5$} & P1S1M & $123.263,20$ & 96,56 \\
\hline & P1S1MTS & $41.378,93$ & 29,06 \\
\hline \multirow[t]{2}{*}{ S6 } & P1S1M & $345.157,60$ & 99,65 \\
\hline & P1S1MTS & $87.750,20$ & 24,01 \\
\hline \multirow[t]{2}{*}{ S7 } & P1S1M & $346.671,70$ & 99,63 \\
\hline & P1S1MTS & $96.341,60$ & 20,69 \\
\hline \multirow[t]{2}{*}{ S8 } & P1S1M & $9.565 .521,70$ & 99,97 \\
\hline & P1S1MTS & $37.315,53$ & 19,74 \\
\hline \multirow[t]{2}{*}{ S9 } & P1S1M & $1.737 .835,20$ & 99,85 \\
\hline & P1S1MTS & $43.253,50$ & 21,72 \\
\hline \multirow[t]{2}{*}{ S10 } & P1S1M & $275.445,90$ & 99,54 \\
\hline & P1S1MTS & $37.315,53$ & 18,22 \\
\hline
\end{tabular}

Tabela 4.4: Custo total e GAP dos exemplares reais

A Tabela 4.5 apresenta os valores dos limites superiores (Sup), limites inferiores (Inf), GAP (GAP (\%)) do número de nós da árvore do Branch-and-Cut (Nós) e do número de planos de corte (Planos de Corte) de cada um dos exemplares (S1 - S10) dos modelos P1S1M e P1S1MTS gerados no nó raiz. A Tabela 4.6 apresenta os planos de corte utilizados durante a resolução de cada um dos exemplares. Os planos de corte gerados (usando parâmetros default do CPLEX 10.0) foram: Inequações GUB (Generalized Upper Bounding) (GUB), Inequações de Cobertura (IC), Inequações de Cobertura de Fluxo (ICF), Mixed Integer Rounding (MIR), Inequações de Gomory (IG), Clique (CC), Implied Bound Cuts (IBC) e Inequações de Cobertura de Caminho de Fluxo (ICCF). 
Podemos observar que em um tempo de processamento de 3 horas para ambos os modelos, o número de nós da árvore do Branch-and-Cut e o número de planos de corte gerados foram muito maiores nos exemplares para o modelo P1S1MTS do que para o modelo P1S1M. Por causa desse desenvolvimento maior na árvore do Branch-and-Cut, podemos concluir que o modelo P1S1MTS foi "mais rápido"para encontrar uma solução viável mais próxima da ótima dentro do mesmo tempo limite de processamento que o modelo P1S1M (ver Tabela 4.4).

Uma outra maneira de analisar o tempo de resolução de cada modelo é observando o tempo gasto para a resolução da relaxação linear no nó raiz. Este tempo, calculado em segundos, é mostrado na Tabela 4.7. Podemos observar que o modelo P1S1MTS encontra um valor para a relaxação linear no nó raíz em média, 95,57 \% mais rápido que o modelo P1S1M, fazendo, consequentemente, com que a resolução dos exemplares utilizando o modelo P1S1M seja mais lenta. 


\begin{tabular}{|c|c|c|c|c|c|c|}
\hline Exemplar & Modelo & Sup & Inf & GAP $(\%)$ & Nós & Planos de Corte \\
\hline \multirow[t]{2}{*}{$\mathrm{S} 1$} & P1S1M & 7.495.073,6 & $1.792,5$ & 99,98 & 4.188 & 416 \\
\hline & P1S1MTS & $6.926 .199,6$ & $33.031,3$ & 99,52 & 907.601 & 1.991 \\
\hline \multirow[t]{2}{*}{$\mathrm{S} 2$} & P1S1M & $7.549 .867,6$ & $2.114,4$ & 99,97 & 7.060 & 366 \\
\hline & P1S1MTS & $6.926 .199,6$ & $38.614,2$ & 99,44 & $1.270,85$ & 1.135 \\
\hline \multirow[t]{2}{*}{ S3 } & P1S1M & 7.481.661,1 & $4.228,8$ & 99,94 & 6.103 & 340 \\
\hline & P1S1MTS & $6.927 .992,1$ & $44.509,4$ & 99,36 & 695.401 & 1.580 \\
\hline \multirow[t]{2}{*}{ S4 } & $\mathrm{P} 1 \mathrm{~S} 1 \mathrm{M}$ & $7.129 .158,9$ & $2.114,4$ & 99,97 & 4.204 & 342 \\
\hline & P1S1MTS & $6.926 .199,6$ & $16.322,5$ & 99,76 & $1.170,61$ & 1.618 \\
\hline \multirow[t]{2}{*}{ S5 } & P1S1M & $7.126 .523,4$ & $4.228,8$ & 99,94 & 6.437 & 410 \\
\hline & P1S1MTS & $6.927 .992,1$ & $21.275,8$ & 99,69 & $1.172,76$ & 1.596 \\
\hline \multirow[t]{2}{*}{ S6 } & $\mathrm{P} 1 \mathrm{~S} 1 \mathrm{M}$ & $9.509 .573,7$ & $1.209,0$ & 99,99 & 4.089 & 466 \\
\hline & P1S1MTS & $8.219 .979,7$ & $1.209,0$ & 99,99 & 776.001 & 1.908 \\
\hline \multirow[t]{2}{*}{ S7 } & P1S1M & $9.494 .368,7$ & $1.255,8$ & 99,99 & 4.293 & 480 \\
\hline & P1S1MTS & $8.219 .979,7$ & $1.255,8$ & 99,98 & 697.299 & 1.710 \\
\hline \multirow[t]{2}{*}{ S8 } & $\mathrm{P} 1 \mathrm{~S} 1 \mathrm{M}$ & $9.565 .521,7$ & $2.418,1$ & 99,97 & 3.055 & 512 \\
\hline & P1S1MTS & $8.221 .133,7$ & $2.418,1$ & 99,97 & $1.006,86$ & 1.744 \\
\hline \multirow[t]{2}{*}{ S9 } & P1S1M & $9.127 .437,4$ & $2.511,6$ & 99,97 & 4.297 & 464 \\
\hline & P1S1MTS & $8.221 .133,7$ & $2.511,6$ & 99,97 & $1.053,31$ & 1.939 \\
\hline \multirow[t]{2}{*}{$\mathrm{S} 10$} & P1S1M & $9.125 .256,0$ & $1.255,8$ & 99,99 & 3.440 & 446 \\
\hline & P1S1MTS & $8.219 .979,7$ & $1.255,8$ & 99,98 & $1.049,90$ & 1.776 \\
\hline
\end{tabular}

Tabela 4.5: Testes com exemplares reais com os modelos P1S1M e P1S1MTS. 


\begin{tabular}{|c|c|c|c|c|c|c|c|c|c|}
\hline Exemplar & Modelo & GUB & IC & $\mathrm{ICF}$ & MIR & IG & $\mathrm{CC}$ & IBC & ICCF \\
\hline \multirow[t]{2}{*}{ S1 } & P1S1M & 35 & 93 & 258 & 3 & 27 & 0 & 0 & 0 \\
\hline & P1S1MTS & 0 & 32 & 344 & 249 & 65 & 5 & 1250 & 46 \\
\hline \multirow[t]{2}{*}{$\mathrm{S} 2$} & P1S1M & 38 & 103 & 195 & 5 & 17 & 0 & 7 & 1 \\
\hline & P1S1MTS & 0 & 31 & 348 & 202 & 60 & 3 & 448 & 43 \\
\hline \multirow[t]{2}{*}{ S3 } & P1S1M & 39 & 93 & 187 & 1 & 17 & 0 & 2 & 1 \\
\hline & P1S1MTS & 0 & 23 & 377 & 197 & 55 & 4 & 875 & 49 \\
\hline \multirow[t]{2}{*}{$\mathrm{S} 4$} & $\mathrm{P} 1 \mathrm{~S} 1 \mathrm{M}$ & 33 & 52 & 228 & 3 & 13 & 3 & 9 & 1 \\
\hline & P1S1MTS & 0 & 34 & 315 & 172 & 57 & 3 & 1007 & 30 \\
\hline \multirow[t]{2}{*}{$\mathrm{S} 5$} & $\mathrm{P} 1 \mathrm{~S} 1 \mathrm{M}$ & 43 & 112 & 216 & 5 & 23 & 0 & 10 & 1 \\
\hline & P1S1MTS & 0 & 65 & 311 & 180 & 59 & 3 & 933 & 45 \\
\hline \multirow[t]{2}{*}{ S6 } & P1S1M & 53 & 76 & 305 & 5 & 22 & 1 & 4 & 0 \\
\hline & P1S1MTS & 0 & 35 & 432 & 150 & 74 & 4 & 1145 & 68 \\
\hline \multirow[t]{2}{*}{$\mathrm{S} 7$} & $\mathrm{P} 1 \mathrm{~S} 1 \mathrm{M}$ & 51 & 80 & 307 & 7 & 19 & 4 & 10 & 2 \\
\hline & P1S1MTS & 0 & 35 & 366 & 188 & 83 & 5 & 976 & 57 \\
\hline \multirow[t]{2}{*}{ S8 } & $\mathrm{P} 1 \mathrm{~S} 1 \mathrm{M}$ & 62 & 105 & 309 & 7 & 23 & 1 & 5 & 0 \\
\hline & P1S1MTS & 0 & 13 & 364 & 140 & 73 & 3 & 1085 & 66 \\
\hline \multirow[t]{2}{*}{ S9 } & $\mathrm{P} 1 \mathrm{~S} 1 \mathrm{M}$ & 50 & 100 & 285 & 1 & 15 & 5 & 6 & 2 \\
\hline & P1S1MTS & 0 & 33 & 310 & 185 & 93 & 2 & 1264 & 52 \\
\hline \multirow[t]{2}{*}{$\mathrm{S} 10$} & $\mathrm{P} 1 \mathrm{~S} 1 \mathrm{M}$ & 51 & 76 & 292 & 1 & 15 & 4 & 5 & 2 \\
\hline & P1S1MTS & 0 & 21 & 346 & 148 & 81 & 5 & 1121 & 54 \\
\hline
\end{tabular}

Tabela 4.6: Planos de corte usados durante a resolução dos exemplares S1-S10. 


\begin{tabular}{ccc}
\hline Exemplar & P1S1M & P1S1MTS \\
\hline \hline S1 & 2,03 & 0,03 \\
S2 & 0,63 & 0,03 \\
S3 & 0,64 & 0,03 \\
S4 & 0,64 & 0,03 \\
S5 & 0,63 & 0,03 \\
S6 & 1,09 & 0,03 \\
S7 & 0,67 & 0,05 \\
S8 & 0,66 & 0,03 \\
S9 & 0,66 & 0,03 \\
S10 & 0,66 & 0,05 \\
\hline
\end{tabular}

Tabela 4.7: Tempo de resolução da relaxação linear no nó raiz.

Para uma melhor análise dos modelos e melhor avaliar o desempenho do modelo P1S1MTS, na próxima seção apresentaremos alguns experimentos com dados aleatórios.

\subsection{Exemplares Aleatórios}

\subsubsection{Geração dos dados}

Para a realização dos testes foram gerados 10 exemplares aleatórios a partir do exemplar S1. Foram considerados os mesmos valores para os parâmetros considerados para o exemplar S1. Assim, foram considerados 27 itens e 10 xaropes, um horizonte de planejamento contendo 5 períodos os quais possuem 24 preparos (subperíodos) exceto para o primeiro, que possui 8 preparos da máquina (subperíodos). A capacidade do tanque considerada é de 84000 litros. Os parâmetros gerados aleatoriamente são mostrados na Tabela 4.8. Os custos de atraso e estoque, a capacidade necessária para a produção de uma unidade de cada item, o tempo de troca, a demanda, o estoque inicial e a quantidade de xarope necessária para a produção de uma unidade de cada item são gerados aleatoriamente através de uma distribuição uniforme nos respectivos intervalos que correspondem aos valores mínimo e máximo para cada parâmetro existentes no exemplar S1.

Os custos de troca $\left(s_{i j}\right)$ são obtidos multiplicando por 0,5 os tempos de troca $b_{i j}$, pois os custos de troca são proporcionais aos tempos de troca, quanto maior o tempo de 
troca maior o custo. Os tempos de produção de bebidas variam de 0,04 a 0,15 minutos. A demanda varia de 0 a 53.020. Supondo que se tenha uma demanda máxima de 53.020 itens e que o tempo de produção de cada bebida seja o tempo máximo de 0,15 minutos, então são necessários 7.953 minutos de tempo disponível para a produção dos itens. Além disso, o tempo de troca dos itens está no intervalo de 10 a 150 minutos. Considerando que o tempo de troca de todos os itens é de 150 minutos e que sempre são realizadas 26 trocas, então são consumidos 3.900 minutos. Assim, a capacidade da máquina considerada nos experimentos aleatórios é de 11.853 minutos, que é uma capacidade considerada folgada. Aqui também foram contados os custos de troca entre períodos.

\begin{tabular}{ll}
\hline Parâmetros & Valores \\
\hline \hline Custo de estoque $\left(h_{j}\right)$ & {$[0,007 ; 0,014]$} \\
Custo de atraso $\left(g_{j}\right)$ & {$[4,68 ; 10,14]$} \\
Capacidade para produção de uma unidade para o item j $\left(a_{j}\right)$ & {$[0,04 ; 0,15]$} \\
Tempo de troca $\left(b_{i j}\right)$ & {$[10 ; 150]$} \\
Custo de troca $\left(s_{i j}\right)$ & $0,5 \mathrm{x} b_{i j}$ \\
Demanda $\left(d_{j}\right)$ & {$[0,53.020]$} \\
Estoque inicial $\left(\right.$ estini $\left._{i}\right)$ & {$[0 ; 15.985]$} \\
Quantidade de xarope por bebida $j\left(r_{l j}\right)$ & {$[0,5 ; 2]$} \\
\hline
\end{tabular}

Tabela 4.8: Geração dos dados.

\subsubsection{Testes com dados aleatórios}

Nesta seção serão apresentados testes com os 10 exemplares (A1-A10) gerados aleatoriamente para uma melhor comparação entre os modelos P1S1M e P1S1MTS. Os problemas foram resolvidos pelo Branch-and-Cut do pacote computacional CPLEX 10.0 no seu default. Como os exemplares foram gerados a partir do exemplar S1, o número de restrições e varíaveis é igual ao dos exemplares reais. A Tabela 4.9 mostra o valor da função objetivo $(Z)$, os tempos de processamento (TEMPO $(s)$ ) em segundos e o valor do GAP para os modelos P1S1M e P1S1MTS. O modelo P1S1MTS encontrou a solução ótima de todos os exemplares com um tempo de execução 99,67\% mais rápido que o limite estabelecido de 3 horas. No caso do modelo P1S1M, apesar do valor do GAP estar abaixo de $2 \%$ em todos os casos, testes executados com o tempo de processamento duplicado 
mostraram que o valor do GAP quase não se altera. Estas diferenças nos tempos de execução podem ocorrer por causa das diferenças no tempo que cada modelo leva para encontrar um valor para a relaxação linear no nó raiz durante a resolução de cada um dos exemplares, como mencionado na análise dos exemplares reais. Observando a Tabela 4.10, notamos que a resolução da relaxação linear do modelo P1S1MTS é em média, 96,31\% mais rápido que a resolução da relaxação linear do modelo P1S1M.

\begin{tabular}{|c|c|c|c|c|}
\hline Exemplares & Modelo & $\mathrm{Z}$ & TEMPO (s) & $\operatorname{GAP}(\%)$ \\
\hline \multirow[t]{2}{*}{$\mathrm{A} 1$} & $\mathrm{P} 1 \mathrm{~S} 1 \mathrm{M}$ & $43.324 .000,00$ & 10800 & 1,46 \\
\hline & P1S1MTS & & $42.929 .235,15$ & 0 \\
\hline \multirow[t]{2}{*}{$\mathrm{A} 2$} & P1S1M & $51.025 .300,00$ & 10800 & 1,73 \\
\hline & P1S1MTS & $50.530 .147,69$ & 139 & 0 \\
\hline \multirow[t]{2}{*}{ A3 } & $\mathrm{P} 1 \mathrm{~S} 1 \mathrm{M}$ & 57.843 .700 & 10800 & 0,52 \\
\hline & P1S1MTS & $57.681 .840,85$ & 15,3 & 0 \\
\hline \multirow[t]{2}{*}{$\mathrm{A} 4$} & $\mathrm{P} 1 \mathrm{~S} 1 \mathrm{M}$ & $51.958 .868,00$ & 10800 & 1,07 \\
\hline & P1S1MTS & $51.688 .169,04$ & 9,3 & 0 \\
\hline \multirow[t]{2}{*}{ A5 } & P1S1M & $47.886 .200,00$ & 10800 & 1,12 \\
\hline & P1S1MTS & $47.593 .059,06$ & 18,2 & 0 \\
\hline \multirow[t]{2}{*}{ A 6} & $\mathrm{P} 1 \mathrm{~S} 1 \mathrm{M}$ & $52.865 .100,00$ & 10800 & 0,61 \\
\hline & P1S1MTS & $52.699 .500,72$ & 5,5 & 0 \\
\hline \multirow[t]{2}{*}{$\mathrm{A} 7$} & $\mathrm{P} 1 \mathrm{~S} 1 \mathrm{M}$ & $40.006 .056,00$ & 10800 & 1,84 \\
\hline & P1S1MTS & $40.082 .871,36$ & 77,6 & 0 \\
\hline \multirow[t]{2}{*}{ A 8} & P1S1M & $45.760 .100,00$ & 10800 & 0,79 \\
\hline & P1S1MTS & $45.602 .868,67$ & 51,14 & 0 \\
\hline \multirow[t]{2}{*}{ A9 } & $\mathrm{P} 1 \mathrm{~S} 1 \mathrm{M}$ & 49.669.700,00 & 10800 & 1,53 \\
\hline & P1S1MTS & $49.220 .094,51$ & 7,6 & 0 \\
\hline \multirow[t]{2}{*}{ A10 } & P1S1M & $45.911 .800,00$ & 10800 & 1,10 \\
\hline & P1S1MTS & $45.641 .390,62$ & 6,3 & 0 \\
\hline
\end{tabular}

Tabela 4.9: Resultados dos exemplares aleatórios.

Podemos notar que nos exemplares aleatórios, o tempo computacional para solução ótima é menor. Assim, o número de nós da árvore do Branch-and-Cut no modelo P1S1MTS é pequeno se comparado ao número de nós apresentados pelo modelo P1S1M. 


\begin{tabular}{ccc}
\hline Exemplar & P1S1M & P1S1MTS \\
\hline \hline A1 & 1,38 & 0,03 \\
A2 & 1,25 & 0,03 \\
A3 & 1,25 & 0,05 \\
A4 & 1,2 & 0,03 \\
A5 & 1,17 & 0,05 \\
A6 & 0,92 & 0,03 \\
A7 & 0,97 & 0,05 \\
A8 & 1,16 & 0,05 \\
A9 & 1,11 & 0,05 \\
A10 & 0,98 & 0,05 \\
\hline
\end{tabular}

Tabela 4.10: Tempo de resolução da relaxação linear - Exemplares aleatórios.

O número de planos de corte usados no modelo P1S1MTS foi similar ao número de planos de corte usado no modelo P1S1M. Se comparado ao número de planos de corte utilizados na resolução dos exemplares reais, para a resolução dos exemplares aleatórios, os modelos P1S1MTS e P1S1M não necessitaram de muitos planos de corte. A Tabela 4.11 mostra o número de nós e o número de planos de corte utilizados durante a resolução dos exemplares A1-A10 pelos modelos P1S1M e P1S1MTS. A Tabela 4.12 mostra quais planos de corte foram utilizados durante a resolução dos exemplares. Estes planos de corte são os mesmos encontrados na análise dos exemplares reais (ver Seção 4.1.2). 


\begin{tabular}{|c|c|c|c|}
\hline Exemplar & Modelo & Nós & Planos de Corte \\
\hline \multirow[t]{2}{*}{ A1 } & P1S1M & 16200 & 385 \\
\hline & P1S1MTS & 2153 & 331 \\
\hline \multirow[t]{2}{*}{$\mathrm{A} 2$} & P1S1M & 12737 & 505 \\
\hline & P1S1MTS & 22414 & 545 \\
\hline \multirow[t]{2}{*}{ A3 } & P1S1M & 30470 & 293 \\
\hline & P1S1MTS & 1110 & 195 \\
\hline \multirow[t]{2}{*}{$\mathrm{A} 4$} & P1S1M & 16374 & 392 \\
\hline & P1S1MTS & 565 & 279 \\
\hline \multirow[t]{2}{*}{ A 5} & $\mathrm{P} 1 \mathrm{~S} 1 \mathrm{M}$ & 18274 & 570 \\
\hline & P1S1MTS & 1123 & 272 \\
\hline \multirow[t]{2}{*}{ A 6} & P1S1M & 23335 & 445 \\
\hline & P1S1MTS & 190 & 215 \\
\hline \multirow[t]{2}{*}{$\mathrm{A} 7$} & P1S1M & 8811 & 463 \\
\hline & P1S1MTS & 6980 & 467 \\
\hline \multirow[t]{2}{*}{ A 8} & P1S1M & 20300 & 441 \\
\hline & P1S1MTS & 4962 & 369 \\
\hline \multirow[t]{2}{*}{ A9 } & P1S1M & 13248 & 355 \\
\hline & P1S1MTS & 430 & 262 \\
\hline \multirow[t]{2}{*}{ A10 } & P1S1M & 31348 & 440 \\
\hline & P1S1MTS & 186 & 214 \\
\hline
\end{tabular}

Tabela 4.11: Número de nós e de planos de corte gerados durante a resolução dos exemplares aleatórios. 


\begin{tabular}{|c|c|c|c|c|c|c|c|c|c|}
\hline Exemplares & Modelo & GUB & $\mathrm{IC}$ & $\mathrm{ICF}$ & MIR & $\mathrm{IG}$ & $\mathrm{CC}$ & IBC & $\mathrm{ICCF}$ \\
\hline \multirow{2}{*}{$\mathrm{A} 1$} & P1S1M & 64 & 104 & 177 & 4 & 22 & 12 & 0 & 2 \\
\hline & P1S1MTS & 0 & 19 & 102 & 14 & 80 & 5 & 110 & 1 \\
\hline \multirow[t]{2}{*}{$\mathrm{A} 2$} & P1S1M & 62 & 108 & 302 & 0 & 15 & 1 & 0 & 17 \\
\hline & P1S1MTS & 0 & 6 & 99 & 21 & 73 & 2 & 340 & 4 \\
\hline \multirow[t]{2}{*}{ A3 } & P1S1M & 49 & 5 & 160 & 22 & 44 & 12 & 0 & 1 \\
\hline & P1S1MTS & 0 & 5 & 72 & 10 & 52 & 0 & 54 & 2 \\
\hline \multirow[t]{2}{*}{$\mathrm{A} 4$} & $\mathrm{P} 1 \mathrm{~S} 1 \mathrm{M}$ & 48 & 169 & 153 & 4 & 9 & 7 & 0 & 2 \\
\hline & P1S1MTS & 0 & 14 & 85 & 18 & 87 & 0 & 74 & 1 \\
\hline \multirow[t]{2}{*}{ A5 } & $\mathrm{P} 1 \mathrm{~S} 1 \mathrm{M}$ & 73 & 147 & 306 & 4 & 20 & 10 & 0 & 10 \\
\hline & P1S1MTS & 0 & 4 & 101 & 14 & 79 & 8 & 62 & 4 \\
\hline \multirow[t]{2}{*}{ A 6} & P1S1M & 45 & 198 & 187 & 0 & 7 & 5 & 0 & 3 \\
\hline & P1S1MTS & 0 & 1 & 88 & 3 & 63 & 0 & 56 & 4 \\
\hline \multirow[t]{2}{*}{ A7 } & $\mathrm{P} 1 \mathrm{~S} 1 \mathrm{M}$ & 0 & 132 & 289 & 1 & 34 & 1 & 0 & 6 \\
\hline & P1S1MTS & 0 & 37 & 102 & 35 & 78 & 6 & 208 & 1 \\
\hline \multirow[t]{2}{*}{ A 8} & $\mathrm{P} 1 \mathrm{~S} 1 \mathrm{M}$ & 48 & 159 & 192 & 1 & 30 & 7 & 0 & 4 \\
\hline & P1S1MTS & 0 & 2 & 96 & 22 & 82 & 8 & 152 & 7 \\
\hline \multirow[t]{2}{*}{ A9 } & $\mathrm{P} 1 \mathrm{~S} 1 \mathrm{M}$ & 76 & 3 & 241 & 13 & 9 & 7 & 0 & 6 \\
\hline & P1S1MTS & 0 & 4 & 107 & 6 & 79 & 0 & 65 & 1 \\
\hline \multirow[t]{2}{*}{ A10 } & $\mathrm{P} 1 \mathrm{~S} 1 \mathrm{M}$ & 77 & 17 & 272 & 35 & 25 & 11 & 0 & 3 \\
\hline & P1S1MTS & 0 & 1 & 96 & 7 & 70 & 5 & 33 & 2 \\
\hline
\end{tabular}

Tabela 4.12: Planos de corte gerados durante a resolução dos exemplares aleatórios. 


\section{Capítulo 5}

\section{Conclusões e perspectivas futuras}

Neste trabalho, propomos um modelo integrado de dimensionamento de lotes e programação da produção para uma fábrica de refrigerantes de pequeno porte denominado P1S1MTS. Neste modelo, as decisões de dimensionamento foram baseadas no modelo P1S1M encontrado na literatura, que é formulado com base no modelo GLSP. Para as decisões de sequenciamento foram utilizadas restrições do problema do caixeiro viajante assimétrico.

Com o intuito de validar o modelo P1S1MTS, foram apresentados testes computacionais com dois exemplares ilustrativos e analisada a factibilidade dos resultados apresentados para o modelo P1S1M. observamos que em situações como a do Exemplar 1 (itens que utilizam o mesmo xarope, número de preparos pequeno,capacidade total do tanque e capacidade de produção apertada), as chances dos resultados obtidos pelo modelo P1S1MTS serem factíveis para o modelo P1S1M são pequenas. Para uma comparação exata entre os modelos, o sequenciamento no modelo P1S1M deve ser feito sem contar a troca entre o último item de um período e o primeiro item do próximo período, como acontece no modelo P1S1MTS (ver Seção 3.4.2). Entretanto, a análise inversa mostra que para que as soluções fornecidas pelo modelo P1S1M sejam factíveis para o modelo P1S1MTS, basta que sejam descontadas as trocas entre os períodos. Portanto, com pequenas modificações é possível que a solução fornecida pelo modelo P1S1MTS seja factível para o modelo P1S1M e que a solução apresentada pelo modelo P1S1M seja factível para o modelo P1S1MTS.

No caso do Exemplar ilustrativo 2 (itens que utilizam diferentes xaropes), não há necessidade de reaproveitamento de xarope pelo modelo P1S1MTS e, por isso, não são 
necessárias modificações nos dados dos modelos para garantir que a solução de um modelo seja factível para o outro, como foi necessário para o Exemplar 1.

Foram realizados também testes computacionais com 10 exemplares baseados em dados reais e 10 exemplares gerados aleatoriamente com uma capacidade de tempo de produção folgada. Os resultados obtidos com o exemplar S1 pelos modelos P1S1MTS e P1S1M foram comparados entre si e com os resultados fornecidos pela fábrica. O modelo P1S1MTS forneceu uma solução de menor custo que as soluções fornecidas pela fábrica e pelo modelo P1S1M. Os demais resultados fornecidos por ambos modelos utilizando exemplares reais mostraram também que o modelo P1S1MTS possui melhor desempenho computacional que o modelo P1S1M, fornecendo uma solução de menor custo em um mesmo tempo de processamento. Nos testes realizados utilizando exemplares aleatórios, o modelo P1S1MTS conseguiu encontrar a solução ótima para todos os exemplares em um tempo de processamento 99,67\% menor que o tempo limite de processamento (3 horas). O modelo P1S1M conseguiu em 3 horas de processamento obter soluções com o GAP menor do que $2 \%$.

Com o desenvolvimento do trabalho, notamos que, apesar das diferenças entre os modelos P1S1M e P1S1MTS, com pequenas modificações, é possível para ambos os modelos retratarem a mesma situação. A partir destas modificações e com os resultados obtidos, podemos concluir que o modelo P1S1MTS possui um tempo de execução computacional menor que o modelo P1S1M, e retrata situações onde é possível haver o aproveitamento maior do tanque.

Como pesquisa futura podemos citar a análise dos planos de corte usados pelo pacote de otimzação CPLEX 10.0 [54] para a resolução dos exemplares; a utilização de inequações válidas para o PCV (ver Apêndice A); a reformulação do sequenciamento no modelo P1S1MTS utilizando o problema do caixeiro viajante assimétrico com setup carryover em que no início de cada período o modelo deve "guardar"o estado de preparação da linha no final do período anterior [87]. 


\section{Referências Bibliográficas}

[1] ABIR, Dados de Mercado,Associação Brasileira das Indústrias de Refrigerantes e de Bebidas Não Alcoólicas.Disponível em: http://www.abir.org.br (última visita em 08/01/2010).

[2] AFREBRAS, Dados de Mercado, Associação dos fabricantes de refrigerantes do Brasil.Disponível em: http://www.afrebras.org.br (última visita em 08/01/2010).

[3] ALDOWAISAN, J.N.D.; ALLAHVERDI, T.; GUPTA, A. A review of scheduling research involving setup considerations. OMEGA - The International Journal of Management Science. v.27, p. 219-239, 1999.

[4] AlmADA-LOBO, B.; KLABJAN, D.; OLIVEIRA, J.F. CARRAVILLA, M.A. Single machine multiproduct capacitated lot sizing with sequence-dependent setups. International Journal of Production Research. v.45, n.20, p.4873-4894, 2007.

[5] AlmadA-LOBO, B.; OLIVEIRA, J.F.; CARRAVILlA, M.A. A note on "the capacitated lotsizing and scheduling problem with sequence-dependent setup costs and setup times". Computers \& Operations Research. v.35, p. 1374-1376, 2008.

[6] ALMADA-LOBO, B.; OLIVEIRA, J.F.; CARRAVILLA, M.A. Production planning and scheduling in the glass container industry: A VNS approach. International Journal Production Economics. v.114, p.363-375, 2008.

[7] ALMEDER, C.; ALMADA-LOBO, B. Synchronization of scarce resources for a parallel machine lotsizing problem. Relatório Técnico. 2009.

[8] ARAuJO, S. A.; ARENAlES, M.N. Problema de Dimensionamento de Lotes Monoestágio com Restrição de Capacidade. Modelagem, Método de Resolução e Resultados Computacionais, Pesquisa Operacional. v. 20, n. 2, p. 287 - 306, dezembro, 2000. 
[9] ARAujO, S. A.; AREnAleS, M.N.; CLARK, A.R. Dimensionamento de lotes e programação do forno numa fundição de pequeno porte. Gestão $\mathscr{G}$ Produção. vol. 11, 2, p. $165-176,2004$.

[10] ARAUJO, S.A.; ARENALES, M.N.; CLARK, A.R. Joint rolling-horizon scheduling of materials processing and lot-sizing with sequence-dependent setups. Journal of Heuristics - Springer. v.13, p.337-358, 2007.

[11] ARAUJO, S.A.; ARENALES, M.N.; CLARK, A.R. Lot sizing and furnace scheduling in small foundries. Computers \& Operations Research. v.35, p.916-932, 2008.

[12] AREnAleS, M.N.; ARMEntano, V.A.; MORABITO, R.; YANASSE, H.H. Pesquisa Operacional, 1.ed. Rio de Janeiro: Campus/Elsevier. v.1, p.523, 2007.

[13] ATAMTURK, A.; NEMHAUSER, G.L.; SAVELSBERGH, M.W.P. Conflict Graphs in Integer Programming. European Journal of Operations Research. v.121, p. 40-55, 2000.

[14] BALAS, E.; CERIA, S.; CORNUEJOLS, G.; NATRAJ, N. Gomory Cuts Revisited. Operations Research Letters.v. 19, p. 1-10, 1996.

[15] BAGCHI, T. P.; GUPTA, J.N.D.; SRISKANDARAJAH, C. A review of TSP based approaches for flowshop scheduling. European Journal of Operational Research. v. 169, p. 816-854, 2006.

[16] BITRAN G.R. e YANASSE H.H. Computational Complexity of the Lot Size Problem. Management Science. v.28, n.10, 1174-1186, 1982.

[17] BLAZEWICZ, J.; ECKER, K.H.; PESCH, E.; SCHMIDT, G.; WEGLARZ J. Scheduling Computer and Manufacturing Process. Springer-Verlag, Berlin, 1996.

[18] BOZEJKO W.; WODECKI, M. Solving permutational routing problems by population-based meta-heuristics. Computers and Industrial Engineerin. v.57, p.269$276,2009$.

[19] BRAhimi, N.; DAUZEREPERES, S.; NAJID, N.M.; NORDLI, A. Single item lot sizing problems, European Journal of Operational Research. v.168, p.1-16, 2006. 
[20] BURIOL, L.; FRANÇA, P.M; MOSCATO, P.; A new memetic algorithm for the asymmetric traveling salesman problem. Journal of Heuristics. v. 10, p. 483-506, 2004 .

[21] BUSTAMANTE, L. M. Minimização do custo de antecipação e atraso para o problema de sequenciamento de uma máquina com tempo de preparação dependente da sequência: aplicação em uma usina siderúrgica.Dissertação de mestrado, Universidade Federal de Minas Gerais, Escola de Engenharia, Fevereiro, 2007.

[22] CALDAS, M.A.F; SANTOS, D.A. Estudo de heurísticas para o roteamento urbano de veículos. Pesquisa Operacional para o Desenvolvimento. v.1, n.3, p. 245-252, 2009.

[23] DEVLIN, K. Quando os computadores não bastam, O problema P versus NP, in Os problemas do milênio. Record, Cap3, 2004.

[24] CARRETERO, M.M. Modelagem matemática e métodos de solução para o problema do caixeiro viajante. Relatório de Iniciação Científica Fapesp. Universidade Estadual Paulista "Julio de Mesquita Filho", São José do Rio Preto, 2008.

[25] CLARK, A. R. Hybrid heuristics for planning lot setups and sizes. Computers \& Industrial Engineering. v.45, p.545-562, 2003.

[26] CLARK, A.R. A local search approach to lot sequencing and sizing.Proceedings of the Third International Workshop of the IFIP WG 5.7 special interest group on "advanced techniques in production planning \& control". Florença, Itália, Fevereiro, 2000.

[27] CONSTANTINO, M. A cutting plane approach to capacitated lot-sizing with startup costs. Mathematical Programming. p. 353-376, 1996.

[28] DESROCHERS, M.; LAPORTE, G. Improvements and extensions to the Miller Tucker - Zemlin subtour elimination constraints. Operations Research. v.10, p.27-36, 1991.

[29] DREXL A.; HAASE K. Proportional Lotsizing and Scheduling. International Journal of Production Economics. v.40, p.73-87, 1995.

[30] DREXL, A.; KIMMS, A. Lot sizing and scheduling - Survey and extensions. European Journal of Operational Research. v.99, p. 221-235, 1997. 
[31] FENATO, A. J. Um Modelo de Caixeiro Viajante Generalizado para Minimizar o Tempo de Preparação de uma Máquina Tubeteira. Dissertação de Mestrado, Mestrado em Engenharia Elétrica, Universidade Estadual de Londrina, 2008.

[32] FERREIRA, D. Abordagens para o Problema Integrado de Dimensionamento e Sequenciamento de Lotes da Produção de Bebidas. Tese de Doutorado, Universidade Federal de São Carlos, Departamento de Engenharia de Produção, Dezembro, 2006.

[33] FERREIRA, D. Um Modelo de Dimensionamento de Lotes Aplicado à Indústria de Bebidas. Dissertação de Mestrado, Programa de Pós Graduação em Matemática Aplicada, IBILCE, UNESP, Campus de S.J. do Rio Preto, v.111, 2002.

[34] FERREIRA, D.; MORABITO, R.;RANGEL, S. Um modelo de otimização inteira mista e heurísticas relax and fix para a programação da produção de fábricas de refrigerantes de pequeno porte. Produção. v.18, n.1, p.76-88, 2008.

[35] FERREIRA, D., MORABITO, R. e RANGEL, S. Solution approaches for the soft drink integrated production lot sizing and scheduling problem. European Journal of Operational Research. v.196, n.2, p.697-706, 2009.

[36] FERREIRA, D., MORABITO, R. e RANGEL, S. Relax and fix heuristics to solve one-stage one-machine lot-scheduling models for small-scale soft drink plants. Computers and Operations Research. v. 37, n.4, p. 684-691, 2010.

[37] FERREIRA, D.; CLARK, A.R.; ALMADA-LOBO, B.; MORABITO, R. Uma reformulação monoestágio de um modelo de programaçao da produção de bebidas dois estágios com sincronia. In: XLI SBPO-Simpósio Brasileiro de Pesquisa Operacional, 2009, Porto Seguro. Anais, 2009.

[38] FLEISCHMANN, B.; MEYR H. The General Lotsizing and Scheduling Problem. OR Spektrum. v.19, p.11-21, 1997.

[39] FLEISCHMANN B. The Discrete Lot-sizing and Scheduling Problem. European Journal of Operational Research. v.44, p.337-348, 1990.

[40] FLEISCHMANN, B. The discrete lot-sizing and scheduling problem with sequencedependent set-up costs. European Journal of Operational Research. v. 75, n. 2, p. 395-404, 1994. 
[41] FLORIAN, M.; LENSTRA, J.K.; RINOOY KAN, A.H.G. Deterministic production planning and complexity. Management Science. v.26, p.669-679, 1980.

[42] FOURER, R., GAY, M. D., e KERNIGHAN, B. W. AMPL - A Modeling Language for Mathematical Programming. The Scientific Press, Danvers, Massachusetts, 1993.

[43] GICQUEL, C.; MINOUX, M.; DALlERY, Y. On the discrete lotsizing and scheduling problem with sequence-dependente changeover times.Operations Research Letters. v. 37, p. 32-36, 2009.

[44] GICQUEL, C.; MIĖGEVILle, N.; MINOUX, M.; DALLERY, Y. Discrete lotsizing and scheduling using product decomposition into attributes. Computers and Operations Research. v. 36, p. 2690-2698, 2009.

[45] GOLDBARG, M.C.; LUNA, H.P.L. Otimização Combinatória e Programação linear - Modelos e Algoritmos. Campus. 2000.

[46] GOMORY, R.E. An Algorithm for the Mixed Integer Problem. Technical Report RM2597, The RAND Corporation. 1960.

[47] GU, Z.; NEMHAUSER, G.L.; SAVELSBERGH, M.W.P. Lifted Cover Inequalities for 0-1 Integer Programs. INFORMS Journal on Computing. v. 10, p. 417-426, 1998.

[48] GU, Z.; NEMHAUSER, G.L.; SAVELSBERGH, M.W.P. Lifted Flow Covers for Mixed 0-1 Integer Programs. Mathematical Programming. v. 85, p. 439-467, 1999.

[49] GUPTA, D.; MAGNUSSON, T. The capacitated lot-sizing and scheduling problem with sequence-dependent setup costs and setup times. Computers and Operations Research. v.32, p.727-747, 2005.

[50] HAASE, K.; KIMMS, A. Lot Sizing and Scheduling With Sequence-dependente Setup Costs and Times and Efficient Rescheduling Opportunities. International Journal Production Economics. v.66, p.159-169, 2000.

[51] HINDI, K.S. Solving the single-item, capacitated dynamic lot sizing problem with startup and reservation costs by tabu search. Computer and Industrial Engineering. v.24, n.4, p.701-707, 1995. 
[52] HOFFMAN, K; PADBERG, M.W. Improving Representations of Zero-One Linear Programs for Branchand- Cut. ORSA Journal of Computing. v.3, p.121-134, 1991,

[53] HOTO, R.; BORSSOI, A.; FENATO, A.J. Redução do tempo de preparação de uma máquina tubeteira por meio de modelos baseados no problema do caixeiro viajante clássico e generalizado. In: XLI SBPO-Simpósio Brasileiro de Pesquisa Operacional, 2009, Porto Seguro. Anais, 2009.

[54] ILOG Using the CPLEX Callable Library, Copyright, ILOG, 2006.

[55] JONHSON, L.A.; MONTGOMERY, D.C. Progress in Linear Programming-Based Algorithms for Integer Programming: An Exposition, INFORMS. Journal on Computing. v. 12, n.1, 2000.

[56] KARIMI, B.; FATEMI GHOMI, S.M.T.; WILSON, J.T. The capacitated lot sizing problem:a review of models and algorithms. Omega International Journal of Management Science. v.31, p.365-378, 2003.

[57] KIMMS A. A genetic algorithm for multi-level, multi-machine lot sizing and scheduling. Computers \& Operations Research. v.26, p.829-848, 1999.

[58] KUIK, R.; SALOMON, M.; WASSENHOVE, L. Batching Decisions: Structure and Models. European Journal of Operational Research. v.75, p.234-263, 1994.

[59] LAPORTE, G. The traveling salesman problem: An overview of exact and approximate algorithms. European Jounal of Operational Research. v. 59, p. 231-247, 1992.

[60] LAWLER, E.L.; LENSTRA,J.K.; KINNOOY KAN A.K.G.; SHMOYS,D.B. The Traveling Salesman Problem, John Wiley e Sons Ltd, 1986.

[61] LUCHE, J. R.; MORABITO, R. Otimização na programação da produção de grãos eletrofundidos: Um estudo de caso. Gestão \& Produção. v. 12, n. 1, p.135-149, 2005.

[62] MARCHAND, H; WOLSEY, L.A. Aggregation and Mixed Integer Rounding to Solve MIPs. Operations Research. v.49, n. 3, p. 363-371, 2001.

[63] MARCHAND, H.; MARTIN, A.; WEISMANTEL, R.; WOLSEY, L. Cutting planes in integer and mixed integer programming. Discrete Applied Mathematics. v.123, p. 397-446, 2002. 
[64] MEYR H. Simultaneous Lotsizing and Scheduling by Combining Local Search with Dual Reoptimization. European Journal of Operational Research. v. 120, p. 311-326, 2000.

[65] MEYR H. Simultaneous lotsizing and scheduling on parallel production line. European Journal of Operational Research. v.39, p.277-292, 2002.

[66] NETTO, P. O. B.; JURKIEWICZ, S. Grafos: Introdução e Prática. Blucher, 2009.

[67] OLIVEIRA, L.K.; BERRETA, R. Uma abordagem baseada em relaxação lagrangiana e busca tabu para o problema de dimensionamento de lotes muliestágio. Gestão da Produção. v.4, p. 77-94, 2007.

[68] ONCAN T., et al. A comparative analysis of several asymetric traveling salesman problem formulations. Computers and Operations Research, v.36, p. 637-654 2009.

[69] OZGUR, C.O.; BROWN, J.R. A two - stage traveling salesman procedure for the single machine sequence-dependent scheduling problem. Omega. v.23, n.2, p. 205-219, 1995.

[70] PADBERG, M.W.; VAN ROY, T.J.; WOLSEY, L.A. Valid Inequalities for Fixed Charge Problems. Operations Research v. 33, p.842-861, 1985.

[71] PADBERG, M.; RINALDI G. A Branch-and-Cut Algorithm for the Resolution of Large - Scale Symmetric Traveling Salesman Problems. Society for Industrial and Applied Mathematics. v. 33, n.1, p. 60-100, 1991.

[72] PICARD, J.C.; QUEYRANNE, M. The time-dependent and its application to the tardiness problem in one-machine scheduling. Operations Research. v.26, n.1, 1978.

[73] PINEDO, M. Scheduling - Theory, Algorithms and Systems. Prentice Hall, 1995.

[74] POCHET, Y.; WOLSEY, L.A. Production planning by mixed integer programming. New York: Springer Verlag, 2006. (Series in Operations Research and Financial Engineering).

[75] RANGEL, S.; FERREIRA, D. Um Modelo de Dimensionamento de Lotes Aplicado à Indústria de Bebidas. TEMA - Tendências em Matemática Aplicada, 2003. 
[76] RANGEL, S. Introdução à Construção de Modelos de Otimização Linear e Inteira Notas em Matemática Aplicada: 18, São Carlos, SP : SBMAC; São Paulo: Plêiade, 2005, p. 82.

[77] SALOMON, M.; KROON, L.G.; KUIK, R.; WASSENHOVE, L.N.V. Some extensions of the discrete lotsizing and scheduling problem. Management Science. v. 37, n. 7, p. 801-812, 1991.

[78] SALOMON, M.; SALOMON, M.M.; WASSENHOVE, L.N.V.; DUMAS, Y.; DAUZĖRE-PÉRĖS, S. Solving the discrete lotsizing and scheduling problem with sequence dependent setup costs and setup times using the traveling salesman problem with time windows. European Journal of Operational Research. v. 100; p. 494-513, 1997.

[79] SHAPIRO. J.F. Mathematical Programming Models and Methods for Production Planning and Scheduling. Handbooks in Operational Research and Management Sciense. ed. Elsevier, v. 4, p. 371-443, 1993.

[80] SHERALI, D. H.; DRISCOLL,P. J. On Tightening the Relaxations of Miller-TuckerZemlin Formulations for Asymmetric Traveling Salesman Problem. Operations Research. v.50, p.656-669,2002.

[81] STAGGEMEIER, A. T.; CLARK, A.R. A survey of lot-sizing and scheduling models. In: XXXIII SBPO-Simpósio Brasileiro de Pesquisa Operacional, 2001, Campos do Jordão. Anais, 2001.

[82] TOLEDO, C. F. M.; FRANÇA, P. M.; MORABITO, R.; KIMMS, A. Um Modelo de Otimização para o Problema Integrado de Dimensionamento de Lotes e Programação da Produção em Fábrica de Refrigerantes. Pesquisa Operacional. v.27, p.155-186, 2007.

[83] TOLEDO, C.F.M.; FILHO, J.E.F.J; SIMEONE, F.; ROSA, G.P. Meta-heuristicas aplicadas ao problema geral de dimensionamento de lotes e programação da produção. In: XLI SBPO-Simpósio Brasileiro de Pesquisa Operacional, 2009, Porto Seguro. Anais, 2009. 
[84] TOLEDO, C.F.M.; OLIVEIRA, L.; OLIVEIRA, R.R.R.; FERREIRA, D. Algoritmo genético e programação matemática na resolução de um modelo matemático para um problema de programação da produção de bebidas. In: XLI SBPO-Simpósio Brasileiro de Pesquisa Operacional, 2009, Porto Seguro. Anais, 2009

[85] TOLEDO, C.F.M; FRANÇA, P.M.; MORABITO, R.; KIMMS, A. Multi-population genetic algorithm to solve syncronized and integrated two-level lot sizing and scheduling problem. International Journal of Production Research. v. 47, n.11, p. 3097-3119, 2009.

[86] TOSO, E.A.V. ; MORABITO, R. Otimização do dimensionamento e sequenciamento de lotes de produção: Estudo de caso numa fábrica de rações. Gestão $\mathscr{G}$ Produção. v.12, n.2, 203-217,2005.

[87] TOSO, E.A.V.; MORABITO, R.; CLARK, A. Combinação de abordagens GLSP e ATSP para o problema de dimensionamento e sequenciamento de lotes da produção de suplementos para nutrição animal. Pesquisa Operacional. v.28, n.3, p.423-450, 2008.

[88] TOSO, E.A.V. Dimensionamento e sequenciamento de lotes de produção na indústria de suplementos para nutrição animal. Tese de doutorado. Universidade Federal de São Carlos, Departamento de Engenharia de Produção, 2008.

[89] TOSO, E.A.V.; MORABITO, R.; CLARK, A.R. Lotsizing and sequencing optimisation at an animal-feed plant. Computer $\&$ Industrial Engineering. v.57, p. 813-821, 2009.

[90] Brasil ganha espaço no ranking de vendas de multinacionais. http://www.tribunaimpressa.org.br/conteudo/Brasil-ganha-espaço-no-rankingde-vendas-de-multinacionais. 03 de Janeiro de 2010. (última visita em 08/01/2010).

[91] TRIGEIRO, W.W.; THOMAS, L.J.; MCCLAIN, J.O. Capacitated Lotsizing with setup times. Management Science. v. 35, n. 3, 1989.

[92] VAN ROY, T.J.; WOLSEY, L.A. Valid Inequalities and Separation for Uncapacitated Fixed Charge Networks. Operations Research Letters. v.4, p. 105-112, 1985. 
[93] WAGNER, H. M.; WHITIN, T. M. A Dynamic Version of the Economic Lot-sizing Model. Management Science. v. 5, p. 89-96, 1958.

[94] WOLSEY, L.A. Integer Programming. John Wiley \& Sons, 1998.

[95] WOLSEY, L.A. Solving Multi-item Lot-Sizing Problems with an MIP Solver Using Classification and Reformulation. Management Science. v.48, n.12, p.1587-1602, 2002.

[96] WOLSEY, L.A. Strong formulations for mixed integer programs: valid inequalities and extended formulations. Mathematical programming, Series B. v. 423-447, 2003. 


\section{Apêndice A}

\section{Reformulações para o problema do caixeiro viajante}

O problema do caixeiro viajante $(\mathrm{PCV})$ tem repercutido bastante na literatura, pois além de possuir várias aplicações práticas, é um problema NP-difícil, ou seja, o tempo gasto para resolvê-lo pode ser de ordem exponencial de acordo com número de restrições [23], [41]. Com base na Teoria dos Grafos [13], neste capítulo apresentamos formulações para o problema do caixeiro viajante [60] e algumas reformulações propostas na literatura.

\section{A.1 Definição do problema e formulações}

Considere as Definições A.1, A.2, A.3, A.4 e A.5.

Definição A.1. Dois vértices são ditos adjacentes se houver uma aresta entre eles. Duas arestas são ditas adjacentes se elas incidirem em um mesmo vértice.

Definição A.2. Um percurso em um grafo é uma coleção de vértices (ou de arestas) sequencialmente adjacentes.

Definição A.3. Um caminho é um percurso (em um grafo orientado) onde todos as arestas estão orientadas no sentido início do percurso-fim do percurso.

Definição A.4. Um circuito é um caminho sem repetição de vértices e que o vértice inicial é igual ao final. 
Definição A.5. Um circuito hamiltoniano é um circuito que inclui todos os vértices do grafo.

Com base na Definição A.5, o PCV pode ser definido da seguinte forma:

Definição A.6. Dado um grafo $G=(V, A)$, onde $V$ é o conjunto de $n$ vértices e $A$ um conjunto de $m$ arestas, tal que a cada aresta $(i, j)$ está associado um valor (custo ou distância, ou tempo) $c_{i j}$, o problema do caixeiro viajante consiste em determinar em $G$ um circuito hamiltoniano de valor total mínimo. O caso assimétrico (PCVA) considera que $c_{i j} \neq c_{j i}$ para algum $i, j \in V$ [59].

Uma formulação matemática para o PCV apresentada por Dantzig, Fulkerson e Johnson (DFJ) [60] é dada pela expressão (A.1)-(A.5).

$$
\begin{gathered}
\text { Min } \sum_{i=1}^{n} \sum_{j=1}^{n} c_{i j} z_{i j} \\
\text { sujeito a: } \\
\sum_{i=1}^{n} z_{i j}, j=1, \ldots, n . \\
\sum_{j=1}^{n} z_{i j}, i=1, \ldots, n . \\
\sum_{i \in Q} \sum_{j \in Q} z_{i j} \leq|Q|-1,2 \leq|Q| \leq n-1, \\
z_{i j} \in\{0,1\}, i, j=1, \ldots, n .
\end{gathered}
$$

O problema de programação inteira (A.1)-(A.3), junto com a restrição de integralidade $z_{i j}=1$ ou 0, é conhecido como Problema da Designação. Entretanto, as restrições (A.2) e (A.3) não eliminam a possibilidade de subrotas, como mostra a Figura A.1. Portanto, é necessária a inclusão das restrições (A.4) para eliminação de subrotas. Note que em (A.4) qualquer subgrafo associado à uma solução deve ter menos arestas do que nós. Logo, seja $|Q|$ a cardinalidade de $Q \subseteq V$. Podemos impor então que no máximo $|Q|-1$ arestas sejam incluídas em um subgrafo da solução. 

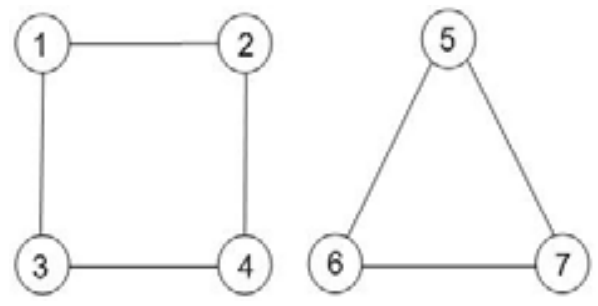

Figura A.1: Ilustração de subrotas

Uma outra proposta de restrições para eliminação de subrotas foi apresentada por Miller, Tucker e Zemlim [60] que propõem o conjunto de inequações (A.6) e (A.7):

$$
\begin{gathered}
u_{j} \geq\left(u_{i}+1\right)-(n-1)\left(1-z_{i j}\right), \forall i \neq j, i, j=2, \ldots, n . \\
1 \leq u_{j} \leq(n-1), z_{i j} \in\{0,1\},, i, j=2, \ldots, n .
\end{gathered}
$$

As variáveis $u_{i}, i=1, \ldots, n$ representam a ordem em que o vértice $i$ é visitado, com o vértice base começando com zero $\left(u_{1}=0\right)$. Assim, o modelo de Miller, Tucker e Zemlim (MTZ) é dado por:

$$
\begin{gathered}
\operatorname{Min} \sum_{i=1}^{n} \sum_{j=1}^{n} c_{i j} z_{i j} \\
\text { sujeito a: } \\
\sum_{i=1}^{n} z_{i j}, j=1, \ldots, n . \\
\sum_{j=1}^{n} z_{i j}, i=1, \ldots, n . \\
u_{j} \geq\left(u_{i}+1\right)-(n-1)\left(1-z_{i j}\right), \forall i \neq j, i, j=2, \ldots, n . \\
1 \leq u_{j} \leq(n-1), z_{i j} \in\{0,1\},, i, j=1, \ldots, n .
\end{gathered}
$$

A atração desse modelo é que permite uma representação polinomial da ordem $O\left(n^{2}\right)$, que é particularmente útil quando estamos tratando de um contexto com problemas grandes.

\section{A.2 Reformulações para o PCV}

Uma vantagem da formulação de Miller, Tucker e Zemlin (MTZ) para o problema do caixeiro viajante é que as restrições de eliminação de subrotas podem ser incorporadas 
em outros tipos de formulação do problema junto com restrições mais fortes. Motivados por esse fato, Desrochers e Laporte [28] propuseram, a partir das restrições de eliminação de subrotas de MTZ formas mais fortes destas inequações. Nas proposições A.1 e A.2 abaixo Desrochers e Laporte provaram que as duas inequações são válidas e que definem facetas para o PCV [28], [68], [24].

Proposição A.1. As restrições $u_{j} \geq\left(u_{i}+1\right)-(n-1)\left(1-z_{i j}\right)+(n-3) z_{j i}, i, j=2, \ldots, n$ com $u_{i}, u_{j} \in[1 ; n-1]$, são inequações válidas para o PCV.

Proposição A.2. As restrições $1+\left(1-z_{1 j}\right)+(n-3) z_{j 1} \leq u_{j} \leq n-1-(n-3) z_{1 j}-$ $\left(1-z_{j 1}\right), j=2, \ldots, n$ são válidas para o $P C V$.

Sherali e Driscoll [80] propuseram as restrições (A.13)-(A.16) para eliminação de subrotas, cuja ordem é de $O\left(n^{2}\right)$ :

$$
\begin{aligned}
& \sum_{j=2}^{n} y_{i j}+(n-1) z_{i 1}=u_{i}, i=2, \ldots, n \\
& \sum_{i=2}^{n} y_{i j}+1=u_{j}, j=2, \ldots, n \\
& z_{i j} \leq y_{i j} \leq(n-2) z_{i j}, i, j=2, \ldots n . \\
& u_{j}+(n-2) z_{i j}-(n-1)\left(1-z_{i j}\right) \leq y_{i j}+y_{j i} \leq u_{j}-\left(1-z_{j i}\right) \\
& \quad i, j=2, \ldots, n . \\
& 1+\left(1-z_{1 j}\right)+(n-3) z_{j 1} \leq u_{j} \leq(n-1)-(n-3) z_{1 j}-\left(1-z_{j 1}\right), \\
& j=2, \ldots, n .
\end{aligned}
$$

Carretero [24] faz um estudo sobre o problema do caixeiro viajante, apresentando algumas inequações válidas e métodos de solução para o PCVA.

\section{A.3 O problema do caminho hamiltoniano}

Em alguns problemas do mundo real envolvendo sequenciamento e/ou dimensionamento e sequenciamento integrado (ver [87], [88] e também Capítulo 2), o objetivo não é encontrar um circuito hamiltoniano, mas sim um caminho hamiltoniano [60]:

Seja $C=\left[c_{i j}\right]$ uma matriz $n \times n$ tal que $c_{i j}$ é a distância entre a cidade $i$ e a cidade j. Queremos encontrar um caminho hamiltoniano e não importa a cidade de partida e a 
de chegada. Este problema é equivalente ao problema do caixeiro viajante com $(n+1)$ cidades em que o nó acrescentado é chamado nó artificial (ver Figura A.2). Note que $c_{n+1, j}=0, \forall j$ e $c_{j, n+1}=0, \forall j$.

Se a cidade de origem $s$ e a cidade de destino $t$ forem pré-especificadas, o problema é equivalente ao problema do caixeiro viajante com $n-1$ nós. Os vértices $s$ e $t$ são substituidos por um único vértice $u$ e os custos associados são:

$$
\left\{\begin{array}{l}
C_{i j}^{\prime}=c_{s j} \quad \text { se } i=u \\
C_{i j}^{\prime}=c_{i t} \quad \text { se } j=u \\
C_{i j}^{\prime}=c_{i j} \quad \text { caso contrário. }
\end{array}\right.
$$

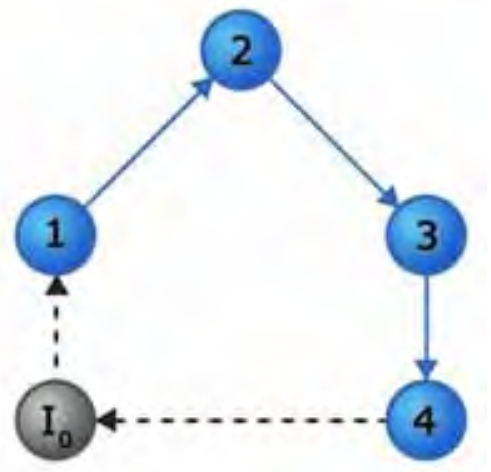

Figura A.2: Grafo com nó artificial 


\section{Apêndice B}

\section{Dados dos exemplares ilustrativos}

Nesta seção, apresentamos os dados utilizados no exemplar ilustrativo usado na Seção 3.4. O exemplar considera 4 itens, 2 tipos de xaropes e 2 períodos. O xarope 1 pode ser utilizado para fabricar apenas o item 4. Já o xarope 2 é usado para fabricar os itens 1 , 2 e 3. A capacidade da máquina é de 1000 unidades por período. A capacidade total do tanque também é 1000. O estoque inicial considerado é 0 e a quantidade mínima de xarope $\left(q_{l t}\right)$ que deve ser produzida também é 1000. O número máximo de preparos (subperíodos) por período é 6. As Tabelas B.1, B.2, B.3, B.4, B.5, B.6 mostram, respectivamente, os custos de troca dos itens, de estoque e atraso, a capacidade de tempo necessária para a produção de uma unidade de cada item, a demanda dos itens nos períodos, a quantidade necessária de xarope para a produção de uma unidade de cada item e os tempos de troca dos itens.

\begin{tabular}{ccccc}
\hline Item & 1 & 2 & 3 & 4 \\
\hline \hline 1 & 0 & 6 & 9,2 & 12,3 \\
2 & 7,9 & 0 & 9,2 & 12,3 \\
3 & 2,9 & 10 & 0 & 12,3 \\
4 & 19,9 & 20,1 & 18,5 & 0 \\
\hline
\end{tabular}

Tabela B.1: Custo de troca dos itens na máquina $\left(s_{i j}\right)$. 


\begin{tabular}{ccc}
\hline Item & Estoque & Atraso \\
\hline \hline 1 & 0,007 & 15 \\
2 & 0,006 & 15 \\
3 & 0,007 & 16,2 \\
4 & 0,009 & 18,9 \\
\hline
\end{tabular}

Tabela B.2: Custos de estoque $\left(h_{j}\right)$ e atraso $\left(g_{j}\right)$ dos itens.

\begin{tabular}{cc}
\hline Item & Tempo (s) \\
\hline \hline 1 & 0,03 \\
2 & 0,06 \\
3 & 0,03 \\
4 & 0,06 \\
\hline
\end{tabular}

Tabela B.3: Tempo por unidade de produção $\left(a_{j}\right)$.

\begin{tabular}{ccc}
\hline Item \Período & 1 & 2 \\
\hline \hline 1 & 1464 & 1459 \\
2 & 4691 & 2719 \\
3 & 753 & 746 \\
4 & 12958 & 12666 \\
\hline
\end{tabular}

Tabela B.4: Demanda dos itens por período $\left(d_{j t}\right)$. 


\begin{tabular}{rcc}
\hline Item $\backslash 1$ & 1 & 2 \\
\hline \hline 1 & - & 0,29 \\
2 & - & 0,29 \\
3 & - & 0,237 \\
4 & 0,29 & - \\
\hline
\end{tabular}

Tabela B.5: Quantidade de xarope por unidade de produção $\left(r_{l j}\right)$.

\begin{tabular}{ccccc}
\hline Item & 1 & 2 & 3 & 4 \\
\hline \hline 1 & 0 & 9 & 15 & 30 \\
2 & 12 & 0 & 15 & 30 \\
3 & 4 & 15 & 0 & 30 \\
4 & 30 & 30 & 30 & 0 \\
\hline
\end{tabular}

Tabela B.6: Tempos de troca dos itens $\left(b_{i j}\right)$. 
Autorizo a reprodução xerográfica para fins de pesquisa.

São José do Rio Preto, 10 de Março de 2010.

Cristiane Maria Defalque 